\title{
Patterns of migration/mobility and HIV risk among female sex workers: Karnataka 2007-08
}

Shiva S. Halli

Raluca Buzdugan

Ravi K. Verma

Stephen Moses

James Blanchard

See next page for additional authors

Follow this and additional works at: https://knowledgecommons.popcouncil.org/departments_sbsr-hiv

Part of the Demography, Population, and Ecology Commons, Family, Life Course, and Society Commons, International Public Health Commons, and the Migration Studies Commons How does access to this work benefit you? Let us know!

\section{Recommended Citation}

Halli, Shiva S., Raluca Buzdugan, Ravi K. Verma, Stephen Moses, James Blanchard, Anrudh K. Jain, Saumya RamaRao, Suvakanta N. Swain, and Niranjan Saggurti. 2008. "Patterns of migration/mobility and HIV risk among female sex workers: Karnataka 2007-08." New Delhi: Population Council. 


\section{Authors}

Shiva S. Halli, Raluca Buzdugan, Ravi K. Verma, Stephen Moses, James Blanchard, Anrudh K. Jain,

Saumya RamaRao, Suvakanta N. Swain, and Niranjan Saggurti 


\section{PATTERNS OF MIGRATION/MOBILITY AND HIV RISK AMONG FEMALE SEX WORKERS}

\section{Karnataka 2007-08}

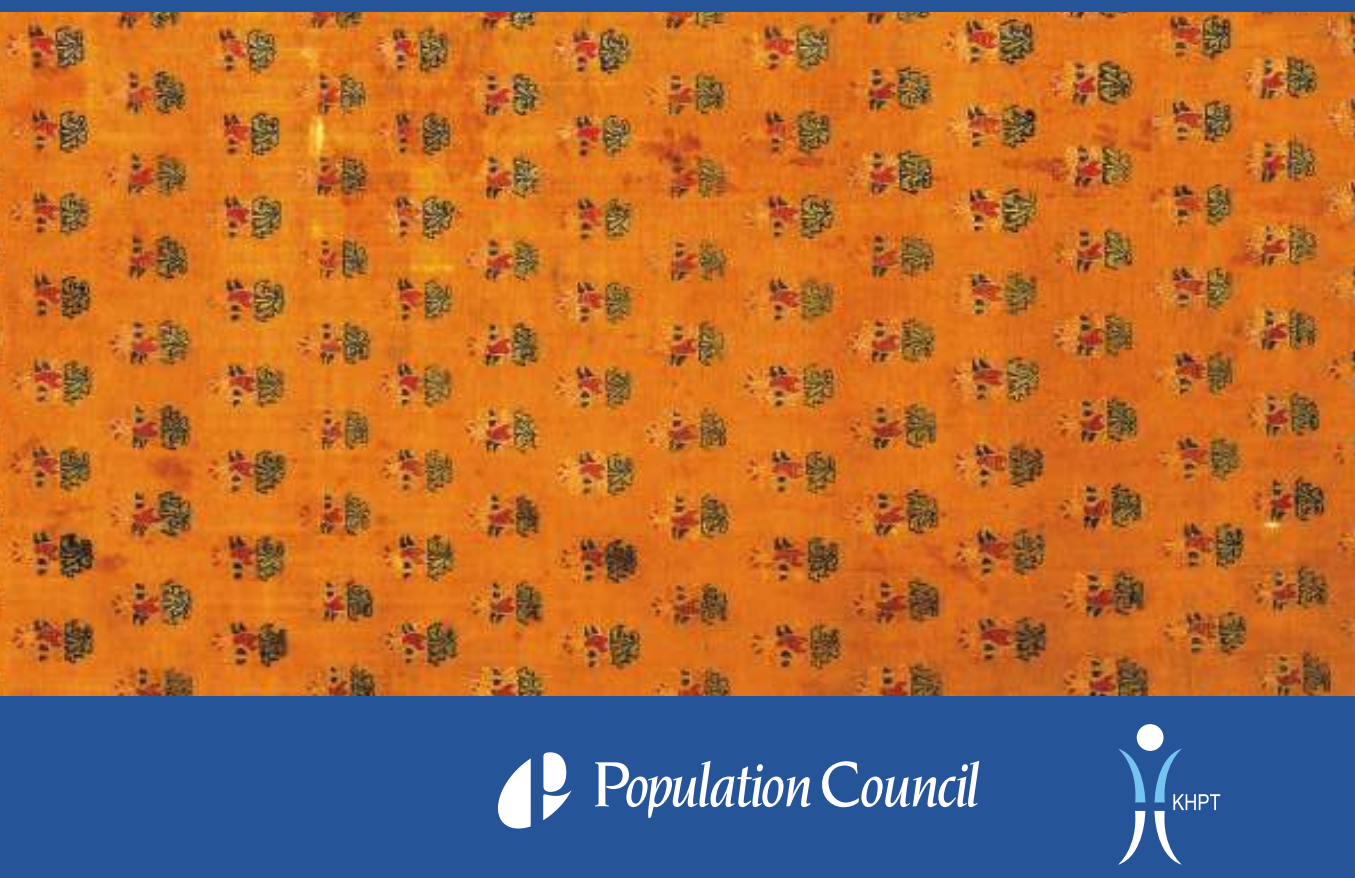


The migration/mobility of female sex workers in search of more clients and more money has been recognized as a challenge in HIV prevention interventions in India. Little is known, however, about the patterns of migration/mobility of female sex workers in India, the facilitators and drivers of their mobility, and the implications of such mobility for the HIV pandemic. This lack of understanding has been an impediment in planning effective HIVprevention programmes for these vulnerable populations.

A research study designed to increase understanding of the patterns and factors related to migration and mobility of at-risk populations of sex workers and male migrant workers and to examine the links of migration and mobility with HIV risk was conducted in four states of India experiencing high HIV prevalence, namely Andhra Pradesh, Karnataka, Tamil Nadu, and Maharashtra. This report presents the findings from the female sex workers study on volume and patterns of mobility and their linkages with HIV risk. The field work among female sex workers in Andhra Pradesh was implemented by TNS India Private Limited and the Population Council in New Delhi.

For additional information about the study, please contact:

Dr. Saggurti Niranjan HIV and AIDS Program

Population Council India Habitat Center Lodi Road

New Delhi 110003.

Telephone: 011- 24651314

Fax: 011 - 24645060

e-mail: nsaggurti@popcouncil.org website: www.popcouncil.org
For additional copies of this report, please contact:

South and East Asia Regional Office Zone 5A, India Habitat Centre

Lodi Road

New Delhi 110003

Tel: +91 11 24642901/02

Fax: +91 1124642903

Email: vthomas@popcouncil.org website: www.popcouncil.org 
The Karnataka Health Promotion Trust (KHPT) was set up as a partnership between the Karnataka State AIDS Prevention Society (KSAPS) and the University of Manitoba, Canada, in 2003. KHPT focuses on supporting and implementing initiatives related to HIV/AIDS and reproductive health.

\section{Q1 Population Council}

The Population Council seeks to improve the well-being and reproductive health of current and future generations around the world. The Council's biomedical, public health, and social scientists identify and evaluate responses to the most important population, health, and development issues. Work is focused on three programme areas: HIV and AIDS; Poverty, Gender, and Youth; and Reproductive Health.

\section{(C) 2008 The Population Council, Inc.}

This document may be reproduced in whole or part without permission of the Population Council, provided that full source citation is given and reproduction is not for commercial purposes. 


\title{
CONTRIBUTORS
}

\author{
Shiva S. Halli ${ }^{1}$ \\ Raluca Buzdugan ${ }^{1}$ \\ Ravi K. Verma ${ }^{3}$ \\ Stephen Moses ${ }^{1}$ \\ James Blanchard ${ }^{1}$ \\ Anrudh Jain ${ }^{4}$ \\ Saumya RamaRao ${ }^{4}$ \\ Suvakanta N.Swain ${ }^{2}$ \\ Niranjan Saggurti ${ }^{2}$
}

${ }^{1}$ Karnataka Health Promotion Trust, Bangalore, India

${ }^{2}$ Population Council, New Delhi, India

${ }^{3}$ International Center for Research on Women (ICRW), New Delhi, India

${ }^{4}$ Population Council, New York, USA 


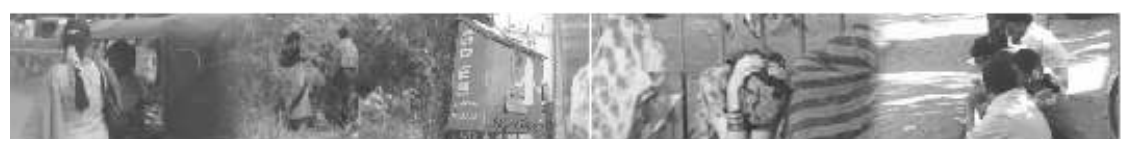

\section{FOREWORD}

In past years, considerable research has been undertaken on the role of female sex workers (FSWs) in the transmission of HIV infection. FSWs have been seen as a major 'source' of infection. Consequently, they have been extensively targeted to prevent its spread, There is, however, a gap in our understanding of the dynamics of sex work, sex workers' patterns of mobility and the relationship of such mobility with risk to HIV infection and gender-based violence.

During November, 2006 - November, 2007, the Population Council undertook a study to examine the patterns of mobility of FSWs and to study its links with HIV risk. The goal was to provide research-based evidence to inform the formulation of policies and to improve the implementation of programs. The study was conducted in 22 districts in four high HIV prevalence states namely Maharashtra, Karnataka, Tamil Nadu and Andhra Pradesh. It was undertaken in collaboration with the Karnataka Health Promotion Trust, the TNS India Private Limited and the GFK-MODE Private Limited.

Ethnographic and survey research methods were employed to collect data on FSWs' patterns and routes of mobility, and the condom use behaviors of over 5500 mobile female sex workers. Support provided by Avahan, Avahan's partner NGOs, the National AIDS Control Organisation, State AIDS Control Societies, other international and national organizations, and most importantly by the study participants themselves, was invaluable in undertaking this study.

The study shows that on average, mobile FSWs moved to four different locations for sex work in the two years prior to the survey. Sixty percent of the FSWs sampled for the survey reported that they had moved to atleast two different locations and that they had moved to atleast one location outside the district in the one in which they lived. There was greater mobility of sex workers in Andhra Pradesh and Karnataka than in Maharashtra and Tamil Nadu. In Andhra Pradesh and Maharashtra, greater mobility showed associations with a consistent decrease in condom use; increased exposure to sexually transmitted infections; and increased perceived risk of HIV. It is likely that since FSWs move to maximize trade opportunities, they use less discretion in using condoms when they are mobile. In Karnataka and Tamil Nadu, however, mobility was not associated with condom use. 


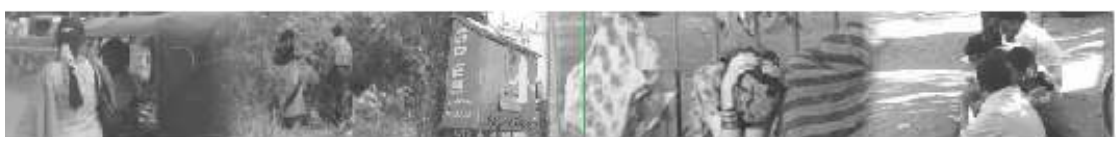

In places where FSWs had the opportunity to get more clients and where transaction time was short for example during Jataras (Pilgrimages), consistent condom use declined sharply in all for states where the study was conducted. About three-fourths of the mobile FSWs who visited places of jatara for sex work did not use condoms consistently. Thus, their vulnerability and risk to infection was enhanced in these situations. These findings indicate the need to design interventions that can be effectively implemented in places of Jatara and other such places.

Over three-fourths of the mobile FSWs, in the study were 19 to 34 years of age. Most were illiterate; many were in debt; and the majority belonged to lower castes such as Dommara, Madigra, Harijana, Devadasi, Kalavanthulu and Lambani. Most of these women were either vidowed, divorced or separated. More then two-fourths worked as domestic servants, vendors, agricultural laborers or construction laborers. The study showed that a large majority ofthe mobile FSWs suffered gender-based violence. Mobile FSWs who faced violence, were in debt, and/or were widowed, separated or divorced were less likely to use condoms. These results underscore the importance of designing program interventions for these specially disadvantaged, vulnerable subpopulations of FSWs.

The study mapped specific districts where mobile FSWs were conconcentrated. Clearly, those districts need special attention. Social support systems in these districts should be strengthened. Strategies should be designed to bring mobile FSWs within the ambit of the program. In addition, district-specific interventions should be designed and implemented to address the needs of these highly vulnerable sub-populations of FSWs.

FSWs have been traditionally categorized by place of work -- in brothels, roadsides, highways, dhabas, homes, railway stations and bus stands, and interventions are targeted to these pre-defined categories of sex workers. Our study, however, shows that mobile FSWs solicit clients in multiple places. And although hotels and lodges are most commonly used, they have sex with their clients, in a number of different places. These findings suggest the need to target interventions at places where significant numbers of FSWs can be reached. 


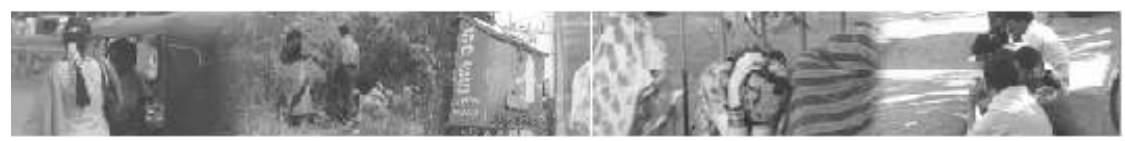

This pioneering research study provides important evidence that should be used at both the national and state levels for the design and implementation of program strategies for the prevention of HIV infection among FSWs and their clients. This information should be used by the national and state-level AIDS control organizations to inform the design of policies and the implementation of government programs. These research findings are also relevant for the large numbers of NGOs and others engaged in programs targeting FSWs and their clients. Thus, there are a number of stakeholders who could utilize the findings of this wide-scale research study for the prevention and control of HIV and AIDS.

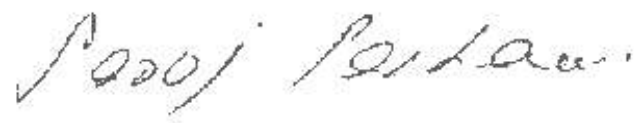

Dr. Saroj Pachauri MD, PhD.

Regional Director

South and East Asia

Population Council 


\section{Table of Contents}

\section{List of Figures}

Acknowledgements

Executive Summary 1

I. INTODUCTION 5

II. STUDY DESIGN AND METHODS $\quad 7$

$2.1 \quad$ Characterization of study areas

2.2 The quantitative survey

2.3 Sample size

2.4 The sample design

$2.5 \quad$ Female sex workers' degree of mobility

III. VOLUME AND PATTERNS OF MOBILITY

$3.1 \quad$ Volume of mobility

3.2 Patterns of mobility

3.3 Jatra/ seasonal mobility of female sex workers

IV. PROFILE OF MOBILE FEMALE SEX WORKERS

4.1 Socioeconomic and demographic profiles

4.2 Reasons for entry into sex work

4.3 Lifestyle characteristics

4.4 Autonomy

4.5 Experiencing of physical violence

4.6 Exposure to the mass media

4.7 Membership in associations

V. HIV VULNERABILITY AMONG FEMALE SEX WORKERS

$5.1 \quad H I V$ vulnerability by district

5.2 Ability to insist on condom use and actual condom use

5.3 Socioeconomic insecurity and HIV risk

5.4 Mobility and HIV Risk

VI. IMPLICATIONS FOR HIV PREVENTION BY LOCATIONS WHERE FEMALE SEX WORKERS SOLICIT AND ENGAGE IN SEX

6.1 Locations for Soliciting and Engaging in Sex

VII. SUMMARY AND RECOMMENDATION 


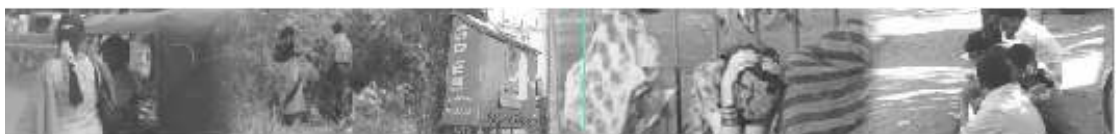

\section{List of Figures/Maps}

Figure 1. Percentage of mobile female sex workers who moved in the past two years, by district, Karnataka State, India, 2006-2007

Figure 2. Volume of mobility of female sex workers, by age and district

Figure 3. Volume of mobility of female sex workers, by age by type of sex work

Figure 4. Marital status of mobile female sex workers, by district

Figure 5. Mobile female sex workers' sources of income, by district

Figure 6. Respondents' reasons for entry into sex work, by district

Figure 7. Percentage of mobile female sex workers who experienced physical violence at least once in the past year, by district

Figure 8. Percentage of mobile female sex workers who reported consistent condom use during last sex, by type of client/partner

Figure 9. Percentage of mobile sex workers who reported experiencing STI symptoms and who continue to have sex while being infected with STIs, by type of client/partner and degree of mobility

Figure 10. Percentage of mobile female sex workers who reported using a condom during last sex, by type of client/ partner, and who experienced STI symptoms and had sex while having STI symptoms, according to whether they went to jatras for work

Figure 11. Percentage of mobile female sex workers, by their most frequently mentioned locations for and means of soliciting and engaging in sex work, according to district

Figure 12. Percentage of mobile female sex workers, by their most frequently mentioned locations for engaging in sex, according to district

Map 1. Study districts in Tamil Nadu

Map 2. Routes of mobile female sex workers currently in Bellary District

Map 3. Routes of mobile female sex workers currently in Bangalore Urban District 


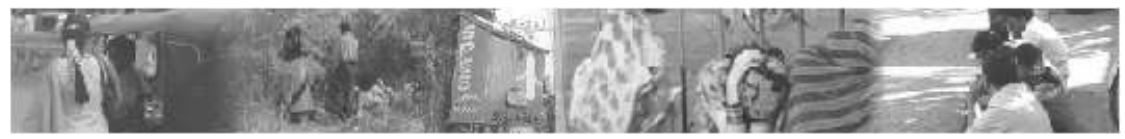

Map 4. Routes of mobile female sex workers currently in Dharwad District

Map 5. Routes of mobile female sex workers currently in Gulbarga District

Map 6. Routes of mobile female sex workers currently in Dakshina Kannada District

Map 7. Main jatra destinations for female sex workers in the study districts

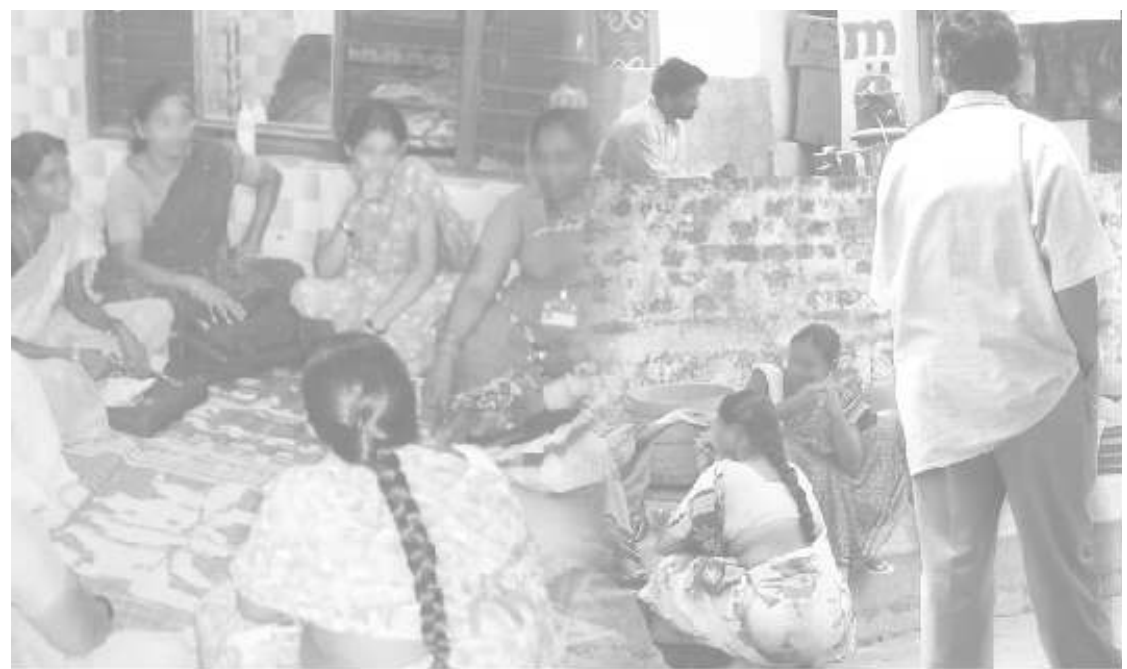




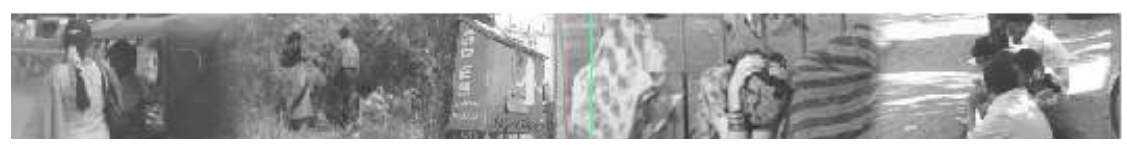

\section{ACKNOWLEDGEMIENIS}

The study of Migration/Mobility and HIV

Risk among Female Sex Workers was successfully completed during 200708. The efforts of a number of individuals who were involved in the study are acknowledged.

First of all, we are grateful to the Bill \& Melinda Gates Foundation for its support for the study through Avahan, its India AIDS Initiative. We are particularly thankful to Mr. Ashok Alexander, Ms. Padma Chandrasekaran, Dr. Gina Dallabetta, Dr. Aparajita Bhalla, Mr. Hari Menon, and Ms. Jayanti Rajagopalan, from Avahan, for their active support and involvement at all stages of the project. However, the views expressed herein are those of the authors and do not necessarily reflect the official policy or position of the Bill $\&$ Melinda Gates Foundation and Avahan.

We would like to acknowledge the support of the members of the Technical Advisory Committee (TAC) for their overall guidance in the smooth conduct of the study. The contributions of the members; Dr. Prem Saxena, Dr. P. M. Kulkarni, Dr. Tarun K. Roy, Dr. R. R. Gangakhedkar, Dr. Rohini Pande, Dr. Gurumurthy Rangaiyan, Dr. Arvind Pandey, Dr. Rajatashuvra Adhikary, Dr. Shiva S. Halli, Dr. Tobi Saidel, and Dr. Shalini Bharat were helpful both through their direct involvement in TAC meetings and through interactions with individual members during the various stages of the project. Special thanks are due to Dr. Saroj Pachauri for chairing the Technical Advisory Committee and for guiding us at each stage of the project.

We acknowledge the contribution and support of the research team at the International Center for Research on Women (ICRW) for their review of and feedback on the study report.

We thank all of the experts who participated in a series of workshops that were organized to prepare qualitative research tools; undertake training of the research teams; plan qualitative data analysis; and prepare the questionnaires, the sample design, and the tabulation plan for the report.

We are grateful to our consultants Dr. Pertti J. Pelto, Senior Anthropologist, Ms. Lakshmi Ramachandar, and Mr. Zaheer Ahmad Khan for their assistance. Special thanks to Mr. V. L. Thomas, Executive Assistant at the Population Council, for his administrative support throughout the study and his expert 


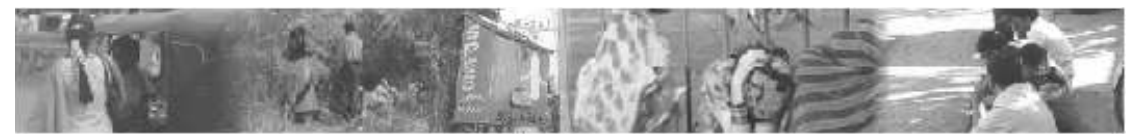

assistance in creating the tables and graphs and for formatting the report. We would like to convey our special thanks to Dr. Ajay K. Khera, Mr. Aslam Naved, and Ms. Lakshmi Murthy from the National AIDS Control Organization (NACO) and the authorities from Karnataka State AIDS Prevention Society (KSAPS) for their help in facilitating data collection and interpretation and dissemination of findings.

We thank the Population Research Center, Dharwad, for their support and help, especially Mr. Channakki and Dr. Purnima for help with supervision of the fieldwork. We appreciate and acknowledge the untiring efforts of our field research team. We also would like to thank the KHPT NGO partners and the agencies for their cooperation in data collection. Of course, we are also thankful to our colleagues in KHPT: Mr. Raghavendra, Dr. B.M. Ramesh, Mrs. Vandana Gurnani, Dr. Reynold Washington, and other support staff.

Most importantly, we are immensely grateful to the participants of this study who have, without hesitation, given their time and narrated their experiences and views regarding their mobility and HIV risk.

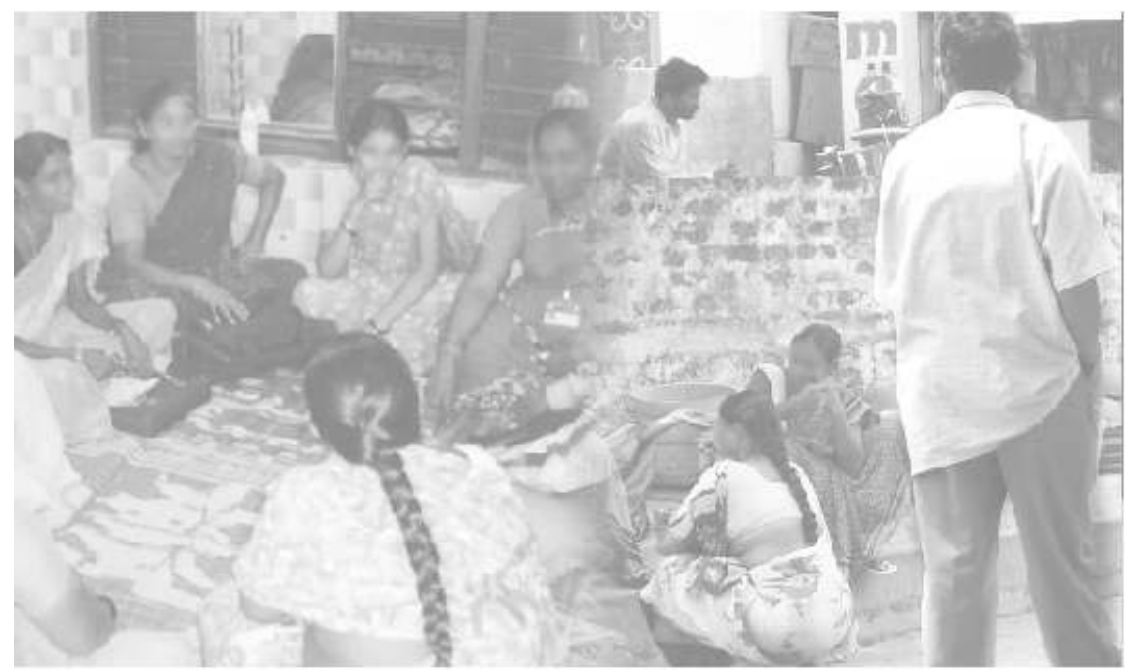




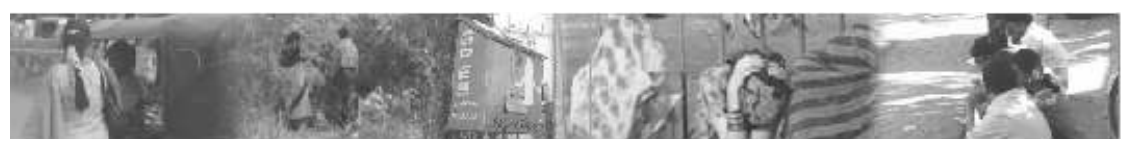

EXECUTIVE SUMMARY
Karnataka, a South Indian state, is known to have a high prevalence of HIV infection. The epidemic is largely driven by heterosexual transmission. Although the infection is spreading to the wider society, female sex workers (FSWs) remain a high-risk group. In an effort to gain control over the epidemic in

India, the HIV/AIDS programme has made substantial efforts in the last few years towards offering female sex workers access to information about sexually transmitted infections/HIV/AIDS and to condoms, clinics, and other medical services. Sex workers who tend to move from place to place for the purpose of finding clients have been particularly difficult to cover by the programme, compared with sex workers who remain in the same location. Those who are mobile are difficult to contact, follow-up, treat, and empower.

The present study was undertaken by the Karnataka Health Promotion Trust (KHPT) and the Population Council to determine the patterns and factors that drive mobility among female sex workers and the association of mobility with HIV risk. The specific objectives of the study are:

- $\quad$ assess the volume and patterns of mobility of female sex workers;

- describe the characteristics of mobile female sex workers; and

- examine the determinants of HIV risk among female sex workers, with particular emphasis on mobility-related characteristics.

The study was conducted in 2007 in five districts of Karnataka: Bangalore Urban, Dakshina Kannada, Bellary, Dharwad, and Gulbarga. In each of the selected districts, maps were drawn that identified the areas where female sex workers are found in order to estimate their numbers. This information was used to select the study sites within each district. Both qualitative and quantitative research methods were employed. For the qualitative phase of the study, a variety of methods was used: key-informant interviews (KII), geographical and route mapping for mobile populations, and in-depth interviews (IDI). A total of 434 interviews, both KIIs and IDIs, were carried out in all the five study areas. Mobility maps were drawn for all those selected for the in-depth interviews. In the quantitative phase, a total of 2,406 sex workers were contacted in the survey, of which 1,499 were selected for comprehensive interviews by means of a structured survey instrument. 


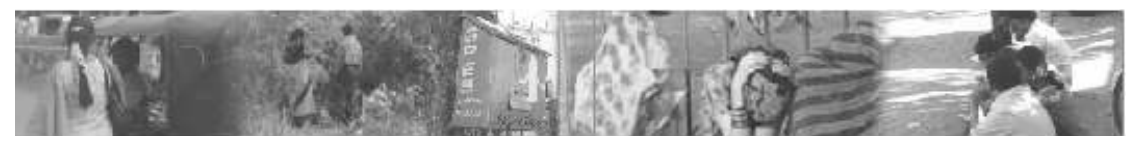

Results indicate that 84 percent of sex workers interviewed had moved at least once for sex work in the past two years, and three-fourths of the female sex workers had moved at least once across the district. On average, female sex workers moved 3.5 times in the past two years for sex-work purposes, and 2.8 of these moves were made across the district. Although little variation is found across districts, women practicing sex work on highways, in lodges, and in brothels are more mobile than street and home-based sex workers. In terms of age, mobility is greatest among sex workers aged 25-29.

The study has allows us to identify the main routes of mobility for female sex workers in the study districts. Bangalore is the central point of female sex workers' routes in Karnataka. In Southern Karnataka, frequent connectivity is found between Bangalore and Dakshina Kannada, but also with Mysore and other neighbouring districts. In Northern Karnataka, mobility is great between neighbouring districts, and especially on the route Belgaum to Dharwad to Bellary.

The jatra(pilgrimage)-related mobility in Karnataka is important to document, because one-third of sex workers have gone to jatras in the past year. Moving to pilgrimage sites is a greater phenomenon among female sex workers in Northern Karnataka and among those working in the street, in their homes, and on the highways. Important jatra sites in Northern Karnataka are Saundatti in Belgaum District and Munirabad in Bellary District. A substantial number of women go to various jatra locations in their own districts or in neighbouring districts.

The sociodemographic profile of mobile female sex workers show that threefourths of the women are aged 18-29, and more than half of them are 25-29 years old. Almost 60 percent of them have less than fifth standard education, and around one-third are illiterate. Two-thirds of the mobile female sex workers in Karnataka are divorced, widowed, or separated, and one-fourth have never been married. Nearly 60 percent of the study participants reported that they drank alcoholic beverages in the month prior to the survey, an important finding in the context of the AIDS pandemic.

Overall, more than 60 percent of sex workers reported membership in a selfhelp group, community-based organization, nongovernmental organization, or sex- workers' collective. In terms of the benefits received, the large majority of sex workers reported having received condoms, information about sexually 


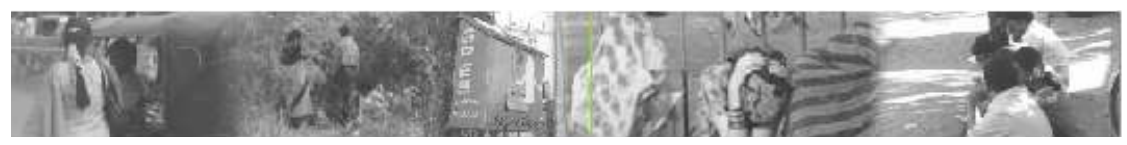

transmitted infections (STIs), and referrals to health centres. The programme seems to be most effective at condom distribution in Bellary and Gulbarga districts at providing knowledge about STIs in Gulbarga, and at providing referrals to health centres in Bangalore.

In light of the above-mentioned programme coverage, the finding is unsurprising that only half of the mobile female sex workers surveyed reported using a condom at last sex with occasional clients and one-third reported condom use with regular clients. Consequently, the large majority of respondents have experienced STI symptoms in the six months prior to the survey. One of the principal explanations for the low level of reported condom use is these women's weak sexual negotiation skills. Low condom use is found as well for women who reported consuming alcohol. Another factor in their vulnerability to infection is their marital status; divorced/widowed/ separated mobile female sex workers are at higher risk for HIV, compared with nevermarried or currently married female sex workers.

In terms of assessing the link between female sex workers' mobility and their HIV risk, we note that sex workers who move to a greater number of locations report similar levels of condom use with occasional clients and similar percentages of STI symptoms as those moving to fewer places. On the other hand, they report lower levels of condom use with nonpaying partners, and more of them report having sex while experiencing STI symptoms than do female sex workers who are not mobile. Condom use with regular clients is more frequent among female sex workers with greater mobility, which might be explained by their brief stay in each location. Although the relationship between female sex workers' degree of mobility and HIV risk is not straightforward, those who go to jatras for work are at higher risk for HIV, compared with those who do not. Female sex workers at jatras, particularly those going in a group rather than alone, report lower levels of condom use with any type of partner and higher incidence of STI symptoms. A greater number of these women continue to have sex while experiencing STI symptoms than do those who do not go to jartras.

To increase the impact of programme interventions, it is useful to determine the main locations where female sex workers solicit clients in Karnataka. Although they solicit in many places, the most common means of obtaining clients is by telephone (40 percent), and by standing at the roadside, at railway station/bus stand, and at marketplaces. Hotels and other sorts of lodging places are also popular solicitation sites. Some female sex workers solicit from their homes, 


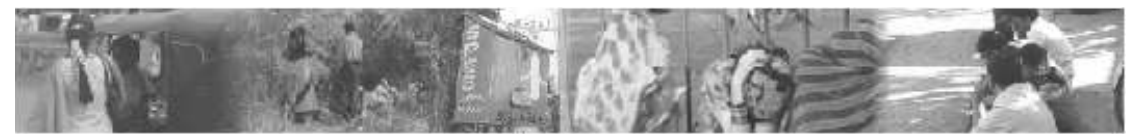

and some are based in brothels. Similarly, mobile female sex workers engage in sexual transactions in many locations, particularly in hotels and lodges (40 percent), outdoors in forests, gardens, jungles, hills, mountains, and rented rooms, and from their own homes.

This study identified hotels, railway stations, bus stands, marketplaces, the female sex workers' homes, brothels, and dhabas (fast-food places), as the six solicitation locations that are most feasible for programme interventions. More than 95 percent of mobile female sex workers in Bellary, Bangalore, and Dakshina Kannada, more than 90 percent in Gulbarga, and close to 85 percent in Dharwad can be contacted by covering these six places simultaneously

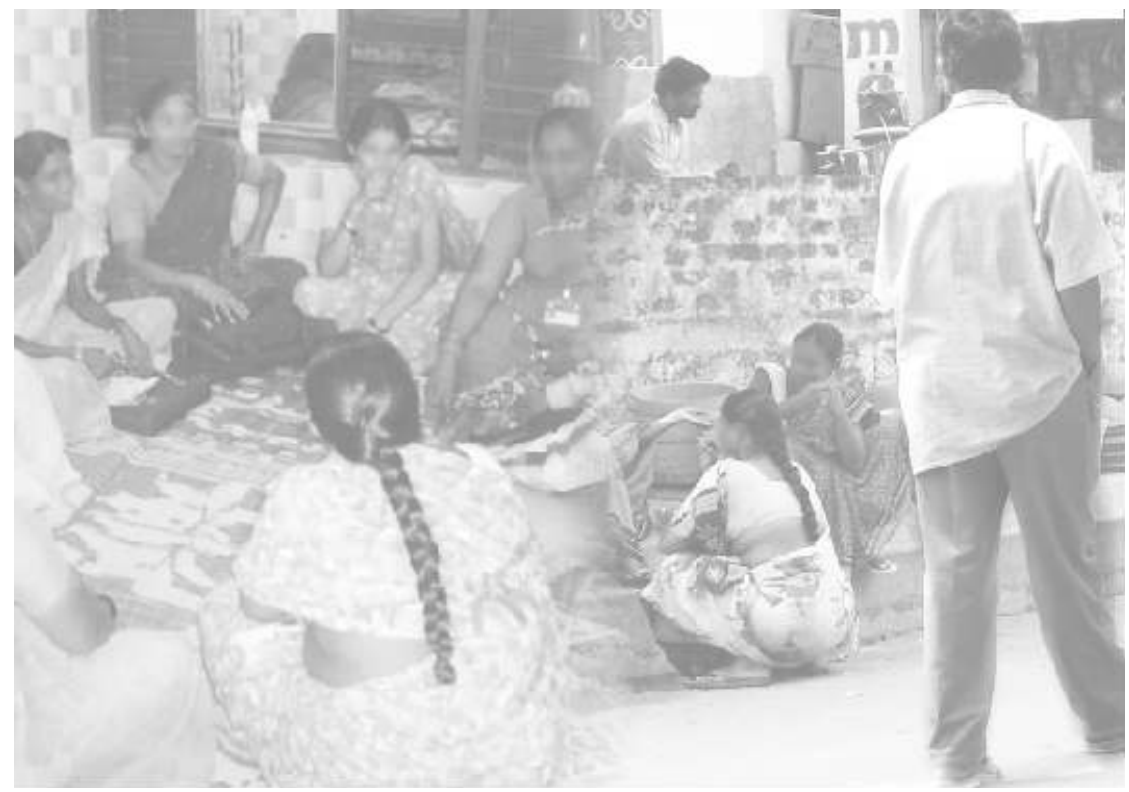




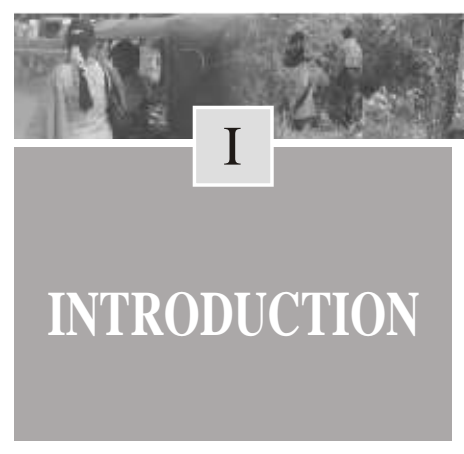

Karnataka is one of the states in India with high HIV prevalence. Results from the National Family and Health Survey-3 (NFHS-3) indicate that in 2005-06, 0.69 percent of adults aged 15-49 are infected with HIV. According to India's surveillance systems, HIV prevalence among pregnant women receiving antenatal care in Karnataka is 1 percent (NACO, 2006). The data also suggest that in 18 out of the 27 districts in Karnataka, the prevalence rate is more than 1 percent among pregnant women attending antenatal clinics. Prevalence among patients receiving treatment for sexually transmitted infections (STIs) increased from 10 percent in 2003 to 14 percent in 2005. In South India in general and Karnataka in particular, the epidemic is largely driven by heterosexual transmission, which accounts for more than 86 percent of reported infections (NACO, 2003). Although the epidemic is spreading to the wider society, sex workers remain a high-risk group. Surveillance data from 2006 among female sex workers in Karnataka indicate an HIV prevalence of 10 percent (NACO, 2006).

In an effort to gain control over the HIV epidemic in India, the HIV/AIDS programme has made substantial efforts in the last few years towards offering sex workers access to information about sexually transmitted infections including HIV/AIDS and to condoms and referrals to clinics and other medical services. Sex workers who move for the purpose of finding clients are found to be particularly difficult for the programme to cover, compared with sex workers who tend to remain at the same location. Those who are on the move are more difficult to contact, follow-up, treat, and empower.

The India AIDS Initiative Program of the Bill \& Melinda Gates Foundation has been an important contributor to the HIV/AIDS transmission-prevention programme in India. In its continuing efforts to improve its HIV programme in India, the Foundation has funded a research project through the Population Council of India aimed at understanding the patterns and drivers of female sex workers' mobility and the association of their mobility with HIV risk. This study has been conducted in the states of Tamil Nadu, Maharashtra, Andhra Pradesh, and Karnataka, states having high HIV prevalence. The Karnataka Health Promotion Trust (KHPT) has conducted the research in Karnataka. This report summarizes its findings. 


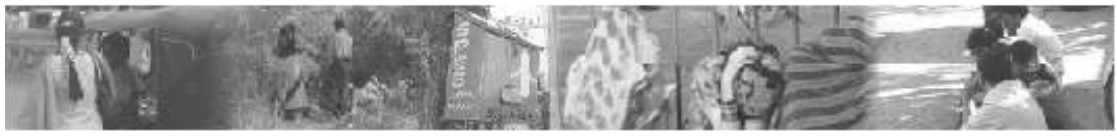

Some questions that the research addressed are: What is the number of female sex workers in any given area that are mobile? What are their destinations, and from where do they originate? What is the frequency and seasonality of this mobility/migration? What are their routes of mobility and duration of their stay in each location? What is the nature and volume of sex work that they obtain along these routes? How do they determine a particular destination? What are the individual, community, and structural factors that determine their mobility? How does their mobility influence their risk of acquiring HIV infection?

The study was undertaken with the following specific objectives:

1. assess the volume and patterns of mobility of female sex workers;

2. describe the characteristics of mobile female sex workers; and

3. examine the determinants of HIV risk among female sex workers, with particular emphasis on mobility-related characteristics.

Overall, the study is designed to examine the patterns and drivers of female sex workers' migration at the destination points, including intermediate destination points and points of origin, and their association with high-risk male migrant workers. This report presents results from the destination and intermediate destination sites of female sex workers in Karnataka.

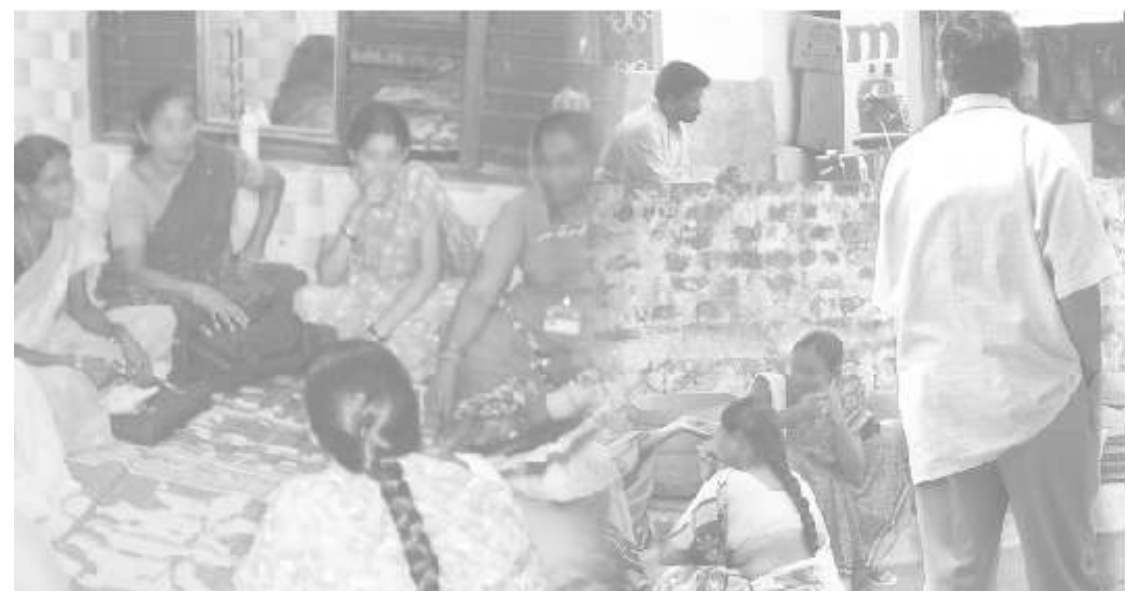




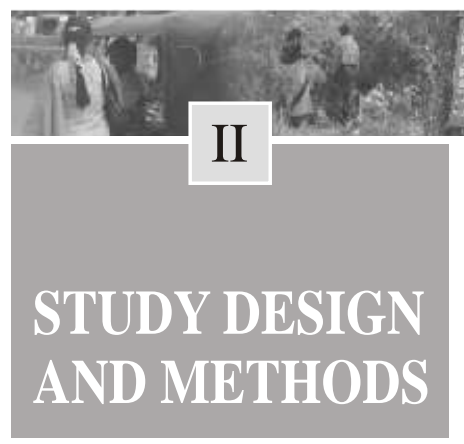

The cross-sectional study design addresses the following objectives and employs both qualitative and quantitative methods:

1. identification of major destination points, including intermediate destination points where female sex workers are concentrated;

2. characterization of destination points, including intermediate destination points, using qualitative research methods; and

3. gathering of quantitative data at destination point, including intermediate destinations.

The fieldwork was carried out during January August 2007. In the first phase, destination points (also referred to here as "study areas") were identified and characterized primarily using qualitative data followed by a quantitative survey.

Major destination and intermediate points were identified using mapping data gathered by the India AIDS Initiative of the Avahan and the NACO's sentinel surveillance data for HIV prevalence. These data were later integrated with the help of key-informant interviews from state and district health programmes and officials connected to the AIDS programme in Karnataka and programme personnel and partners of KHPT. The five major destination points selected were Bangalore Urban, Dakshina Kannada, Bellary, Dharwad, and Gulbarga. Initially, they were referred to as destinations points because of the large concentration of female sex workers in these areas at the time of sample selection. The mobility patterns that emerged, however, and the responses to the key-informant interviews made clear that these destination points constituted part of the sex workers' migration routes and, therefore, served as both "destinations" and as "intermediate destinations" at different times. In this report, therefore, these locations are termed "destinations" or "intermediate destinations" interchangeably as appropriate, and also as "study areas." 


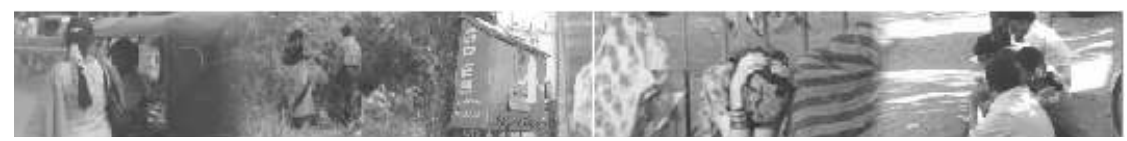

Map 1 : Study districts, Karnataka State, India

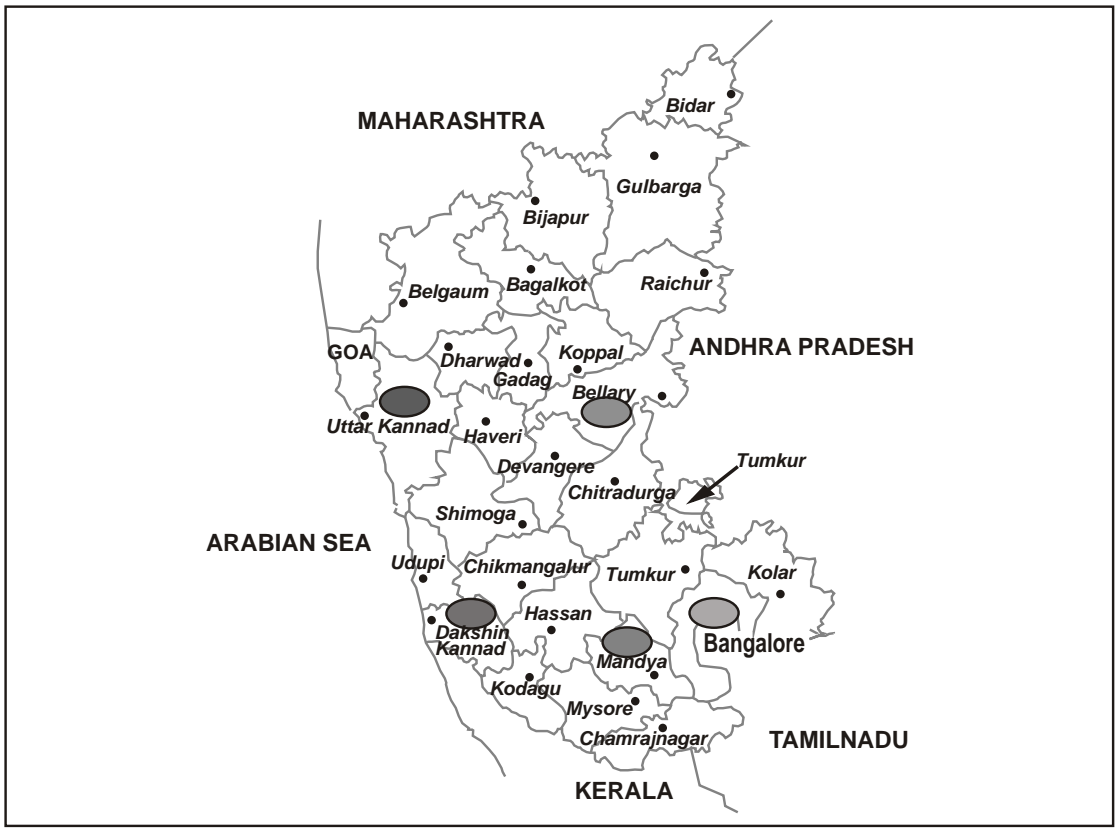

The study districts are shown in Map 1. Bellary is a situated in the northeast of Karnataka state, bordering Andhra Pradesh in the west. The district is known for its hot, dry climate and large-scale industry (for example, iron-ore mining and steel manufacture). Bellary is home to some of the richest and poorest people in Karnataka. The literacy rate is low at 57 percent, according to the 2005 Karnataka Human Development Report (KHDR). The district is a magnet for sex workers from neighbouring Andhra Pradesh and from other districts in the state. HIV prevalence among sex workers in the district has been estimated at 17 percent (IBBA, 2005).

Gulbarga, also in Northern Karnataka District, is hot and dry like Bellary.

Gulbarga borders Andhra Pradesh in the west and Maharashtra in the northeast so that the sex-work industry is strongly connected to these states. The district literacy rate of 50 percent (KHDR, 2005) is the lowest in the state. 


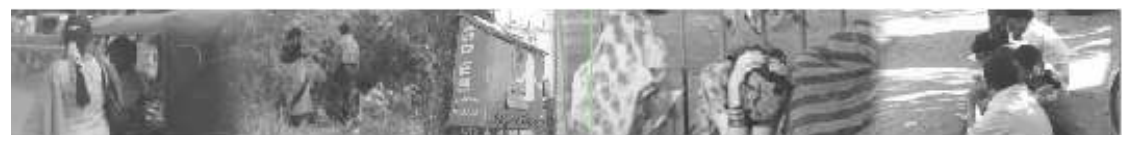

The economy of Dharwad District revolves around Hubli/Dharwad, the second-largest city in Karnataka after Bangalore and the commercial capital of Northern Karnataka. The district has a medium-level literacy rate (72 percent), compared with other districts in the state. Because it is more centrally situated, it is more clearly linked with sex-worker commerce in other districts of Karnataka. The nearest state is Goa to the west, one of the destination points of sex workers in Dharwad.

Dakshina Kannada is a coastal district in South Karnataka, which borders Kerala in the south. It is a wealthy district, much of the economy of which centres around the Mangalore port area, which attracts men to work in fishing and other port activities. Dakshina Kannada has the highest literacy rate in Karnataka ( 83 percent). Sex workers are attracted to the district from other areas of Karnataka and from Kerala.

Bangalore Urban is the capital of Karnataka State, one of the bustling hubs of India. Bangalore borders Tamil Nadu in the south and is close to Andhra Pradesh in the east. Its literacy rate is high ( 83 percent). The capital concentrates millions of people working in a variety of sectors and is the main destination for sex workers in Karnataka. The HIV-prevalence rate among sex workers in Bangalore Urban has been estimated at 11 percent (IBBA, 2006).

\subsection{Characterization of study areas}

Study areas were characterized with the help of qualitative data from a variety of ethnographic sources, including key-informant interviews (KIIs), in-depth interviews (IDIs), and mobility maps drawn by individual female sex workers. The purpose of the characterization was twofold: to identify individual, community, and structural factors that influence the mobility of female sex workers and their risk and vulnerabilities, and to inform the selection of primary sampling units (PSUs) for the quantitative survey. A total of 434 interviews (KIIs and IDIs) were conducted in the five study areas selected. Purposive selection of respondents followed informed-consent procedures.

The qualitative interviews were carried out in four stages. In the first stage, discussions were held with key individuals in each district to characterize all female sex-worker sites in terms of population size, type (brothel, lodge, street, highway, home), female sex-workers' mobility, the existence of programmes aimed at female sex workers and their proximity to highways. District-level interviews were followed by interviews with local key informants, including 


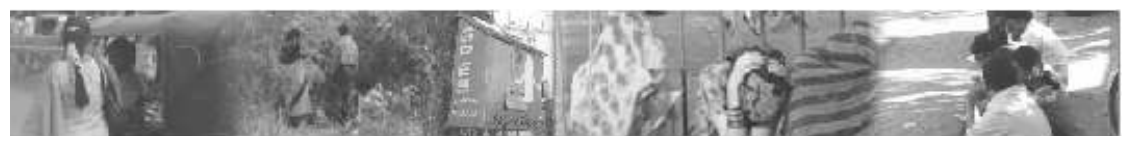

female sex workers, in order to map the physical locations where female sex workers solicit clients and to develop a profile of mobile female sex workers and of their mobility patterns. In the third stage, in-depth interviews were conducted with selected female sex workers to generate individual mobility maps; and finally, group interviews were held with sex workers to obtain information about group dynamics and group mobility.

The qualitative data were gathered by a team of 12 experienced, specially trained investigators (seven women and five men). The information from keyinformant and in-depth interviews and mobility maps were collected in Kannada (the state language of Karnataka). These interviews were translated into English and analyzed with the help of Atlas.ti, a computer-based textsearch programme (Muhr, 1997).

The district-level descriptions helped identify small and large sites where sex workers congregate (hot spots) including brothel areas, soliciting locations such as roads, highways, bus stands, railway stations, and market areas. Lists of hot spots were used to prepare a list of primary sampling units (PSUs). PSUs were formed by combining small areas or by segmenting the large areas such that each PSU included approximately 500 sex workers. Forty-five PSUs were formed, of which 30 were selected randomly to constitute the sampling frame for the quantitative survey.

\subsection{The quantitative survey}

The purpose of the quantitative survey was to provide an estimate of the numbers of mobile female sex workers and to determine the relationship between their mobility factors and their HIV-risk behaviour. For the purpose of the survey, a female sex worker was defined as "mobile" and included in the study if she

a) had been engaged in sex work for at least one year;

b) had visited two or more places for the purpose of sex work in the past to years; and

c) one of those moves/visits was made across the district.

The study was confined to female sex workers aged 18 and older. 


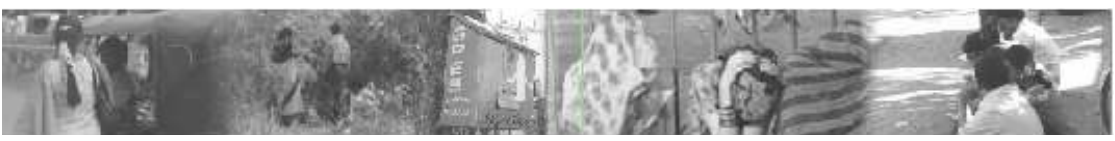

\subsection{Sample size}

Power calculations based on 30 percent inconsistent condom use among female sex workers indicated that a sample of 200 mobile sex workers interviews was sufficiently powerful for determining inconsistent condom use and associated risk factors, including degree of mobility. Assuming that half of the randomly selected female sex workers are mobile in each district, we sought between 300 and 400 female sex workers for interview. A total of 2,406 sex workers were screened, of which 1,499 satisfied the inclusion criteria described above. Thus, in survey terms, 62 percent of all the female sex-workers interviewed in Karnataka were "mobile."

\subsection{The sample design}

Because of the differences in the way sex work is practiced, in every PSU within each district the study adopted two types of sampling procedures for selecting brothel-based and non-brothel-based sex workers, namely two-stage systematic sampling and time-location sampling procedures.

For the selection of brothel-based sex workers, a two-stage systematic sampling procedure was used. First, the lanes/small pockets/areas within each larger brothel site were listed. Using the probability-proportionate-to-size procedure, the number of brothels to be selected in each large area was predetermined. After fixing the number of sex workers to be interviewed from each selected lane, the sublanes or small areas were selected systematically from the lists as first-stage samples. In the second-stage sampling, brothels were systematically selected; the first house was randomly selected, and subsequent houses were selected at a calculated interval. One sex worker from each selected brothel was interviewed using a screening tool.

For selection of sex workers in non-brothel-based areas, a time-location sampling procedure was used. The social maps prepared during the qualitative research formed the base for the selection of these non-brothel-based sex workers. From the social maps of each area, locations of smaller sites were listed. After listing the sites from social maps, the key informants and NGO staff were contacted again to determine the timing of the sex workers' visit to the sites. Thus, for each area, a list was prepared that detailed when sex workers would be available. Time slots were fixed for the interviewers to visit the site and wait for sex workers. Those workers who came to the site at the determined time were selected for interview by means of a screening tool. 


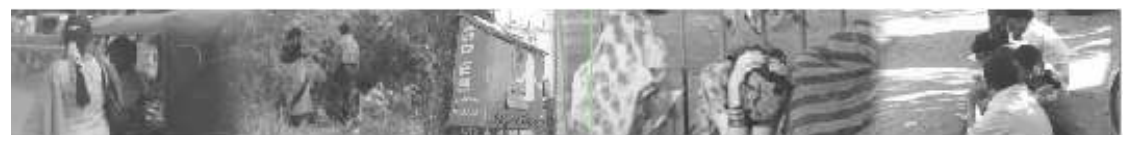

The screening interview collected information on the women's age, place of contact (brothel, lodge, home, street, highway), district where the interview was conducted, number of places the women had visited in their lifetime for sex work, number of places they had visited in the past two years for sex work, and number of places they had visited in the past two years outside of the district where they currently worked. This information helped to identify their mobility according to the study criteria and to estimate the level of mobility among this representative sample.

The survey instrument administered to eligible sex workers included question concerning socioeconomic and demographic characteristics, living conditions, media exposure, lifestyle, support services, migration/mobility pattern, sexwork history, jatra/event-related mobility for sex work, seasonal mobility, relationship to place of origin, clients' profile, experience of violence, availability and access to condoms and the ability to negotiate their use, condom use in current and previous locations, experience of sexually transmitted infections, and knowledge and risk perception concerning HIV/AIDS.

Quantitative surveys in all study areas were conducted using a paper questionnaire by eight trained, experienced interviewers (three women and five men). Interviewers were specially trained in the ethical conduct of interviews concerning sensitive issues and with marginalized populations. Informed consent was obtained from all the respondents, and information was stored in safe places with the research agency. Data quality was ensured through a supervisory structure that provided regular feedback in the field and data cleaning in the office. Data-processing operations included editing in the field, feedback to the team, data entry with a customized data screen, and dataquality checks, cleaning, and tabulation. The Statistical Package for Social Sciences (SPSS) was used for data-consistency checks and analysis.

\subsection{Female sex workers' degree of mobility}

In this study, information about mobile female sex worker is not compared with that of nonmobile female sex worker, but an index was constructed to classify female sex workers on a continuum of mobility ranging from least-to-most mobile. The indicators of mobility used in the study are: total number of locations where the sex worker visited/stayed in the past two years $(1,2,3,4$, and 5+ locations); the number of districts where she visited/stayed in the past two years (1, 2 or $3+$ districts); and whether the sex worker visited jatra areas (No; Yes went alone; or Yes went with a group). 


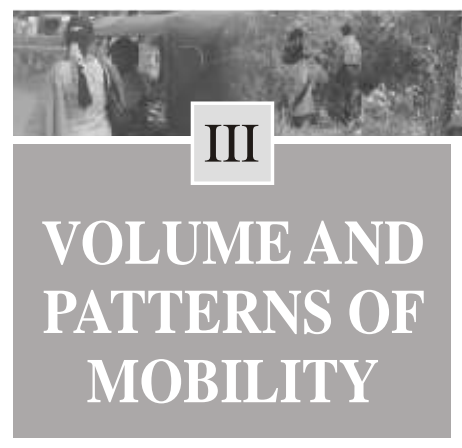

\section{1}

Volume of mobility

The survey data indicate that 84 percent of female sex workers interviewed moved at least once for sex work in the past two years and that 78 percent moved at least twice in that period. Three-fourths of the female sex workers moved at least once across the district. On average, female sex workers moved 3.5 times in the past two years for sex-work purposes, and 2.8 of these moves were made across the district (see Table 1). Figure 1 shows the proportion of those who moved at least once across the district.

Figure 1 : Percentage of mobile female sex workers who moved in the past two years, by district, Karnataka State, India, 2006-2007

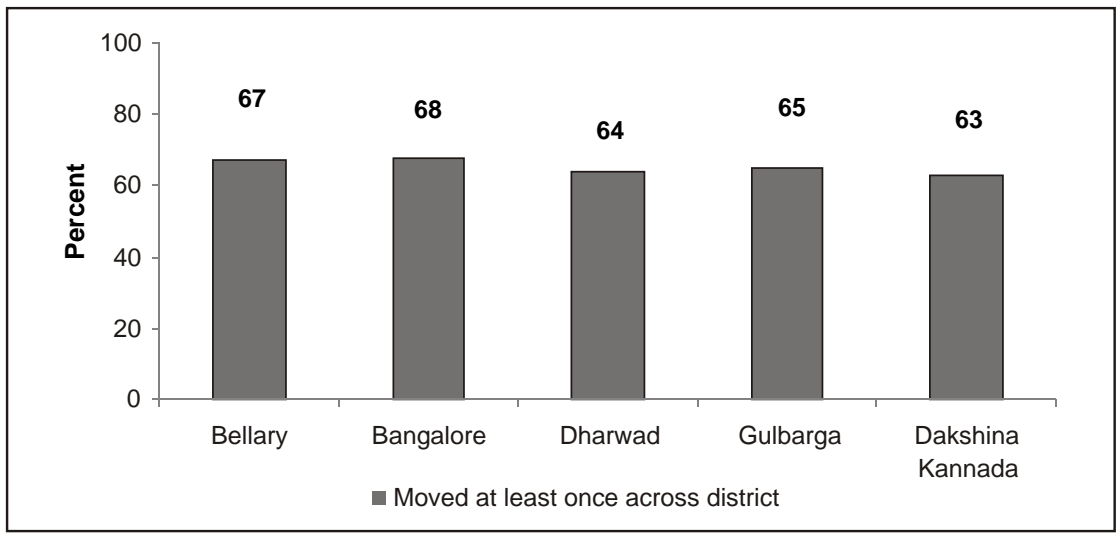

As indicated in Table 1, 65 percent of female sex workers are mobile, and this proportion varies little by district. Women engaging sex work from highways, lodges, and brothels are more mobile than street and home-based sex workers. This finding is consistent for all study districts, with the exception of Bellary. This finding might, as suggested by the qualitative data, indicate that sex workers soliciting on highways tend to services clients who are themselves on the move (for example, truck drivers). Some of them travel to other locations with the help of their clients. One of the characteristics of brothels and lodges is their intense selection process and the constant need for "new faces" for their 


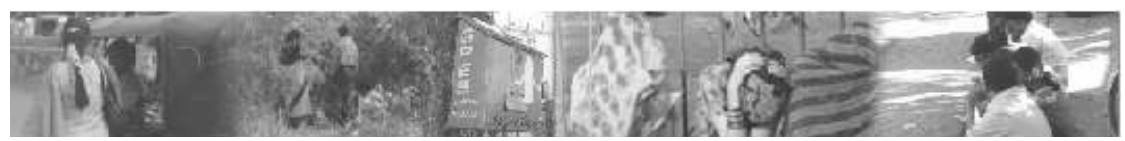

clients. As a result, network operators (pimps, brokers, agents, madams) tend to exchange the girls, which increases the mobility of those working in these setups.

Figure 2 indicates that sex workers across all age groups are mobile. Mobility is highest, however, among sex workers aged 25-29. The younger and older sex workers tend to be less mobile for different reasons; younger sex workers may not have developed a network sufficient for moving from place to place, whereas older sex workers tend to be more settled and less in demand. Younger female sex workers aged 15-24 are more mobile in Gulbarga (67 percent) and Dakshina Kannada (64 percent) districts, compared with those in the other study districts.

Figure 2 : Volume of mobility of female sex workers, by age and district

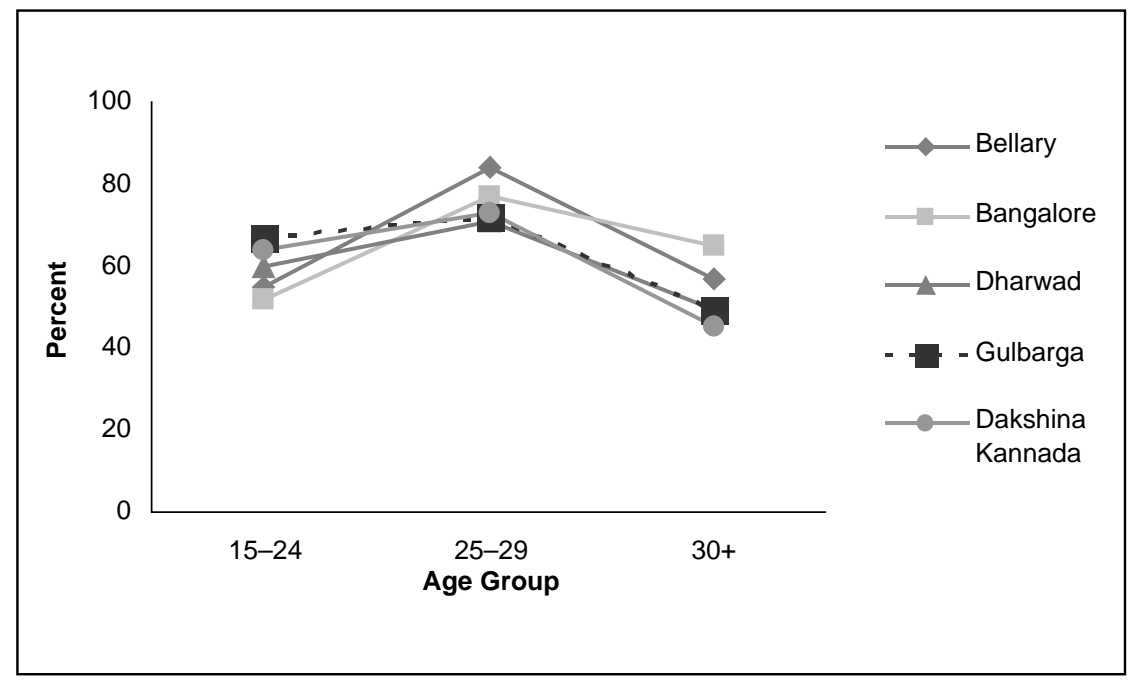




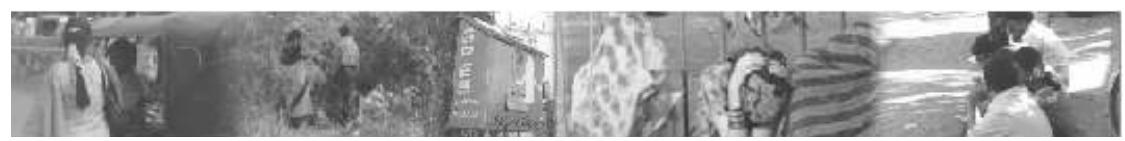

Figure 3 : Volume of mobility of female sex workers, by age by type of sex work

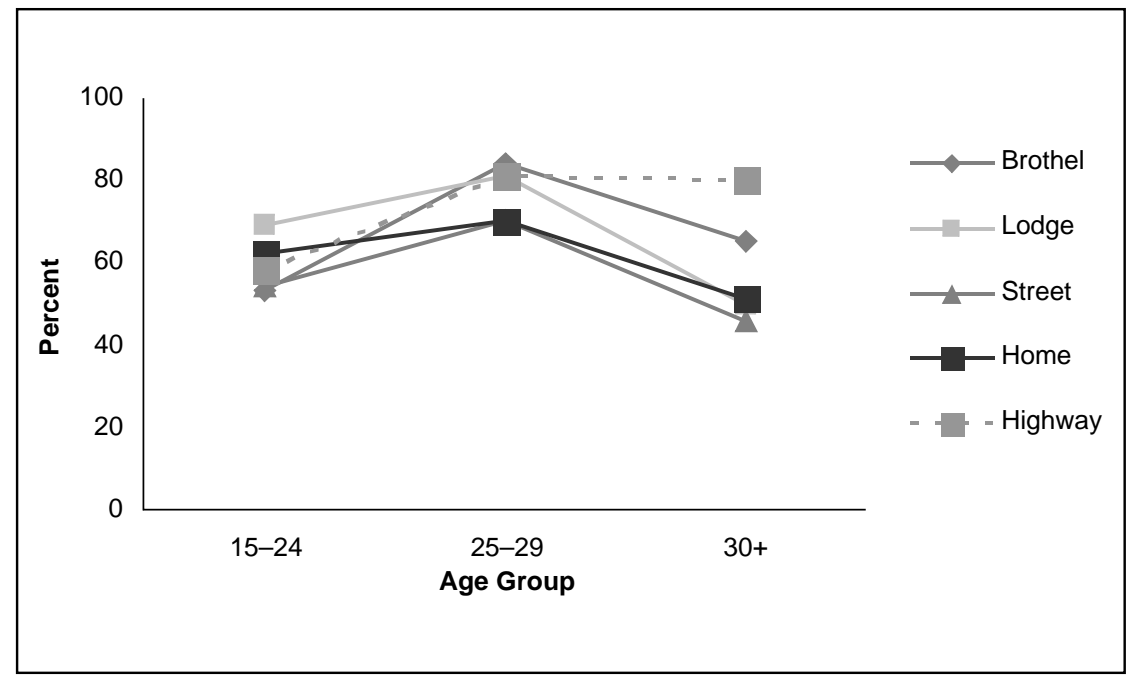

Eighty percent of highway and 71 percent of lodge-based sex workers within age group of 25 to 29 were found to be mobile (see Figure 3). This finding is particularly significant, given the size of the lodge-based sex-work industry in Dakshina Kannada, and Bangalore in particular.

\subsection{Patterns of mobility}

The responses of mobile female sex workers who participated in the survey $(n=1,499)$ provided data that clarify their patterns of mobility. Information about the workers' current locations and their two previous location is presented visually in the maps below (Figures 48). The thickness of the line represents the volume and the arrows indicate the direction of their mobility. We distinguish between interstate (dotted arrows) and interdistrict movement (solid black arrows). 


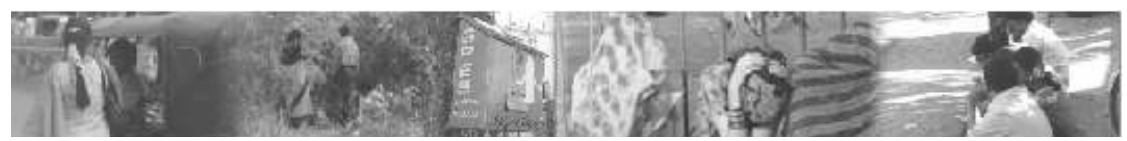

Map 2 : Routes of mobile female sex workers currently in Bellary District

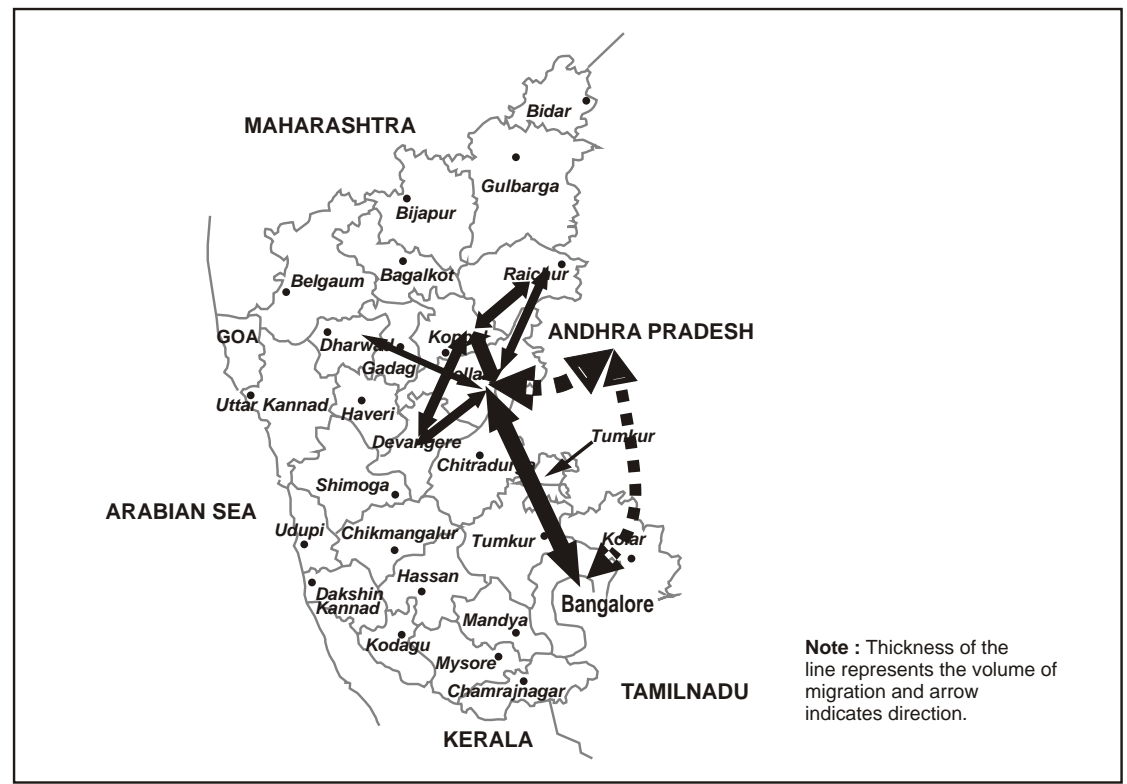

Map 2 shows that Gulbarga District is second to Bellary District for interstate mobility of sex workers. The workers move from and into Andhra Pradesh, the neighbouring state. Women come from either directly or through Bangalore. Within Karnataka, they move from and into Bangalore and Dharwad and also within the neighbouring districts Koppal, Raichur, and Davanagere. 
Map 3 : Routes of mobile female sex workers currently in Bangalore Urban District

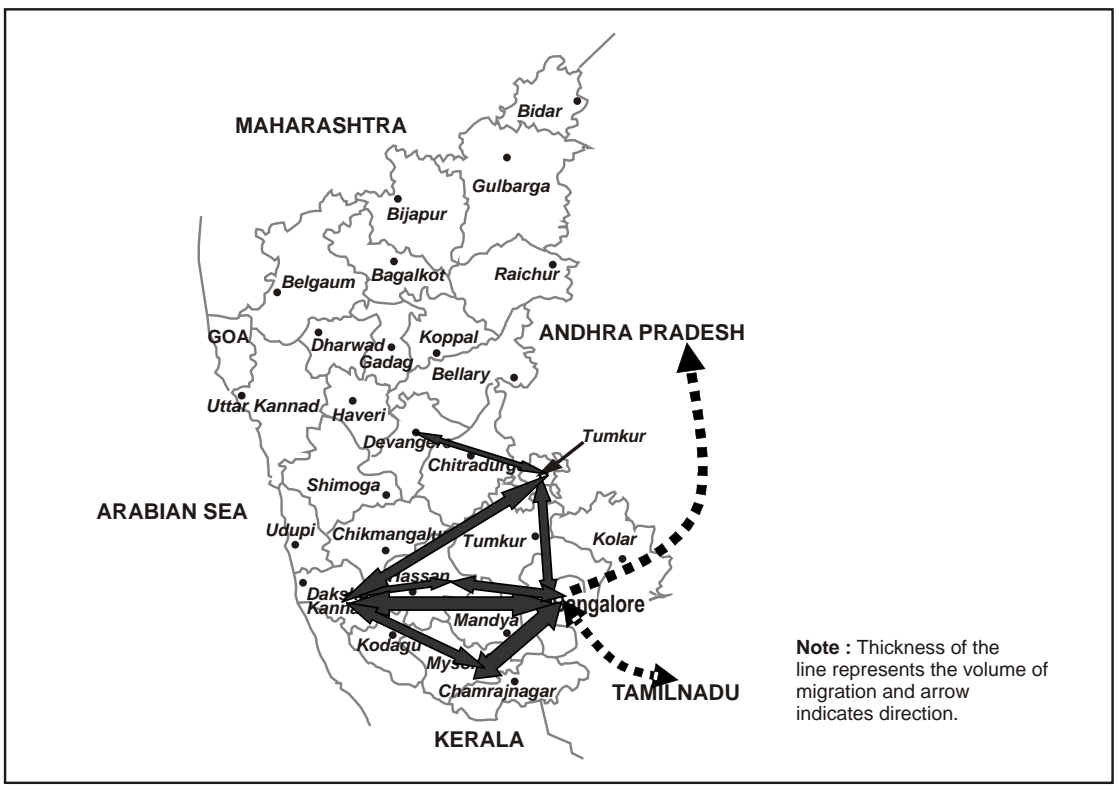

Map 3 illustrates that the sex workers of Bangalore are strongly connected to other districts in South Karnataka, including Mysore, Tumkur, Dakshina Kannada, and to a smaller extent, Mandya and Hassan. These places are both intermediate and destination places. 
Map 4 : Routes of mobile female sex workers currently in Dharwad District

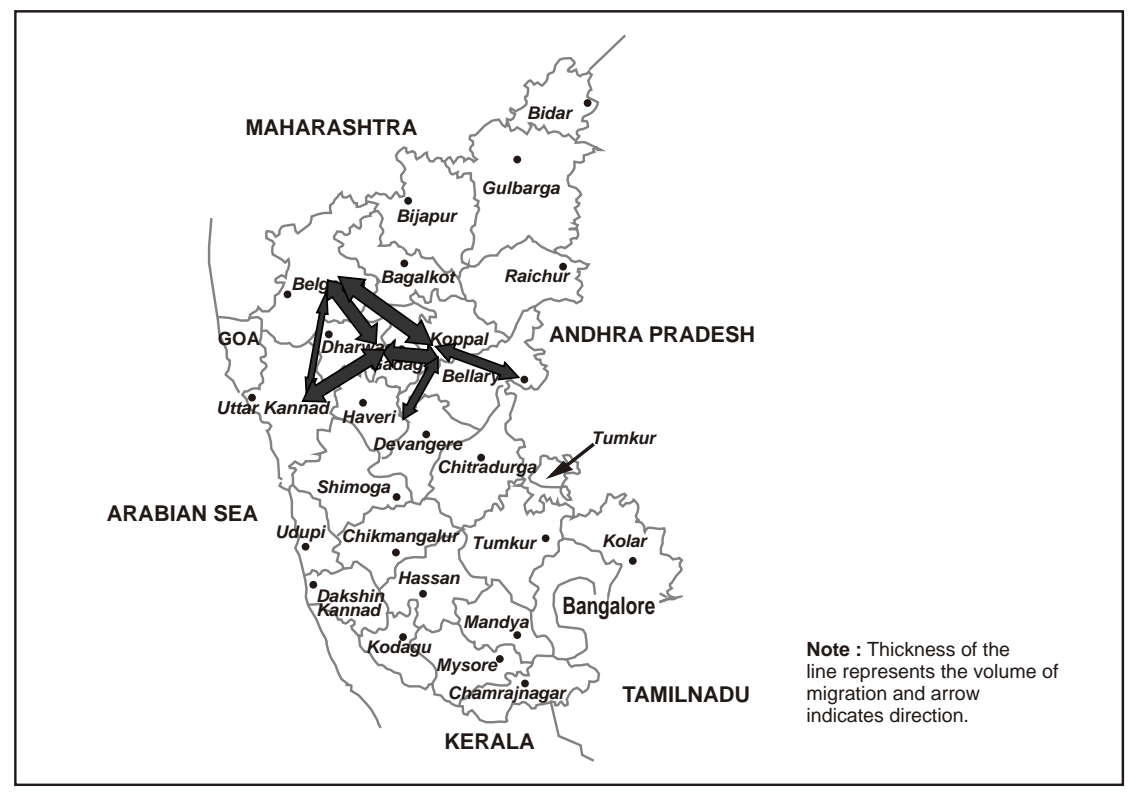

As in the case of Bangalore, Dharwad is mainly connected to the neighbouring districts of Belgaum, Uttara Kannada, and Gadag, which are all interconnected (Map 4). The Bellary Gadag Dharwad route connects Dharwad and Bellary. 


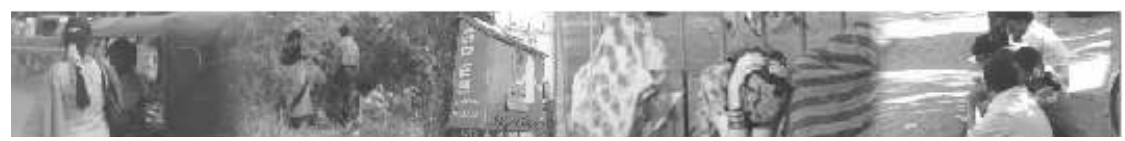

Map 5 : Routes of mobile female sex workers currently in Gulbarga District

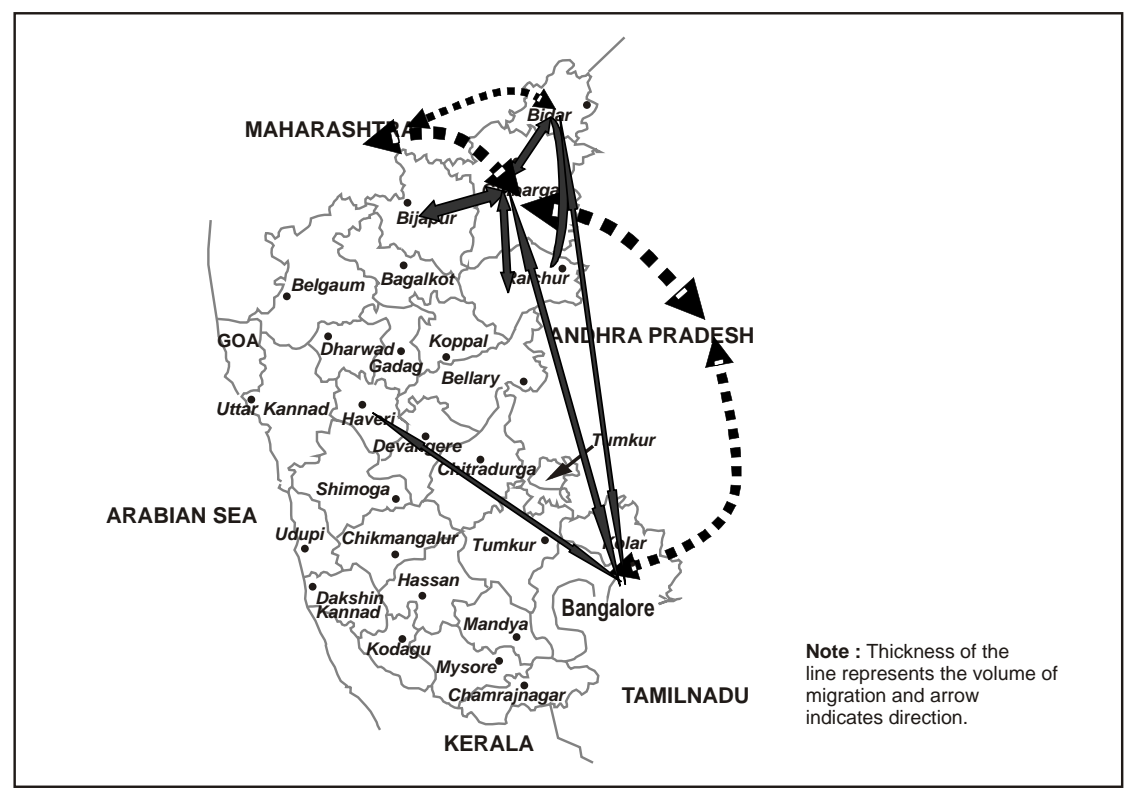

Gulbarga (see Map 5) reveals the strongest interstate mobility of all the study districts, connected particularly with Maharashtra and Andhra Pradesh, Bellary (both directly and through the Karnataka districts of Bidar and Bangalore). Except for Bidar and Bangalore, other districts that are well connected to Gulbarga District are Raichur and, to a smaller extent, Bijapur. 


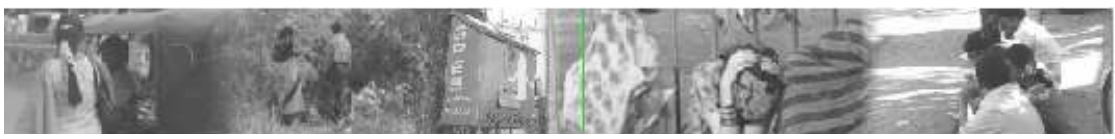

Map 6 : Routes of mobile female sex workers currently in Dakshina Kannada District

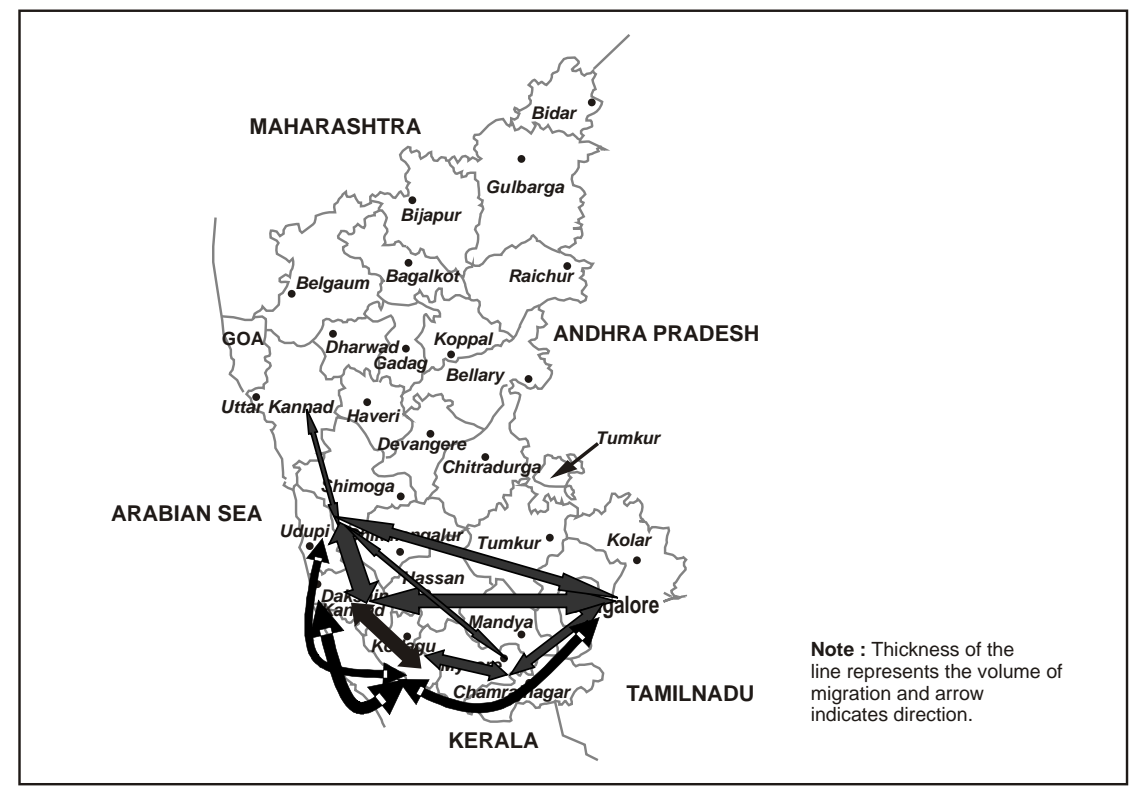

A strong connection exists between Dakshina Kannada District and other districts in southern Karnataka, mainly Bangalore, Mysore, Udupi, and Kodagu (see Map 6). These districts are both intermediate places and places of destination. Dakshina Kannada is also connected to the neighbouring state of Kerala, both directly and though Bangalore, Udupi, and Kodagu.

In summary, Bangalore is the central point of female sex workers' routes in Karnataka. In Southern Karnataka, many female sex workers move between Bangalore and Dakshina Kannada, but also to and from Mysore and other districts. In Northern Karnataka, the volume of female sex workers' mobility is great between neighbouring districts, and especially along the route of Belgaum to Dharwad to Bellary. 


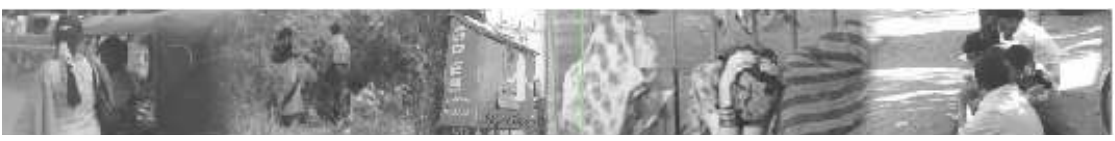

\subsection{Jatra/ seasonal mobility of female sex workers}

Karnataka hosts a number of pilgrimages (jatras) in which many thousands of people assemble for a short time at a specific location. These jatras provide a venue where female sex workers find a ready market for their services. Large numbers of men visit such sites. Determining the extent of the female sex workers' attendance at jatras and their main places of destination in the study districts can provide programmes with potential locations for interventions.

Nearly one-third of the female sex workers surveyed have gone to jatras in the past year (see Table 3). This proportion varies significantly by district and type of sex work, however. Female sex workers go to jatras in Northern Karnataka, half of Gulbarga female sex workers have been to jatras in the past year, as have more than 40 percent of Dharwad female sex workers and more than onethird of those surveyed in Bellary. Far fewer female sex workers go to jatras in the southern districts. More than one-fourth attend them in Dakshina Kannada, and a small minority do so in Bangalore. Few brothel- and lodge-based female sex workers go to jatras, compared with female sex workers working in other ways. More than half of street-based female sex workers, nearly half of homebased female sex workers, and almost one-fifth of highway-based female sex workers travel to jatras. The variability in jatra mobility by type of sex work explains the differences according to the district. The northern districts have high proportions of street and home-based female sex workers, and the southern districts have high proportions of brothel- and/or lodge-based female sex workers.

Map 7 indicates the districts that represent the main jatra destinations for female sex workers from the study districts. The four pattern the arrows indicate of the volume of the movement towards a district: Among the female sex workers in a district who go to jatras, grey solid arrows indicate that 75 percent or more female sex workers have travelled to the indicated district, black outlined empty arrows indicate 50 to 74 percent, grey patterned arrows indicate 25 to 49 percent and black arrows indicate less than 24 percent. 


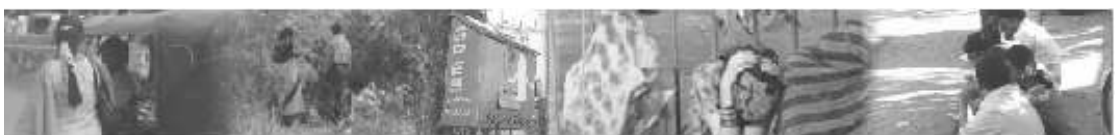

Map 7 : Main jatra destinations for female sex workers in the study districts

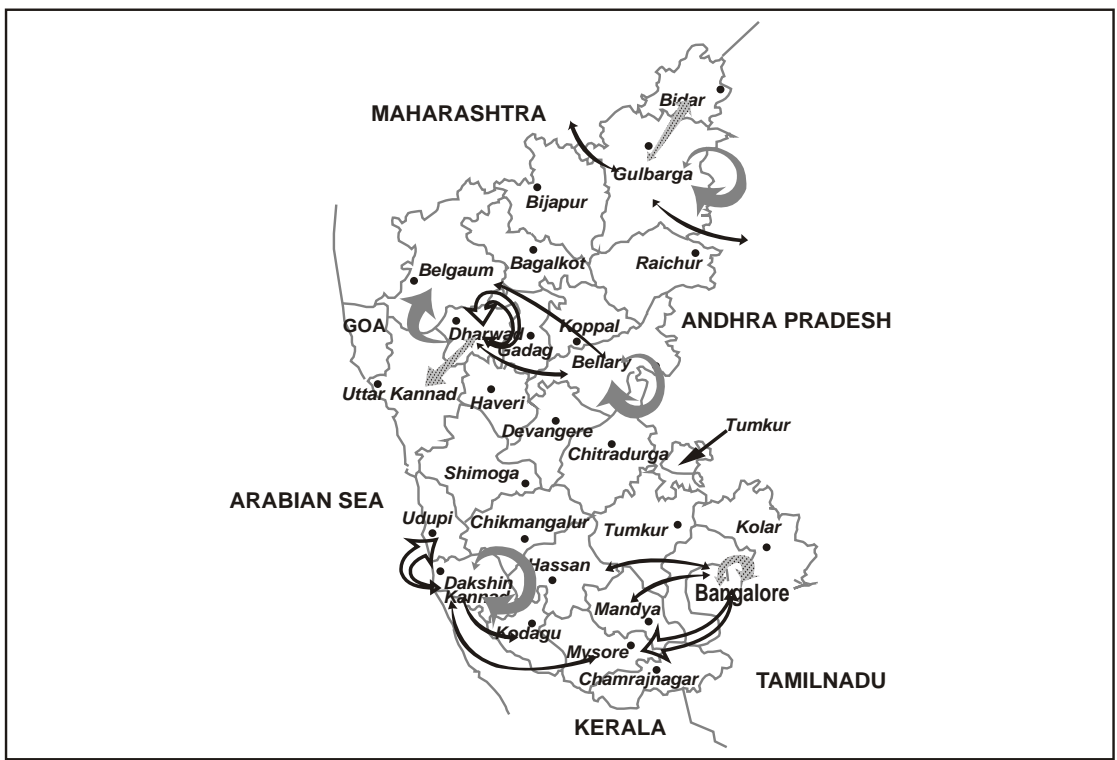

As indicated above, the districts with the highest sex-workers attendance at jatras are the northern districts. In Gulbarga, more than 80 percent of female sex workers who go to jatras go to places within the district, such as Gulbarga and Yadgir. Female sex workers in Gulbarga District, however, also go to jatras in other districts, namely those in the neighbouring districts of Bidar (27 percent), Solapur and Osmanabad (each 22 percent), and Rangareddy (18 percent).

The most popular jatra for female sex workers from Dharwad District is in Saundatti in Belgaum District. Among female sex workers who report having been to jatras in the previous year, 72 percent have been to Saundatti. Many Dharwad female sex workers (56 percent) also go to various jatras within the district, especially to those in Hubli and Garag. The neighbouring district of Uttara Kannada also hosts jatras that are popular destinations for a third of the female sex workers in Dharwad District, especially in Ulavi, but also in Sirsi and Yallapur. 


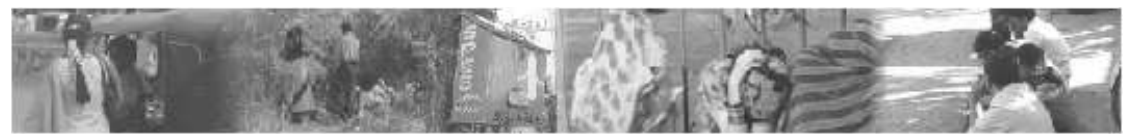

In Bellary District, most female sex workers who go to jatras usually go to several places within the district ( 88 percent). Munirabad and Hampi are the preferred destinations, followed by Bellary and Hospet. Other than the jatras in Bellary, female sex workers also go to Saundatti in Belgaum district.

Jatra mobility is a lesser phenomenon in Southern Karnataka. Most Dakshina Kannada female sex workers who go to jatras go to places within the district (81 percent). The most common destinations are Dharmastala and Subramanya.

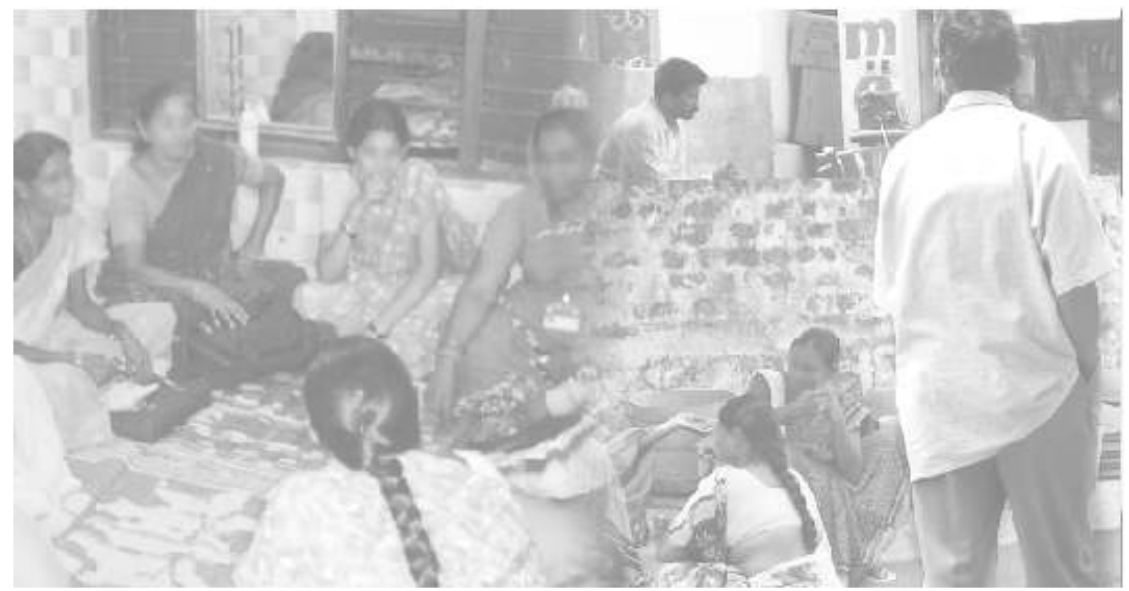




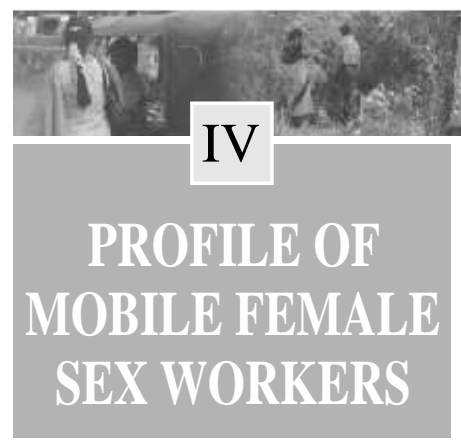

\subsection{Socioeconomic and demographic profiles}

Seventy-eight percent of mobile female sex workers in Karnataka are aged 18-29, more than half of whom are aged 25-29 (as shown

in Table 4). Slight variations in the age distribution of mobile female sex workers were noted across districts. Those in Karnataka have low levels of schooling; nearly 60 percent have less than a fifth standard education and about one-third are illiterate (see Table 4).

As shown in Figure 4, two-thirds of the mobile female sex workers in Karnataka are divorced, widowed, or separated, and one-fourth are never married. The proportion of mobile female sex workers who are divorced/widowed/separated is particularly high in Dharwad (70 percent), Gulbarga (68 percent), and Bangalore (65 percent) districts, compared with that in the other study districts.

Figure 4 : Marital status of mobile female sex workers, by district

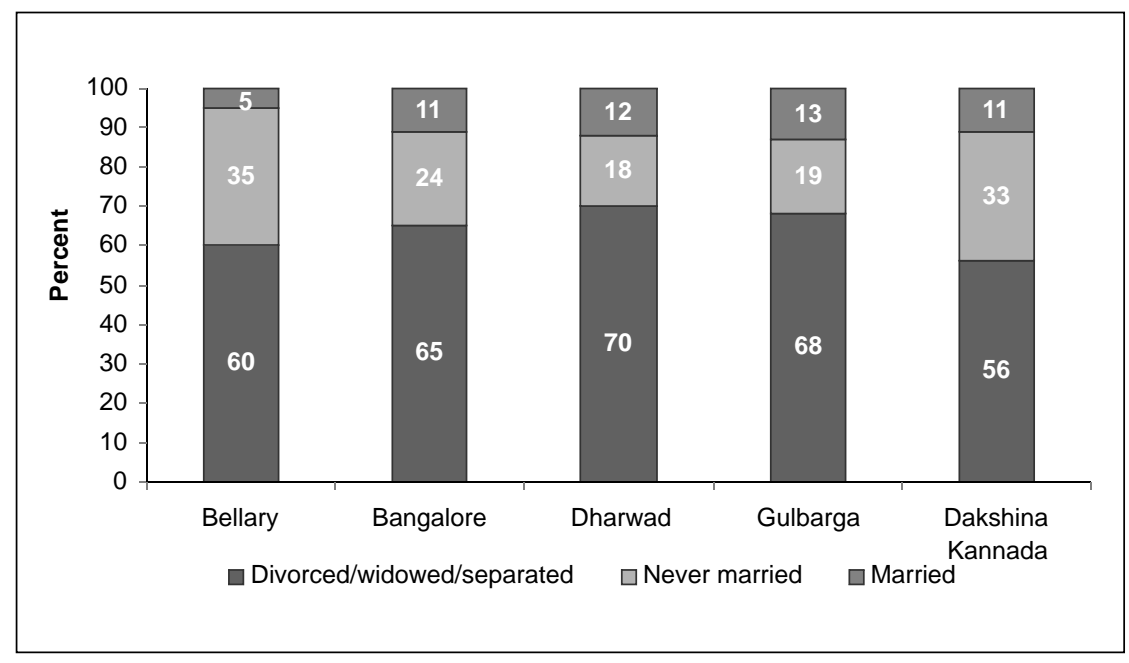




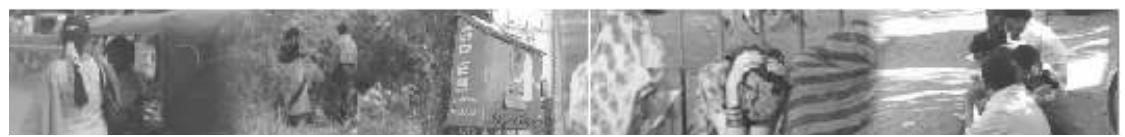

Key informants in most districts have estimated that the majority of female sex workers are divorced/ widowed/ separated:

"Sex workers are poor. Their economic condition is very bad. Widows and those who are separated go to various places in greater numbers." (Dharwad, KI, broker)

"The majority of the women in this profession are separated from their husbands, and a small number will be staying with their husbands, but husbands will be unaware of their profession. The women who are married and separated have children and keep them at a hostel in order to hide their profession from the children." (Bangalore, KI, local NGO representative)

Three-fourths of mobile female sex workers in Bellary and Bangalore and more than half from other districts earn money only from sex work (see Figure 5). One-fourth of mobile female sex workers work at other jobs in addition to performing sex work. Their most common sources of income are from work not related to sex work, such as petty business, housemaid services, nonagricultural labour, and agricultural labour.

\section{Figure 5 : Mobile female sex worker's sources of income by district}

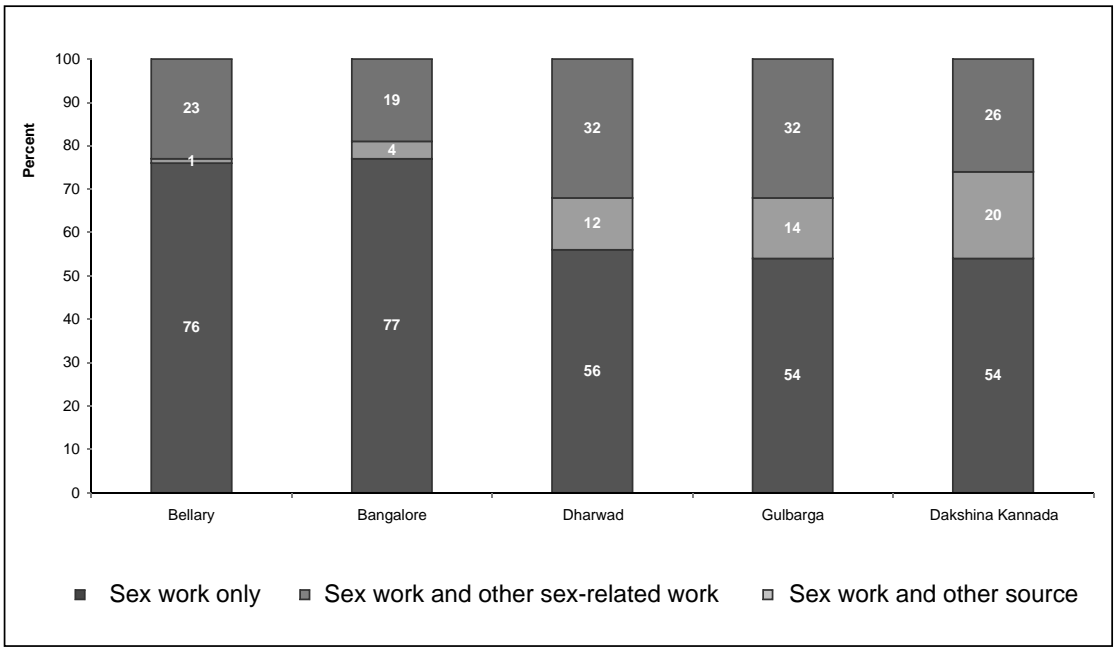




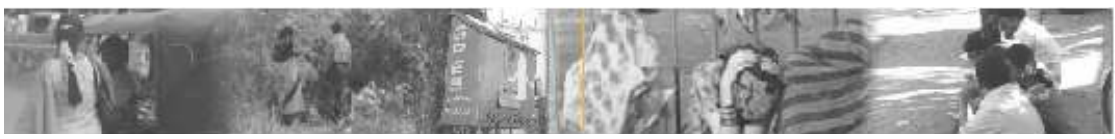

Nearly one-third of mobile female sex workers in Karnataka owe money to others. The amounts they owe range from 300 to 80,000 rupees, (approximately $\$ 6$ to $\$ 1,604$ USD). The median amount of money they owe is 4,000 rupees (\$80). Women who perform work other than sex work (either sex-related or not) tend to have debts, which may be one reason for their working at multiple jobs. Notably, higher proportions of sex workers in the districts of Bellary, Dharwad, and Gulbarga have debts greater than 1,000 rupees (\$20) (as shown in Table 4).

\subsection{Reasons for entry into sex work}

The survey participants were asked about their reasons for entering sex work, and their responses indicate their financial situations as their main motivation (94 percent) (see Figure 6). Of the respondents who were compelled by poor finances, more than one-third were in debt when they began sex work. Almost half of the respondents who are currently in Bellary and Bangalore reported that they had debts when they began sex work.

Most sex workers from Karnataka (especially those from the northern districts) are initiated into sex work through the devadasi tradition Therefore, it came as a surprise that none of the sex workers mentioned that she had entered sex work as a result of this tradition. The question was not phrased with specific reference to traditional reasons. In recent years, the devadasi tradition has become a pretext for entering sex work and enjoying the social sanctions associated with it without performing the functions associated with the tradition. Consequently, respondents may not have considered the tradition as a reason for entering into sex work.

Key informants in all of the study districts mention their financial situation as the main reason for beginning sex work:

"The sex workers are deserted, widows, love failures, or some of the parents or lovers have driven them to this field. They come to do sex work because of their poor family condition. They don't come on their own. Most of them come to do sex work because they don't want their children to face any problems and to maintain their families." (KI, Gulbarga, peer educator) 


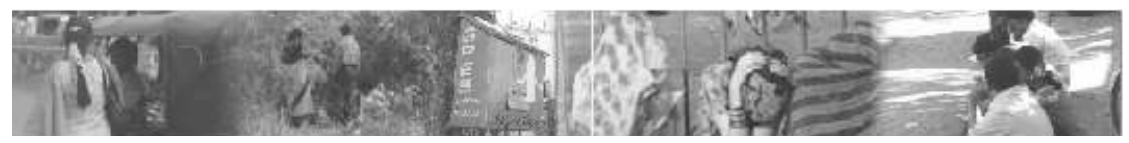

Figure 6 : Respondents' reasons for entry into sex work, by district

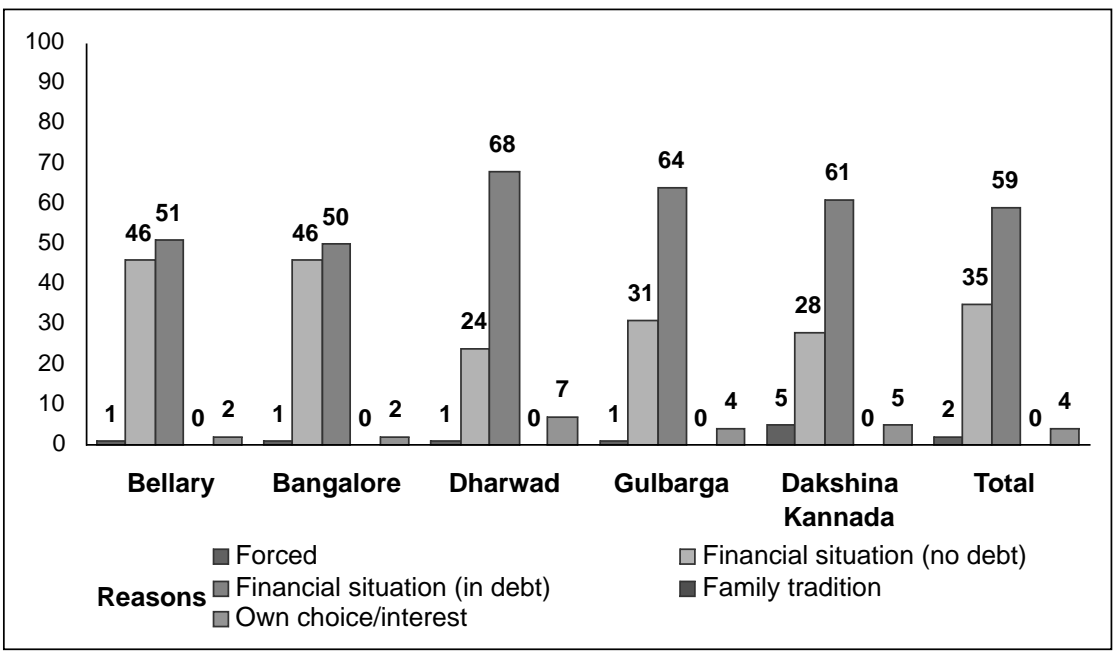

\subsection{Lifestyle characteristics}

Two-thirds of mobile female sex workers consumed tobacco products and nearly 60 percent drank alcoholic beverages in the month prior to the survey (see Table 6). A higher proportion of sex workers in Bellary and Gulbarga use tobacco products than in the other study districts. The proportion of female sex workers using alcohol is highest in Bellary (70 percent), Gulbarga (61 percent), and Dakshina Kannada (61 percent).

\subsection{Autonomy}

Three-fourths of mobile female sex workers in the five study districts reported that they are allowed to have some money set aside (see Table 7). One-fifth of participants have an individual bank account. Higher proportions of sex workers in Dakshina Kannada and Dharward than in the other districts reported having individual bank accounts and being allowed to have money set aside.

More than half of the mobile female sex workers have a cellular telephone, a finding that might be useful for the programme (see Table 7). In Dakshina Kannada more than three-fourths and in Bangalore 60 percent of the sex 


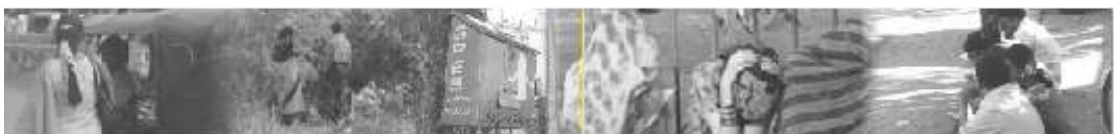

workers interviewed have cellular telephones. Among those who have cellular telephones, 80 percent use them to facilitate their work. The high proportion of cellular telephone user indicates the extent of the sex-work network. More than 60 percent of sex workers who have a cell phone are not willing, however, to disclose their number to the local nongovernmental agencies.

\subsection{Experiencing of physical violence}

Nearly a third of mobile female sex workers from the study districts reported having experienced physical violence in the past year. District-level variations were found in reporting physical violence; a significantly higher proportion of respondents in Bellary (38 percent) reported experiencing physical violence, compared with respondents in the other study districts (see Figure 7).

Among those who experienced violence, almost three-fourths of mobile female sex workers reported clients as the major source of violence (see Table 8). Police, regular sex partners, and others were mentioned far less frequently. Violence perpetuated by clients is reported in almost all of the study districts, whereas violence at the hands of policemen is a greater problem in Bellary and Bangalore. Violence from regular sex partners is greater in Gulbarga, Dakshina Kannada, and Dharwad.

The type of harassment and violence they experienced is described below by two sex workers:

"When I am attracting clients in the street in Bellary, Belgaum, and Hubli, if the police see us, they will scold and beat us. If the clients are drunk, they do not pay us the money we agreed on; they drag and abuse us on the street. Auto drivers harass us while we are attracting clients in the street. The goondas who are surrounding the bus stand will be watching us, and if we are caught when they are drunk they will take all our money from us." (Bellary, street-based female sex worker, from Andhra Pradesh, 26 years old)

"Once a customer called me by telephone. I thought that he would be alone, and I went without telling anybody. He took me to his place. His friends were also there. There were no other people. I was afraid. They all started raping me. I screamed, but they did not listen. Nobody could hear my screams in that place. One among them tightly shut my mouth. On that day I went through a lot of torture." (Bangalore, brothel-based female sex workers, from Calcutta, 22 years old) 


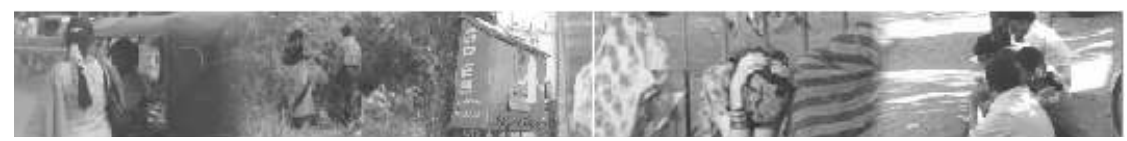

Figure 7 : Percentage of mobile female sex workers who experienced physical violence at least once in the past year, by district

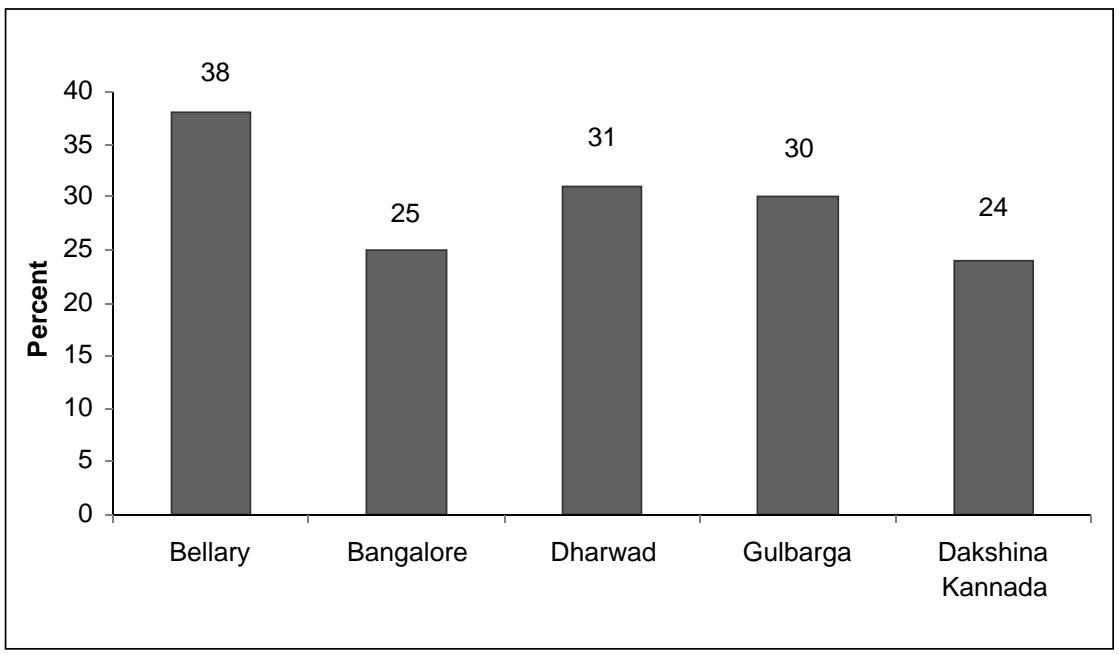

\subsection{Exposure to the mass media}

In the survey, participants were asked about their exposure to the mass media, including newspapers, magazines, radio, television, and cinema. Results indicate that almost every sex worker had watched television or movies in the past month, less than one-third had listened to the radio, and only one-fifth had read newspapers or magazines (see Table 9).

The proportion of sex workers who watch movies and/or television is high in almost all the study districts. Three-fourths of respondents in Bangalore and two-thirds in Dakshina Kannada (who also have higher literacy rates) have been exposed to radio and newspapers, whereas those in Bellary reported the lowest exposure to radio and print media ( 27 percent).

\subsection{Membership in associations}

An important programme consideration is the level of female sex workers' exposure to and membership in various social organizations and exposure to 


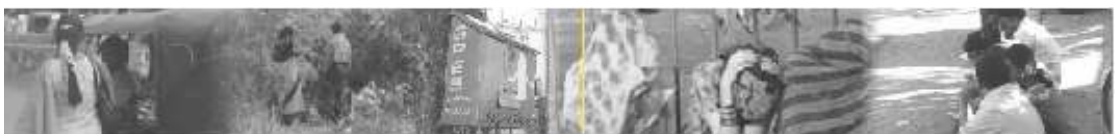

the programme. Overall, more than 60 percent of surveyed respondents reported membership in a self-help group (SHG), a community-based organization (CBO), a nongovernment organization (NGO), or a sex-workers' collective.

Concerning the benefits they gained from these associations, the large majority of sex workers reported having received condoms, information about STIs, and referral to health centres. The programme appears to be most effective in terms of condom distribution in Bellary and Gulbarga, in providing information about STDs in Gulbarga, and in providing health-centre referrals in Bangalore.

Two female sex workers reported a variety of services accessed through the programme and described the support they received:

"A sex worker won't have a house, toilet, or bathroom. These are all necessities. Swati House provides all these. Swati House people call the doctors and ask them to give treatment to the sex workers, and this is a necessity. If I have sexual disease, I receive treatment at Swati House. If clients or the police torture me, my partner will help me. I can face any kind of problem, because the Swati House people solve the problem." (Bangalore, home-based female sex worker, local, 33 years old)

"We receive information about HIV/AIDS from Myrada and Soukhya people, government programmes, and street plays. They also give condoms free of cost. The Myrada office conducts many meetings, and we are also invited there. They teach us how to have safe sex and protect ourselves. They also give us free check-ups and free treatment. Condoms are easily available in the places where I go for sex work. I have requested the Myrada people to provide a residential facility for me in the place where I do sex work. Now we are aware because of the suggestions given by the Myrada and Soukhya people. We can take care of ourselves." (Hospet, street-based female sex worker, from Koppal, 20 years old)

One female sex worker, however, gives a disturbing report of the quality of the programme in Mangalore lodges. This report is particularly important, in light of the extent of the lodge-based sex work in Mangalore.

"We get no help from the NGOs, because the sex work performed in the lodge is not known to anybody. But condoms are available. The lodge people don't allow the NGO people to enter into the lodge. The lodge owners and the pimps get their condoms from the peers so that they can sell them to the clients, but no information is given to the sex worker about STIS/HIV. So the sex workers in 


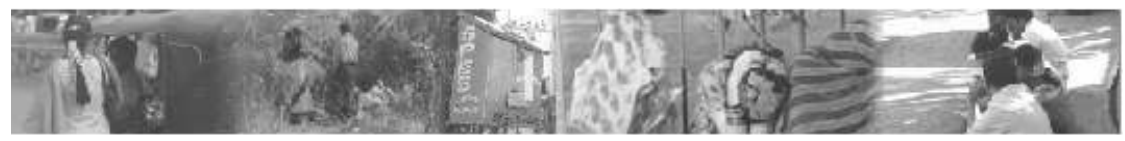

the lodge don't know about the proper use of condoms or about STIs/HIV. The sex workers working in the lodges don't know about STIs/HIV. The NGOs are not allowed to give us information about these issues." (Mangalore, lodgebased female sex worker, from Madikeri, 23 years old)

Sex workers are not always happy with the services offered by the programme. As one interviewer reports:

"Once there was raid by the police and she (respondent) was arrested. The Myrada people rescued her. She doesn't go to the Soukhya clinic because the Myrada doctor is a thief, and he is very bad. She goes for testing in her native place that is Vijayavada. She won't go to the private hospital or to the Myrada clinic in this place because the doctor in Myrada is not a good doctor. He is bad and doesn't give correct treatment." (Hospet, street-based female sex worker, from Andhra Pradesh, 44 years old)

About three-fourths of the sex workers interviewed had visited the local NGO STI clinic, half had visited private doctors, and more than 40 percent accessed the public health system. For each of the study districts, sex workers prefer going to the NGO STI clinic, rather than to private or public doctors.

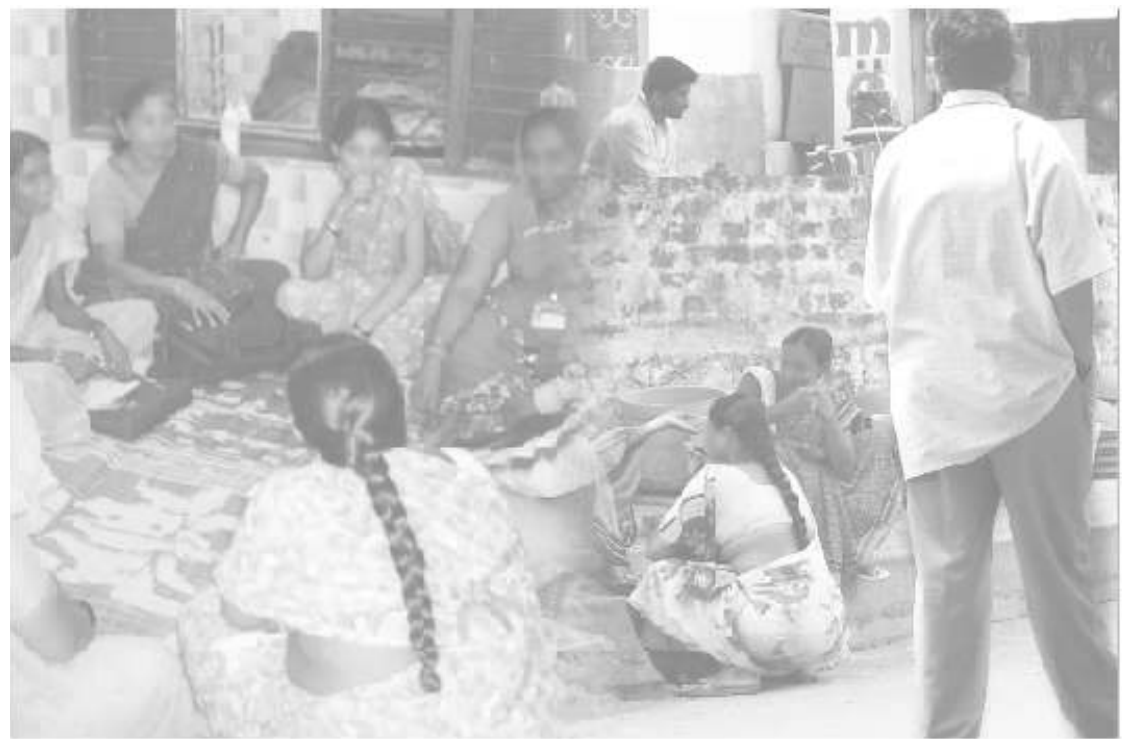




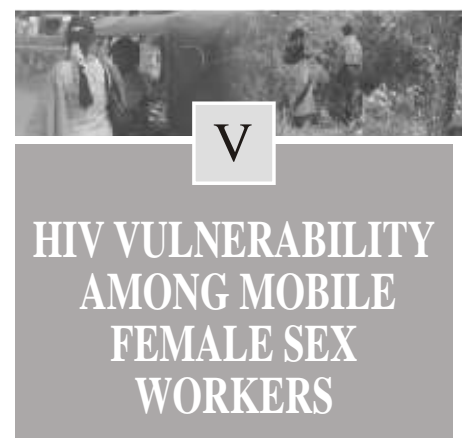

Mobile female sex workers' vulnerability to HIV was measured using the following indicators: condom use at last sex with occasional clients and with regular clients, with occasional or regular clients, with nonpaying partners, and with any partner; experience of STI symptoms in the past six months; having sex while having STI symptoms; condom use during episodes of sexual violence; and self-perception of HIV risk. These indicators were cross-tabulated with condom-use-negotiation variables, sociodemographic and economic characteristics, alcohol use, experience of physical violence, and mobility characteristics. The association between mobility and indicators of HIV risk are examined below.

\subsection{HIV vulnerability by district}

Half of mobile female sex workers reported condom use with occasional clients during last sex. One-third reported condom use at last sex with regular clients and slightly more than one-third of those who had nonpaying partners reported using a condom during last sex with this partner (see Figure 8). Eighty-five percent did not answer the question concerning condom use with nonpaying partners because they did not have a nonpaying partner, have not had sex in the previous week with their nonpaying partner, or did not wish to answer the question. For occasional and regular clients, the highest condom use is reported in Dakshina Kannada (59 percent and 36 percent) and Bellary (54 percent and 38 percent), and the lowest in Dharwad (44 percent and 26 percent).

Female sex workers explain some of the reasons for using condoms less frequently with regular clients and nonpaying partners:

"I do not use a condom with my husband, and I do not use one with my regular customers. My husband doesn't have any diseases, and even I don't have any diseases, therefore I don't use a condom with him. I don't use a condom with regular customers, for the reason that they give me more money." (Bangalore, brothel-based female sex worker, from Calcutta, 22 years old)

"For drinking, my partner gives me money, but I don't give anything to him. He does land work. He is very rich and he is looking after us very well, but he has one condition: that is, while having sex he says that he won't use a condom." (Bangalore, home-based female sex worker, from Anekal, 27 years old) 


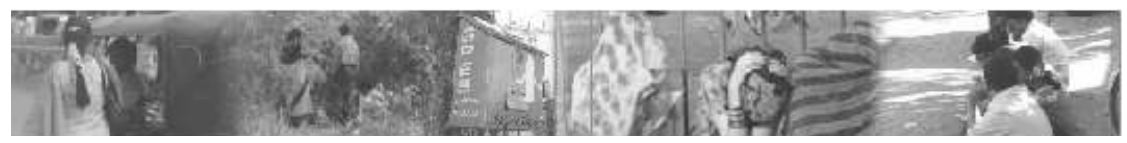

\section{Figure 8 : Percentage of mobile female sex workers who reported consistent condom use during last sex, by type of client/partner}

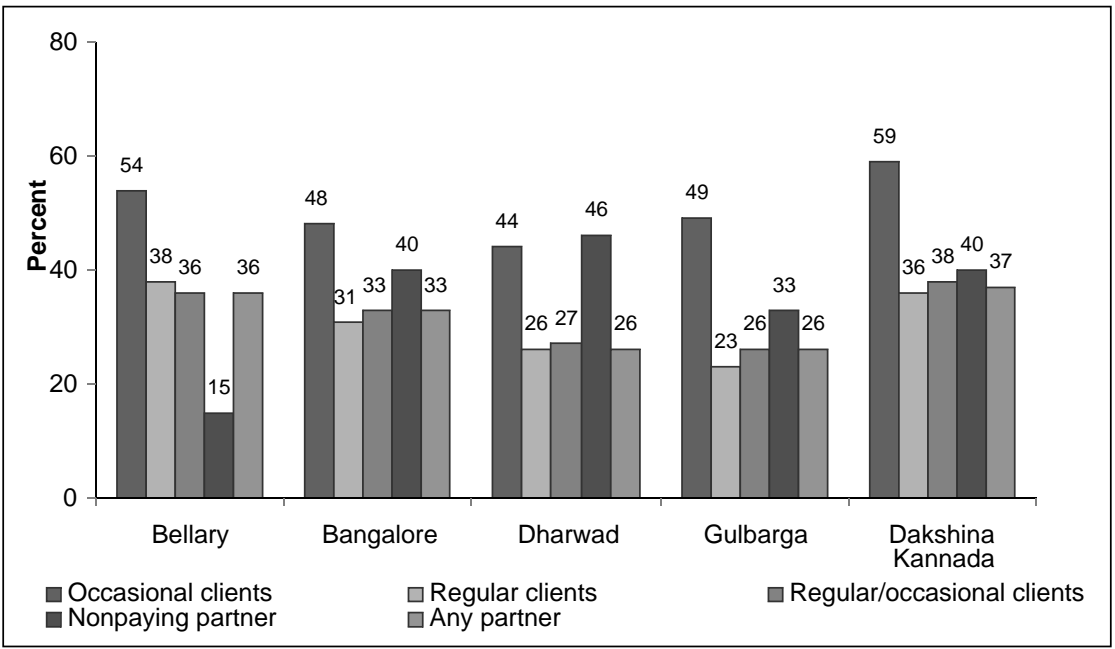

Nearly all of the sex workers surveyed reported having experienced STI symptoms in the past six months, as shown in Table 10. More than threefourths of the women interviewed complained of excessive vaginal discharge, half of them mentioned having pain during intercourse, pain in their lower abdomen, and frequent painful urination (not shown). Many of these symptoms may not be the result of having STIs. One-fourth of the women who reported having had STI symptoms in the past six months continued to have sex. Although little variation is found by district in the proportion reporting STI symptoms, 44 percent of sex workers in Dakshina Kannada and almost onethird of those in Dharwad said that they continue to have sex while having STI symptoms; lower proportions in the other districts reported doing this.

In the light of the reported inconsistency of condom use, female sex workers' experience of STIs is not surprising:

"When we are not able to convince the client to use a condom, then we have sex with him without one. Then we face problems like white discharge. These types of incidents have taken place in my life. We take protective measures, but these mistakes happen in life. People can deceive you very easily. Nobody 


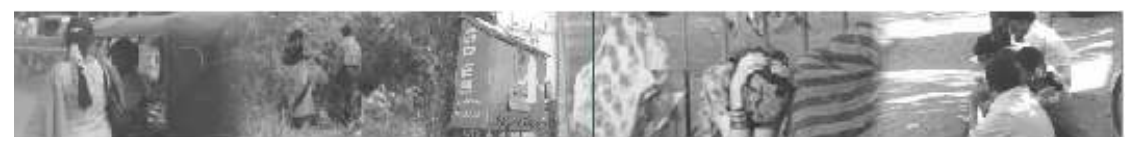

comes when we are suffering from diseases. At the time of having pleasure they easily deceive us, but at the time of giving money they think a lot." (Bangalore, home-based female sex worker, from Anekal, 27 years old)

"I get abdominal pain, pain at anal region, and vaginal pain once in two or three months. At that time, I take tablets from medical stores and get well in two days. If the pain is greater I will not go with clients, and if the pain is less then I go for sex work. What we do for the sake of stomach we have to do." (Bellary, street-based female sex worker, from Andhra Pradesh, 26 years old)

"When I came from Chitradurga, I had the burning urination problem and I took tablets from a medical store. In two days, I got relief, and often I have itching around my vagina. For this I have taken tablets from the medical shop, I have used ointment from a tube and applied it. It will reduce the itching in one or two days. I will not go to the hospital. The problem will be there for two days, and after I take the tablets, it goes away. This type of problem I have once in six months or a year. When I have such problems I have sex with clients, but if I face more problems and pain, I will not have sex." (Bellary, street-based female sex worker, from Kampli, 23 years old)

Almost half of the female sex workers surveyed believe that they are at high or moderate risk for HIV, whereas more than half assess themselves as being at low risk. Half of the women report having undergone HIV testing; the highest percentage tested (63 percent) was in Bangalore and the lowest ( 38 percent) in Dharwad. More than one-third of the women who were tested for HIV were tested voluntarily, however.

\subsection{Ability to insist on condom use and actual condom use}

Women's inability to insist upon condom use is one of the key dimensions of their HIV vulnerability. Nearly two-thirds of mobile female sex workers admit that sometimes condoms are not available and, therefore, are not used (see Table 11). The data also suggest that mobile female sex workers possess fewer negotiation skills; more than three-fourths of the female sex workers admitted that sometimes their clients refuse to use a condom and they agree to have sex without one. Four-fifths of female sex workers claim that sometimes when the client refuses to use a condom, they are able to convince him to use one.

Mobile female sex workers are not always willing to negotiate condom use:

"Office people have told us about condoms, and they have given us some, but clients do not agree to use them, so because I do not want to lose the clients, I 


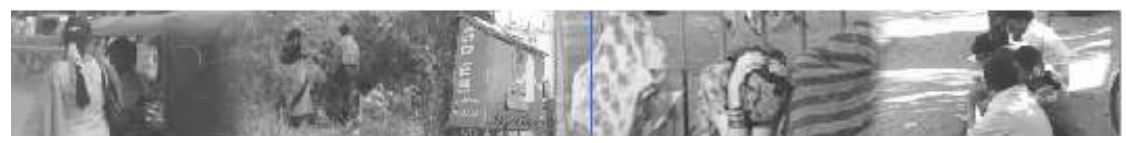

have sex without a condom. Educated clients and factory workers, one or two, will use a condom, but others do not. I do not speak to them much about it, because they will not listen, so I have sex without protection." (Bellary, from Kampli, street-based female sex worker, 23 years old)

"I try to convince my clients by telling them: If I have any disease, it will come to you also. Therefore, I will die and even you will die. If you use a condom, there will be no problem for either of us. In spite of trying to convince them, they don't agree. What they say is: If we have to die, then both of us will die. We will enjoy whatever is there in life. There is no instance when the client has agreed. Those who have knowledge, use it. I can say that those who use condoms are very few in number. When I go to other places, if I don't have condoms with me, I ask the client to bring one. If he doesn't, I have sex without using a condom. Such people give me more money. Money is the main thing for me. I do not break my head over my health." (Bangalore, brothel-based female sex worker, from Calcutta, 22 years old)

"When I go to other places, I take condoms along with me. If, at any time I don't have one with me, I ask the client to bring one. Even if they have not brought one, we give money and buy it in the lodge. But we do not use it. The people there should think that we have used it, because if people in that place find out that we don't, it will be a problem for us. What do they know about my problem? I want money and the clients want happiness; why should we think about anything else? Life will be there and it will go. If it goes, let it go. At present we are fine. In the future, it will be as God wants it." (Bangalore, home-based female sex worker, local, 19 years old)

"Wherever I go, at first I will tell clients to use a condom and tell them about diseases, and then if they agree, it's fine; otherwise I don't force them to use one. If they don't agree, then I will have sex with them without one. I don't use one with my partner and lover. My partner has HIV. He got tested. [Don't you think that you are spreading HIV?] Yes, but what to do? I lead my life by doing sex work. I spend a lot of money, I don't tell the clients because they may not come to me anymore." (Sullya, home-based female sex worker, peer educator, 23 years old)

Women talk about the higher risk associated with certain clients and with certain types of sex, particularly anal sex, when a condom is not usually used:

"Only lorry drivers ask for anal sex and do not agree to use a condom. Office people have given me condoms, but if I ask the client to use a condom, he will go to others, so I do not ask him to use one. [How many lorry drivers do you get in a week who perform anal sex and do they use condoms?] In a week I get five to eight clients; they do not use condoms, and these lorry drivers also ask 


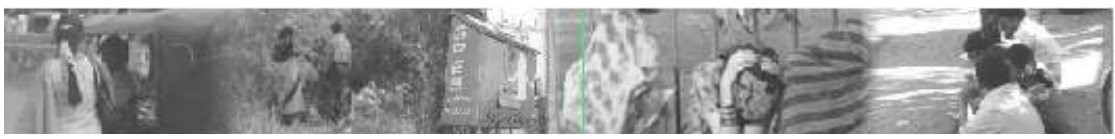

for oral sex. Wherever I go, I get clients who do all types of sex, and very few use condoms while having vaginal sex. For the remaining types of sex, condoms are not used." (Bellary, street-based female sex worker, from Andhra Pradesh, 26 years old)

A small proportion (13 percent) of mobile female sex workers who had problems with condom availability reported that they did not use condom with occasional/regular clients at last sex (see Table 12). Similarly, sex workers who possess strong negotiation skills (that is, those who do not agree to have sex with a client who refuses to use a condom and/or have convinced clients to use condoms) report condom use with occasional/regular clients (36 percent)

\subsection{Socioeconomic insecurity and HIV risk}

Women who reported having experienced physical violence in the previous year report slightly lower condom use, higher perceived risk to HIV, and having sex while having STIs symptoms than those who have not experienced violence (see Table 13).

During the in-depth interviews, numerous respondents mention not using condoms under threat of physical violence. Below are some examples:

"I try to tell clients that if they do not use a condom, they will get diseases. But I do not force those people who do not use one, because if I force them, they will show a knife and shut my mouth. Out of fear for my life I do not force them." (Bangalore, local, street-based female sex worker, 43 years old)

"Clients who are drunkards, police, and rowdies harass us and don't use condoms. When I have sex in some other place, I don't use the condom because the clients threaten my life and have sex. But after having sex they don't even pay and just go. When we go to different places, it becomes very difficult to convince the clients, especially the rowdies, goondas, and the police. In areas such as jungles, the clients threaten our lives, and we have to have sex without condoms." (Bangalore, brothel-based female sex worker, local, 29 years old)

"When we move from one place to another place, it becomes difficult for us to convince the client to use condoms. When we stay in the lodge, they threaten our lives and harass us physically and have sex with us. There is no chance for us to escape from that place, and hence we have sex without condoms and become infected with many diseases." (Bangalore, home-based female sex worker, from Anekal, 27 years old) 


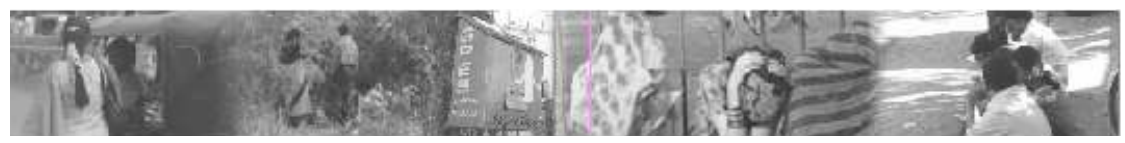

"When I was in the gharwali's house in Madras, rowdies and goondas were my clients. Although I knew about the condom, they never used condoms and there was no chance for me to force them, because the gharwali used to beat me. So I had to have sex without condoms. These types of incidents have taken place when I came to Mangalore as well. My weight is approximately $100 \mathrm{~kg}$ and if somebody beats me then I can't even get up very fast. Recently I had gone to a lodge with a client and had sex without a condom, but I couldn't come out because I had joint pain." (Mangalore, home-based female sex worker, from Karwar, 36 years old)

Similarly, mobile female sex workers who consume alcohol (compared with those who do not) reported less condom use, more STI symptoms, and said that they continue to have sex while experiencing STI symptoms. Sex workers who consume alcohol also perceive that they are at higher risk for HIV than those who do not.

Currently, the extent of alcohol consumption on both the clients' and the women's part is likely underestimated as a factor hindering condom use:

"In Baridabad, most of the clients who visited her were sindi drinkers and even she takes drinks. In these conditions, she did not know whether clients use condom or not, and she was not in a position to negotiate condom use with clients." (Interviewer's report of Sedam, street-based female sex worker, local, 28 years old)

"She told me that with the drunken men, rowdies, and with truck drivers condom use was not possible. She also drinks, so it is difficult for her to use a condom. With rowdies and with drunks, condom negotiation is difficult, so with drunks, rowdies, and with her lover she does not use condoms." (Interviewer's report of Aland, home-based female sex worker, local, 22 years old)

According to female sex workers' reports, the combination of violence and alcohol consumption results in their inability to negotiate condom use with clients:

"The client was drunk and used to smoke. I went with him to the lodge in Mangalore. Because he was drunk, he argued about having sex without a condom. When I refused, he burned my body with the cigarette, and I had sex without a condom." (Suratkal, home-based female sex worker, local, 30 years old) 


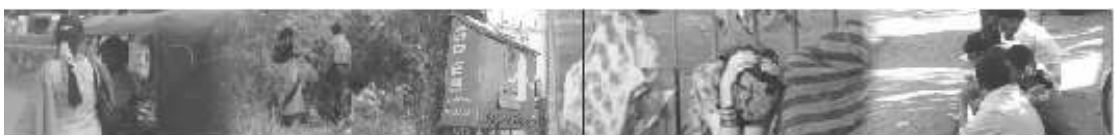

Condom use is frequently lower among mobile female sex workers who earn some income from other occupations than among those who are completely dependent on sex work. This finding suggests a need for strengthening the programme for mobile female sex workers who work at jobs in addition to sex work.

Divorced/widowed/separated mobile female sex workers are at higher risk for HIV, compared with never-married or currently married female sex workers, as indicated by their significantly lower condom use, higher STI symptoms, and higher perception of HIV risk. Most mobile female sex workers fall into this marital category.

\subsection{Mobility and HIV Risk}

Compared with those who visit fewer places for work, sex workers who visit several places for work report similar condom use with occasional clients, and similar proportions report having STI symptoms. They also report lower condom use with nonpaying partners, and more of them report having sex while experiencing STIs symptoms (see figure 9). Surprisingly, increased mobility is associated with higher condom use with regular clients.

In interpreting this finding, we must take into account that a workers increased mobility also means that she stays for a relatively short time in each place. Consequently, sex workers who are more mobile do not have as much time as those working in fewer locations to develop a regular clientele, so that their "regular clients" are similar to occasional clients with whom it is easier to negotiate condom use. 


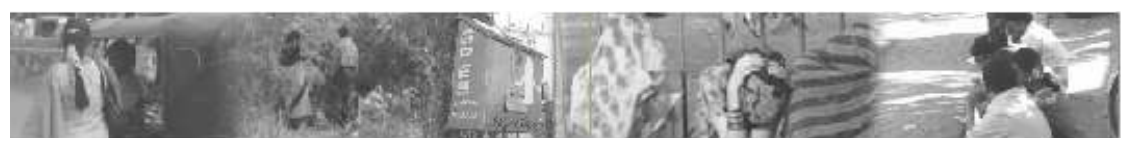

Figure 9. Percentage of mobile sex workers who reported experiencing STI symptoms and who continue to have sex while being infected with STIs, by type of client/partner and degree of mobility

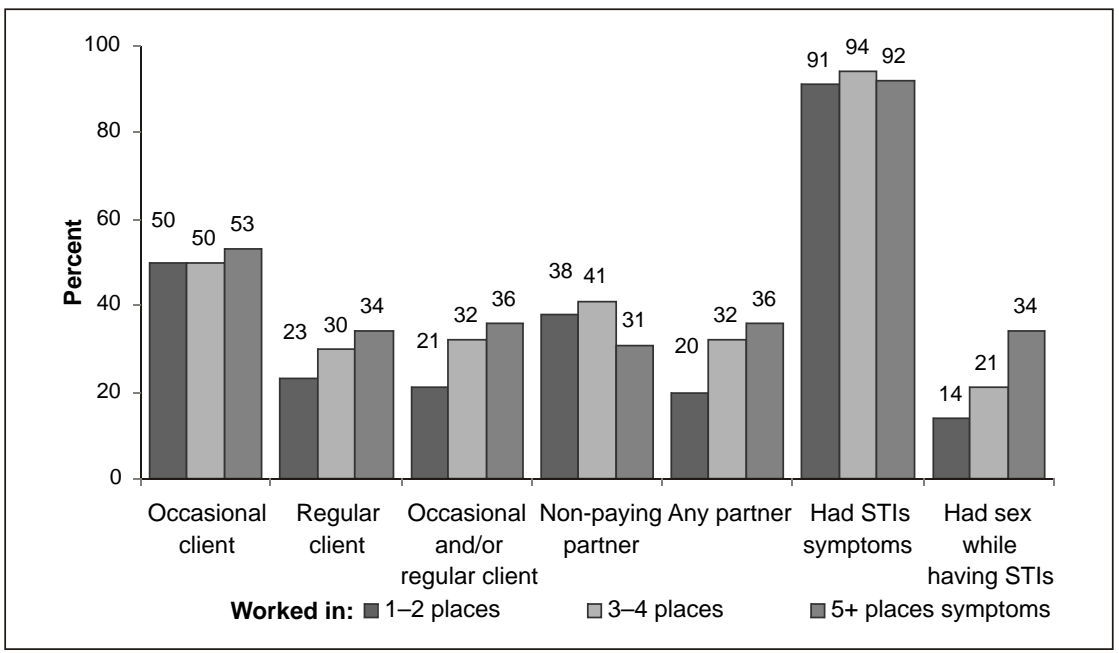

Although the relationship between degree of mobility and HIV risk is not straightforward, female sex workers going to jatras appear to be at higher risk for acquiring HIV, compared with those who do not go to jatras (see Figure 10). This finding is particularly important in the case of Karnataka, in light of the number of female sex workers who attend jatras there, especially in northern Karnataka (see Map 6). Compared with those who do not, female sex workers going to jatras, particularly those going in a group rather than alone report lower condom use with any type of partner, higher incidence of STI symptoms, and more report that they continue to have sex while having STIs symptoms. A similar pattern appears for female sex workers who visit places where many male migrants work (see Table 14). 


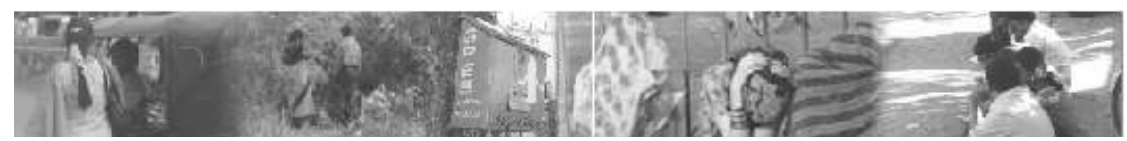

Figure 10. Percentage of mobile female sex workers who reported using a condom during last sex, by type of client/ partner, and who experienced STI symptoms and had sex while having STI symptoms, according to whether they went to jatras for work

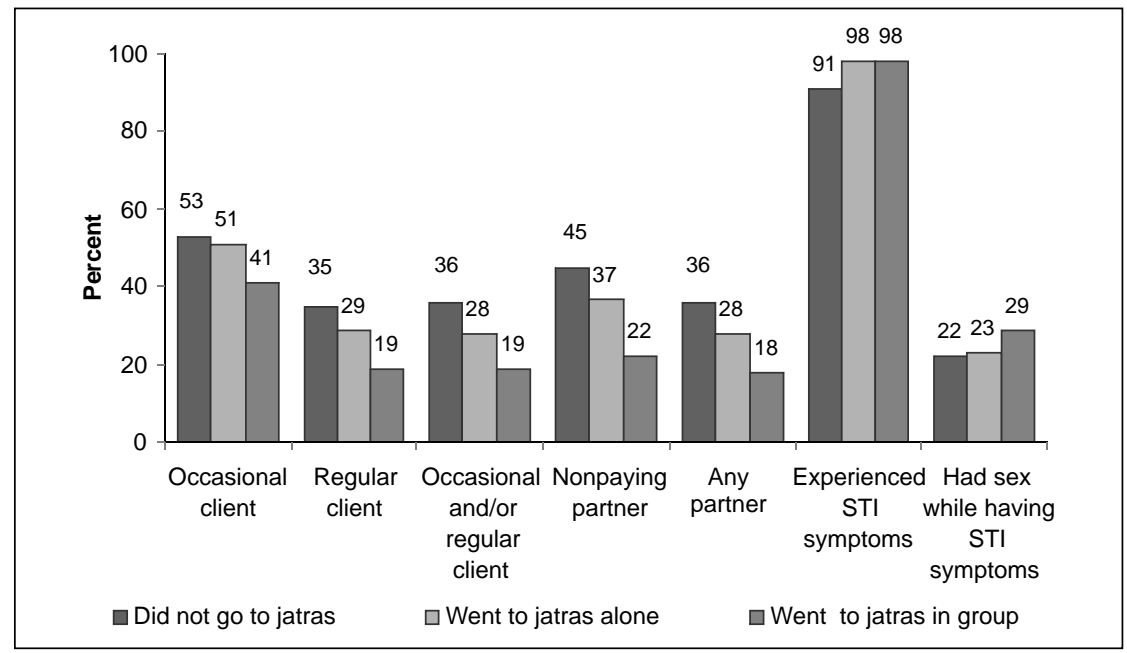

Sex workers who visited more places for work reported higher condom use with both occasional partners and regular partners, compared with those who visited fewer places. At the same time, a higher proportion of sex workers going to more places continue to have sex while suffering from STI symptoms. Examining the relationship between degree of mobility and HIV risk for different periods of migration complicates the pattern (see Table 15).

The highest proportion who report condom use at last sex with any type of partner are sex workers in brothels, followed by home- and lodge-based sex workers and street-based female sex workers, and highway-based female sex workers. Within each type of sex-work arrangement, however, increased mobility is associated with higher condom use, with the exception of highwaybased sex work (see Table 16). 


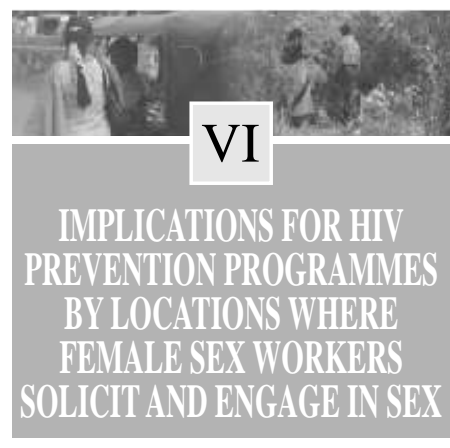

Using the six commonly mentioned locations where sex workers solicit or engage in sex that are feasible for HIV-prevention programme interventions, we calculate the anticipated proportion of workers that would be covered under the programme at each location. We also estimate the number of times each sex worker would interact within the programme.

\subsection{Locations for Soliciting and Engaging in Sex}

In Karnataka, female sex workers solicit their clients in many places. The most common means of soliciting clients for sex is by telephone (40 percent), followed by help of mediators (pimps or madams) (15 percent), which suggests the size of the network operating in the Karnataka sex industry (see Figure 11). The other most common locations for soliciting that respondents mentioned are the roadside, railway stations/bus stands, and markets. Other common places of solicitation are hotels and lodges. Some female sex workers solicit/engage in sex in their homes and some in brothels. Other locations include fast-food places, cinema halls, and rented rooms (see Table 17).

Figure 11. Percentage of mobile female sex workers, by their most frequently mentioned locations for and means of soliciting and engaging in sex work, according to district

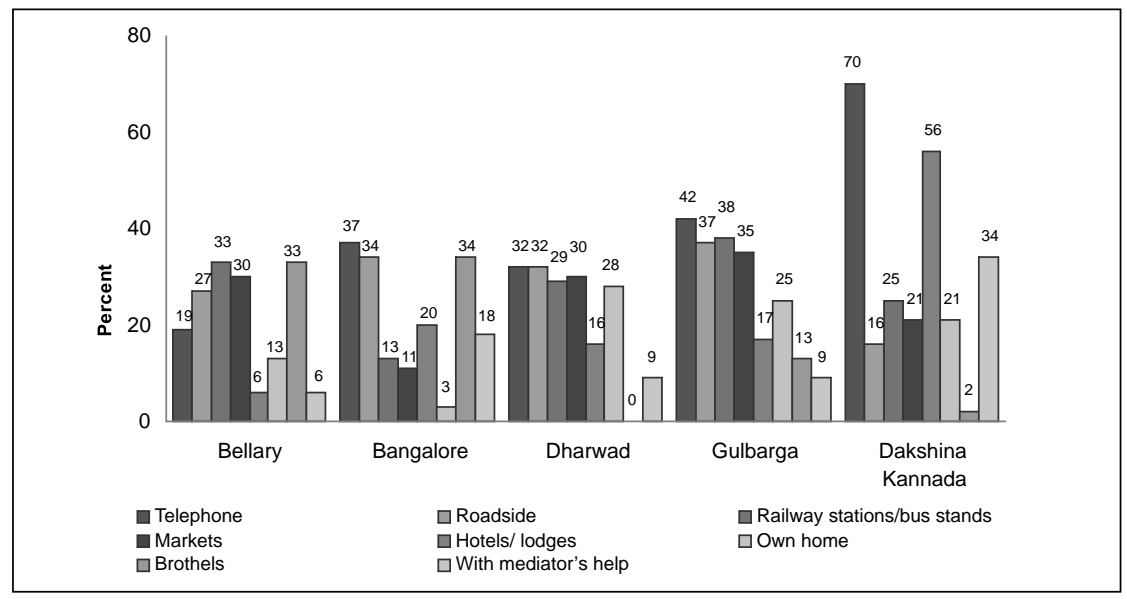




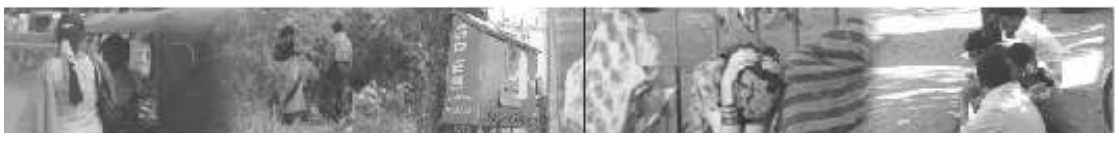

Similarly, mobile female sex workers engage in sex in many different locations (see Figure 12). The most frequently mentioned are hotels and lodges (40 percent). Other places include open spaces such as forests, gardens, jungles, hills, and mountains, and rented rooms and their own homes. Seventeen percent of female sex workers service clients in brothels. Some (usually the highwaybased workers) have sex in vehicles, others in railway stations and bus stands. Because the places where they solicit sex and engage in sex are not the same, classifying workers into a particular category is not possible.

Figure 12. Percentage of mobile female sex workers, by their most frequently mentioned locations for engaging in sex, according to district

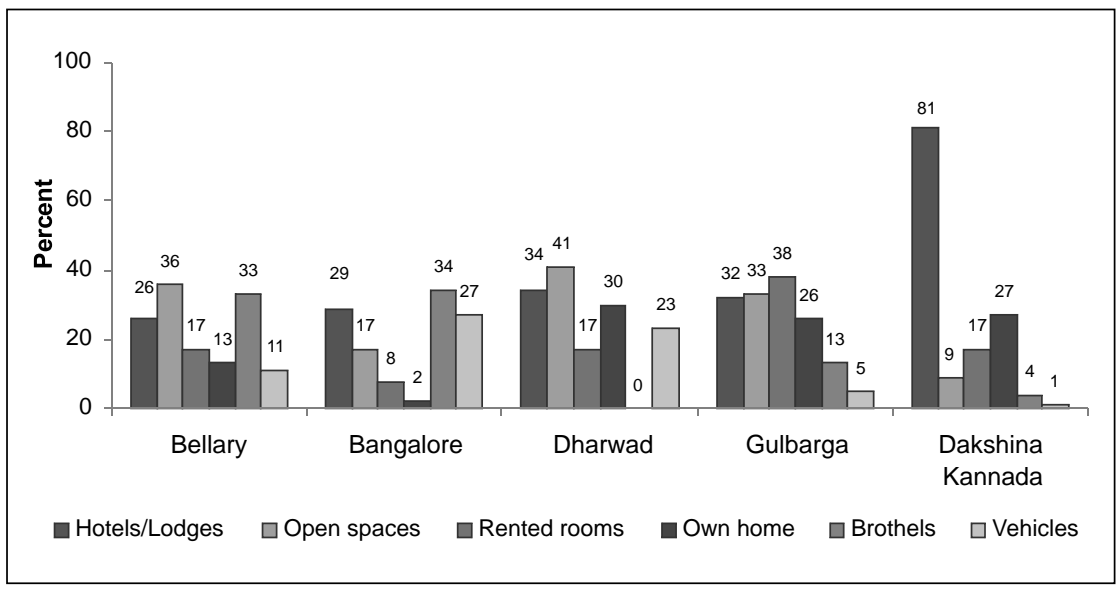

In Bellary, where sex work is mainly street work and brothel and home based, the main locations for solicitation are the railway stations/bus stands, brothels, markets, the roadside, and cinema halls. Soliciting is also performed by telephone. Female sex workers engage in sex mostly in open spaces, brothels, hotels/lodges, railway stations/bus stands, rented rooms, their own homes, in vehicles, and by the roadside.

In Bangalore, with a diverse sex-work industry (all types of female sex workers are represented), the main means for soliciting is the telephone and through mediators, and places of solicitation include the roadside, brothels, fast-food places, hotels/lodges. Female sex workers have sex mostly in brothels, hotels/lodges, vehicles, open spaces, and by the roadside. 


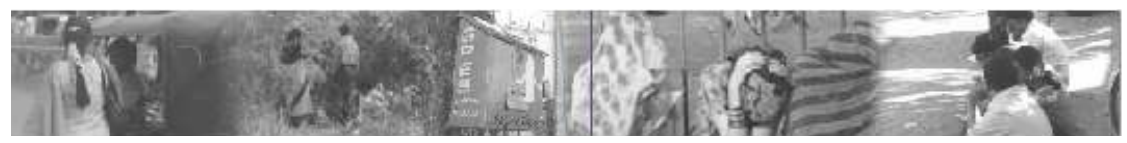

In Dharwad, with female sex workers working in all sorts of arrangements, the main means of solicitation is by telephone. Soliciting places include by the roadside, at markets, railway stations/bus stands, their own homes, fast-food places, and hotels/lodges. The most common places for engaging in commercial sex are open places, hotels/lodges, the sex workers' homes, vehicles, rented rooms, and railway stations/bus stands.

In Gulbarga, with a strong street-based sex workforce in addition to brotheland lodge-based workers, the main means of solicitation is by telephone. Solicitation locations include railway stations/bus stands, by the roadside, markets, female sex workers' homes, in cinema halls, hotels/lodges, rented rooms, and brothels. Female sex workers have sex with clients mostly in rented rooms, open spaces, hotels/lodges, their own homes, brothels, railway stations/bus stands, and in clients' homes.

Dakshina Kannada has a highly networked lodge-based sex-work industry and numerous street and home-based sex workers. The female sex workers solicit sex by telephone and at hotels/lodges, through mediators, at railway stations/bus stands, at markets, from their own homes, by the roadside, and in cinema halls. Sex with clients usually takes place in hotels and lodges, but also in the female sex workers' homes, and in rented rooms, and clients' homes.

In order to determine how mobile sex workers might be covered by programmed interventions, we attempted to cross-tabulate sex workers by type of sex work, as identified by the worker or by the interviewer and location for soliciting and engaging in sex. Results indicate that in Karnataka brothel-based sex workers can be covered mostly in brothels; lodge-based workers in hotels/lodges; street-based workers in railway stations, markets, and hotels; home-based workers in their own homes; and highway-based workers in fastfood places (see Table 18). If we focus on the six locations that are most feasible for programme interventions, we will be able to contact all types of sex workers in all sorts of work arrangement

Alternative scenarios can be suggested for reaching the maximum number of female sex workers with a minimum of resources (see Table 19). The table shows that 95 percent or more of mobile female sex workers in Bellary, Bangalore, and Dakshina Kannada, more than 90 percent in Gulbarga, and nearly 85 percent in Dhawad can be contacted by simultaneously covering hotels, railway stations/bus stands, markets, the sex workers' homes, brothels, and fast-food places. 


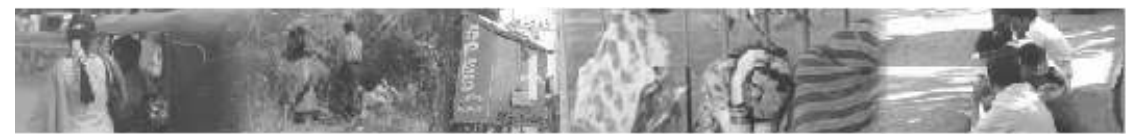

The data suggest that in Karnataka, 65 percent of sex workers solicit clients or have sex in hotels/lodges, railway stations/bus stands, markets, and their own homes. If brothels are included in the programme, the coverage increases to 81 percent, and if fast-food places are also included, it increases to 93 percent. If these six places are targeted, female sex workers can receive more than one dose of intervention.

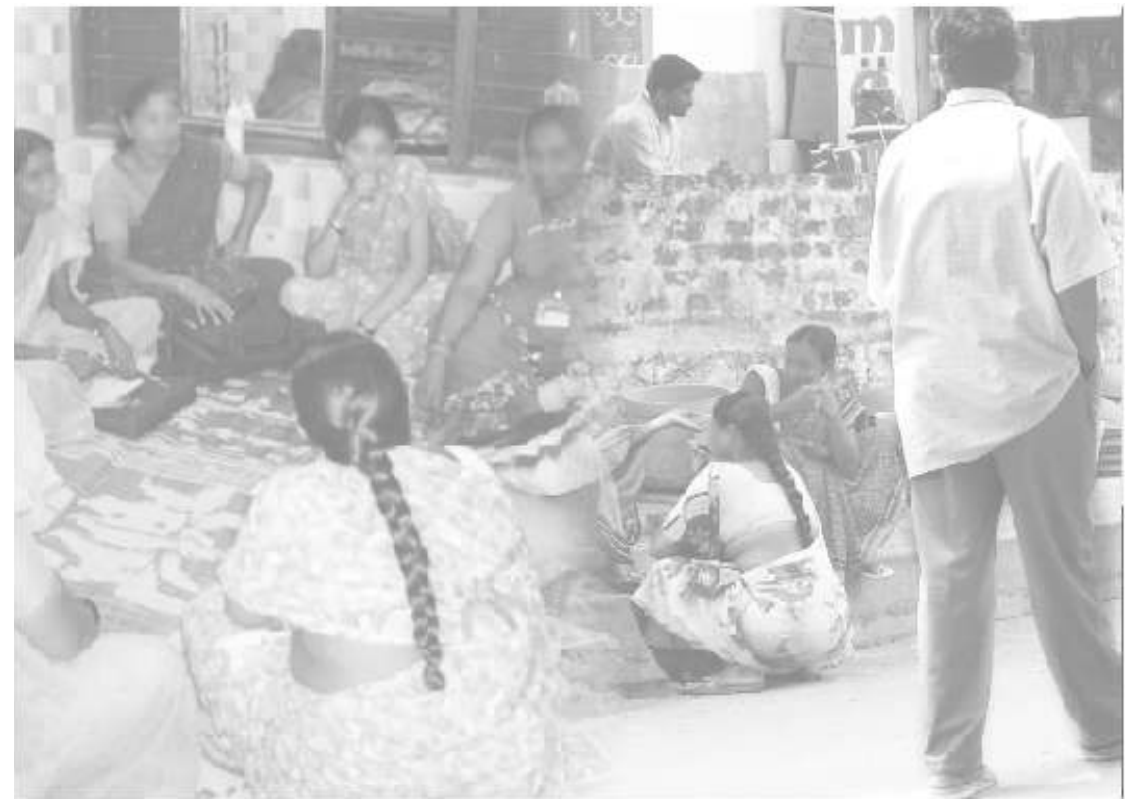




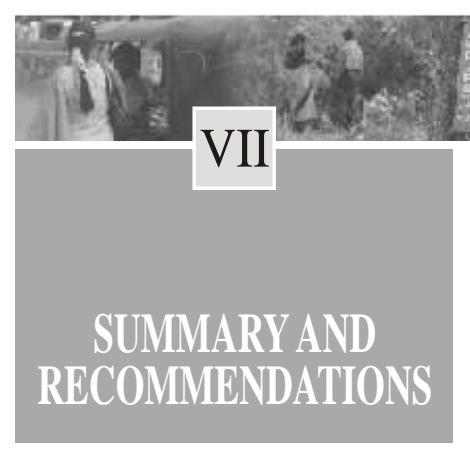

Results indicate that 84 percent of sex workers interviewed moved at least once for sex work in the past two years and threefourths moved at least once across their district. On average, female sex workers made 3.5 moves in the past two years for sexwork purposes, and 2.8 of these moves were made across their district. Although little variation is found by district, women practicing sex work on highways, in lodges, and in brothels are more mobile than street and home-based sex workers. In terms of age, mobility is highest among sex workers aged 25-29.

The study also allows us to identify the main routes for female sex workers used to move through the study districts. Bangalore is the central point of female sex workers' mobility in Karnataka. In southern Karnataka, a large volume of workers move between Bangalore and Dakshina Kannada, but also between Mysore and other neighbouring districts. In northern Karnataka, many female sex workers move between neighbouring districts, and especially along the route from Belgaum to Dharwad to Bellary.

Female sex workers' jatra-related mobility in Karnataka is important; nearly one-third of the workers interviewed reported going to jatras in the past year. This behaviour is greater in northern Karnataka and among those practicing in the street, in their homes, and along highways than among female sex workers working elsewhere. Important jatra sites in northern Karnataka are Saundatti in Belgaum District and Munirabad in Bellary District. A substantial number of women go to various jatra sites in their own and neighbouring districts.

Three-fourths of mobile female sex workers in the survey sample are aged 18-29. More than half are aged 25-29. Nearly 60 percent have less than a fifth standard education, and approximately one-third are illiterate. Two-thirds of the mobile female sex workers in Karnataka are divorced/widowed/separated and one-fourth have never been married. Nearly 60 percent of our study participants consumed alcoholic beverages in the month prior to the su rvey.

Overall, more than 60 percent of sex workers reported holding membership in a self-help group, community-based organization, nongovernmental organization, or sex-workers' collective. In terms of the benefits received, the large majority of sex workers reported having received condoms, information about STIs, and referrals to health centres. The groups' programmes seem to be most effective 


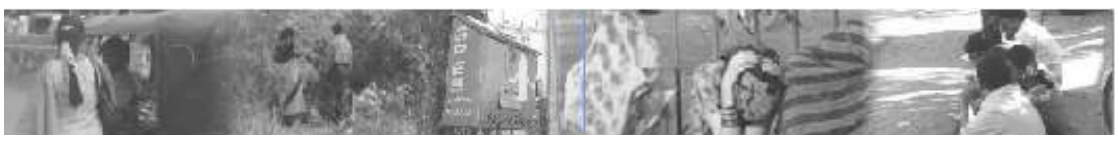

in terms of condom distribution in Bellary and Gulbarga, in providing information about STDs in Gulbarga, and providing referrals to health centres in Bangalore.

Half of the mobile female sex workers surveyed reported condom use during last sex with occasional clients and one-third with regular clients.

Consequently, the large majority of women have experienced STI symptoms in the previous six months. One of the main explanations for the low level of condom use is female sex workers' weak sexual negotiation skills. Condom use is also low for women who reported consuming alcohol. Another HIV vulnerability factor is marital status, because divorced/widowed/separated mobile female sex workers are at higher risk for HIV, compared with their never-married or currently married counterparts.

In assessing the link between mobility and HIV risk, we note that sex workers who visit several locations for work report similar condom use with occasional clients, and similar proportions report experiencing STI symptoms, compared with those who visit few places for work. The more mobile female sex workers report lower condom use with nonpaying partners and more report continuing to have sex while experiencing STI symptoms than do their counterparts who are less mobile. Condom use with regular clients is higher with increased mobility, which might be explained by workers' shorter length of time spent in one place that is associated with being highly mobile. Although the relationship between degree of mobility and HIV risk is not straightforward, female sex workers who go to jatras are at higher risk for HIV, compared with those who do not. Those attending jatras, especially those who go in a group rather than alone, report lower condom use with any type of partner, more experience of STI symptoms, and more frequently report continuing to have sex while having STI symptoms, compared with those who do not visit jatras.

For the HIV-prevention programmes, an awareness of where female sex workers solicit and engage in sex is important. Female sex workers solicit their clients in a variety of places; the most common means of solicitation, however, is by telephone (40 percent); the most popular locations for soliciting sex are by the roadside, at railway stations/bus stands, markets, hotels, and lodges. Home-based female sex workers solicit from their homes and brothel-based female sex workers in brothels. Similarly, mobile female sex workers engage in sex with clients in numerous places, including hotels/lodges (40 percent), forests/gardens/jungles/hills/mountains, rented rooms, and their own homes. 


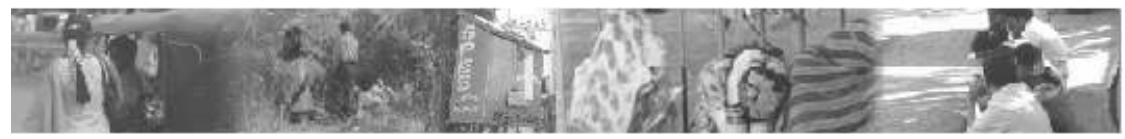

We identified hotels, railway stations/bus stands, markets, female sex workers' own homes, brothels, and fast-food places as the six locations that would be most feasible for programme interventions. Ninety-five percent of mobile female sex workers in Bellary, Bangalore, and Dakshina Kannada, more than 90 percent in Gulbarga, and nearly 85 percent in Dhawad can be contacted by simultaneously covering these six places.

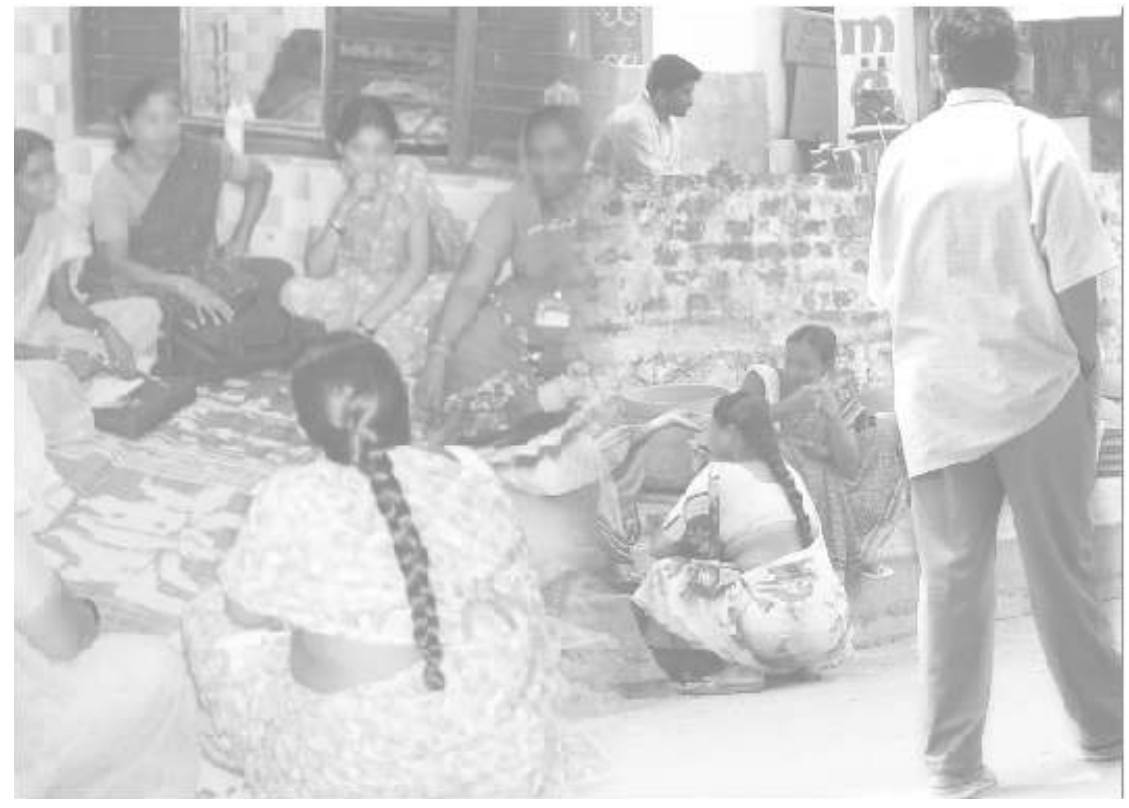




\section{APPENDIX}

Table 1 : Percentage of female sex workers who are mobile, by district, type of sex work, and age group, according to number of locations to which they moved in the two years prior to the survey, Karnataka, India

\begin{tabular}{|c|c|c|c|c|c|c|c|c|}
\hline \multirow[b]{2}{*}{ Characteristic } & \multicolumn{3}{|c|}{ Number of locations } & \multicolumn{3}{|c|}{$\begin{array}{c}\text { Number of moves across } \\
\text { districts }^{\mathrm{a}}\end{array}$} & \multirow{2}{*}{$\begin{array}{l}\text { Moved 2+ } \\
\text { times and at } \\
\text { least once } \\
\text { across district }\end{array}$} & \multirow[b]{2}{*}{$(\mathbf{N})$} \\
\hline & $1+$ & $2+$ & Average & $1+$ & $2+$ & Average & & \\
\hline District & & & & & & & $\%$ & \\
\hline Bellary & 87 & 81 & 3.51 & 69 & 66 & 2.91 & 67 & $(425)$ \\
\hline Bangalore & 84 & 70 & 3.08 & 75 & 73 & 3.08 & 68 & (533) \\
\hline Dharwad & 79 & 75 & 3.69 & 73 & 71 & 2.76 & 64 & (493) \\
\hline Gulbarga & 89 & 84 & 3.57 & 68 & 66 & 2.54 & 65 & $(480)$ \\
\hline Dakshina Kannada & 82 & 79 & 3.53 & 93 & 85 & 2.84 & 63 & $(471)$ \\
\hline \multicolumn{9}{|l|}{ Type of sex work } \\
\hline Brothel & 84 & 71 & 3.11 & 71 & 68 & 3.14 & 66 & $(385)$ \\
\hline Hotel/lodge & 85 & 81 & 3.60 & 90 & 89 & 3.19 & 71 & (366) \\
\hline Street & 84 & 79 & 3.53 & 70 & 67 & 2.72 & 60 & (720) \\
\hline Home & 84 & 76 & 3.44 & 71 & 65 & 2.54 & 62 & $(641)$ \\
\hline Highway & 85 & 81 & 3.64 & 84 & 82 & 2.81 & 78 & (289) \\
\hline \multicolumn{9}{|l|}{ Age group } \\
\hline $15-19$ & 84 & 54 & 2.58 & 54 & 33 & 2.27 & 40 & (57) \\
\hline $20-24$ & 83 & 74 & 3.29 & 70 & 64 & 2.81 & 61 & (531) \\
\hline $25-29$ & 87 & 83 & 3.66 & 83 & 81 & 2.87 & 74 & $(1,196)$ \\
\hline $30-34$ & 84 & 77 & 3.36 & 68 & 66 & 2.80 & 58 & (532) \\
\hline $35+$ & 58 & 37 & 2.62 & 36 & 32 & 2.91 & 24 & (87) \\
\hline Total & 84 & 78 & 3.46 & 75 & 71 & 2.83 & 65 & - \\
\hline$(\mathbf{N})$ & $(2,406)$ & $(2,406)$ & $(2,406)$ & $(2,120)$ & $(2,120)$ & $(2,120)$ & $(2,406)$ & - \\
\hline
\end{tabular}

$-=$ Not applicable. ${ }^{\text {a }}$ Values are missing for 11.9 percent of respondents.

Source: Survey screening questionnaire. 


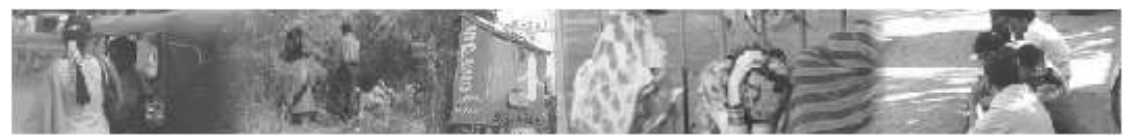

Table 2 : Percentage of mobile female sex workers, by age group and type of sex work, according to study district, Karnataka, India

\begin{tabular}{lccccccr}
\hline Variable & Bellary & Bangalore & Dharwad & Gulbarga & $\begin{array}{c}\text { Dakshina } \\
\text { Kannada }\end{array}$ & $\begin{array}{r}\text { Total } \\
\%\end{array}$ & $\begin{array}{r}\text { Total } \\
\text { (N) }\end{array}$ \\
\hline $\begin{array}{l}\text { Age group } \\
\quad\end{array}$ & & & & & & & \\
$15-24$ & 55 & 52 & 60 & 67 & 64 & 59 & $(588)$ \\
$25-29$ & 84 & 77 & 71 & 72 & 73 & 74 & $(1,196)$ \\
$30+$ & 57 & 65 & 49 & 49 & 45 & 53 & $(619)$ \\
\hline Type of sex & & & & & & & \\
work & & & & & & & \\
Brothel & 65 & 63 & na & 83 & na & 66 & $(385)$ \\
Hotel/lodge & na & 81 & 74 & 76 & 67 & 71 & $(366)$ \\
Street & 64 & 62 & 60 & 57 & 60 & 60 & $(720)$ \\
Home & 72 & 45 & 59 & 68 & 59 & 62 & $(641)$ \\
Highway & 76 & 77 & 82 & 79 & na & 78 & $(289)$ \\
\hline
\end{tabular}

na $=$ Not available .

Source: Screening questionnaire.

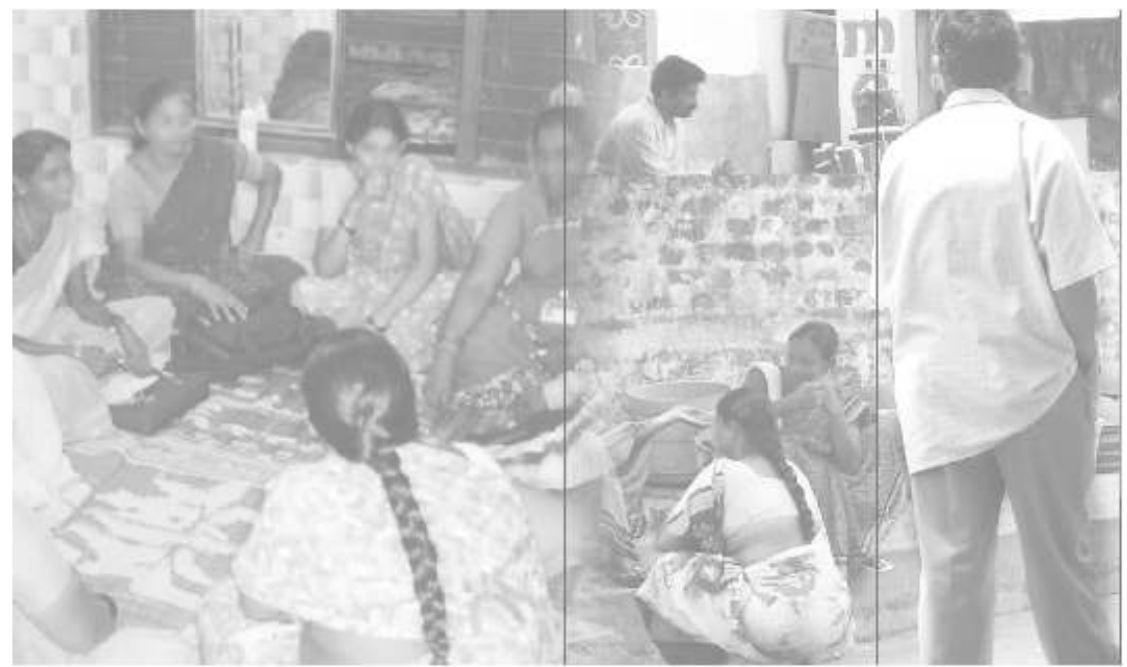


Table 3 : Percentage distribution of female sex workers' jatra-related mobility and condom use during jatras, by study district, Karnataka, India

\begin{tabular}{|c|c|c|c|c|c|c|c|}
\hline Variable & Bellary & Bangalore & Dharwad & Gulbarga & $\begin{array}{l}\text { Dakshina } \\
\text { Kannada }\end{array}$ & Total & $\begin{array}{l}\text { Total } \\
(\mathbf{N})\end{array}$ \\
\hline \multicolumn{8}{|l|}{ Visited jatra in past 12 months } \\
\hline Yes & 35 & 7 & 43 & 49 & 28 & 31 & $(468)$ \\
\hline No & 65 & 93 & 57 & 51 & 72 & 69 & $(1,027)$ \\
\hline \multicolumn{8}{|l|}{ Visited in group ${ }^{a}$} \\
\hline Alone & 33 & 61 & 38 & 35 & 43 & 38 & (177) \\
\hline Group & 67 & 39 & 63 & 65 & 57 & 62 & $(291)$ \\
\hline \multicolumn{8}{|l|}{ Clients in jatra (last visit) ${ }^{b}$} \\
\hline Male migrants from different places & 94 & 75 & 85 & 89 & 85 & 88 & $(260)$ \\
\hline Male migrants of the same district & 5 & 0 & 4 & 4 & 8 & 5 & $(15)$ \\
\hline Local nonmigrant men & 0 & 25 & 6 & 4 & 5 & 5 & (14) \\
\hline Others & 2 & 0 & 4 & 2 & 2 & 2 & (7) \\
\hline
\end{tabular}

Condom use with clients in last visit to jatrab

$\begin{array}{lrrrrrrr}\text { With all clients } & 5 & 25 & 20 & 6 & 20 & 13 & (38) \\ \text { With some clients } & 95 & 67 & 65 & 81 & 75 & 79 & (233) \\ \text { Did not use } & 0 & 8 & 15 & 13 & 5 & 9 & (26)\end{array}$

Visited MMW places seasonally

\begin{tabular}{lrrrrrrr} 
Yes & 9 & 1 & 11 & 14 & 12 & 9 & $(138)$ \\
No & 91 & 99 & 89 & 86 & 88 & $91 \quad(1,358)$ \\
\hline Total percent & $\mathbf{1 0 0}$ & $\mathbf{1 0 0}$ & $\mathbf{1 0 0}$ & $\mathbf{1 0 0}$ & $\mathbf{1 0 0}$ & $\mathbf{1 0 0}$ & - \\
\hline Total $(\mathbf{N})$ & $\mathbf{( 2 7 0 )}$ & $\mathbf{( 3 4 7 )}$ & $\mathbf{( 2 9 9 )}$ & $\mathbf{( 3 0 0 )}$ & $\mathbf{( 2 8 3 )}$ & $\mathbf{( 1 , 4 9 9 )}$ & - \\
\hline
\end{tabular}

$-=$ Not applicable.

${ }^{\text {a }}$ Among those who visited Jatra areas.

b Among those who visited Jatra area in the past 12 months and had sex. 
Table 4 : Percentage distribution of mobile female sex workers, by selected socioeconomic and demographic characteristics, according to district, Karnataka, India

\begin{tabular}{|c|c|c|c|c|c|c|c|}
\hline Characteristic & Bellary & Bangalore & Dharwad & Gulbarga & $\begin{array}{l}\text { Dakshina } \\
\text { Kannada }\end{array}$ & Total & $\begin{array}{c}\text { Total } \\
(\mathbf{N})\end{array}$ \\
\hline \multicolumn{8}{|l|}{ Age group } \\
\hline $18-24$ & 27 & 20 & 13 & 15 & 27 & 20 & $(302)$ \\
\hline $25-29$ & 52 & 54 & 68 & 63 & 54 & 58 & $(871)$ \\
\hline $30+$ & 21 & 27 & 20 & 21 & 19 & 22 & $(326)$ \\
\hline \multicolumn{8}{|l|}{ Education } \\
\hline None & 37 & 27 & 35 & 33 & 15 & 29 & $(439)$ \\
\hline Primary ( $1-4$ class $)$ & 28 & 26 & 33 & 31 & 23 & 28 & (424) \\
\hline Secondary (5-9 class) & 32 & 35 & 31 & 29 & 48 & 35 & $(525)$ \\
\hline High school $+(10+$ class $)$ & 2 & 12 & 1 & 7 & 14 & 7 & $(109)$ \\
\hline \multicolumn{8}{|l|}{ Marital status } \\
\hline Divorced/widowed/separated & 60 & 65 & 70 & 68 & 56 & 64 & $(960)$ \\
\hline Never married & 35 & 24 & 18 & 19 & 33 & 25 & $(381)$ \\
\hline Married & 5 & 11 & 12 & 13 & 11 & 11 & $(157)$ \\
\hline \multicolumn{8}{|l|}{ Sources of income } \\
\hline Sex work only & 76 & 77 & 56 & 54 & 54 & 63 & $(951)$ \\
\hline Sex work+other sex-related work & 1 & 4 & 12 & 14 & 20 & 10 & $(152)$ \\
\hline Sex work+other sources & 23 & 19 & 32 & 32 & 26 & 26 & $(396)$ \\
\hline \multicolumn{8}{|l|}{$\begin{array}{l}\text { How much money do you owe } \\
\text { currently? }\end{array}$} \\
\hline None & 67 & 80 & 63 & 61 & 73 & 69 & $(1,033)$ \\
\hline$<1,000 \mathrm{Rs}$. & 7 & 2 & 9 & 9 & 4 & 6 & $(91)$ \\
\hline $1,001-10,000$ Rs. & 23 & 14 & 25 & 29 & 15 & 21 & (316) \\
\hline 10,001 Rs.+ & 2 & 3 & 3 & 1 & 8 & 3 & $(50)$ \\
\hline Total percent & 100 & 100 & 100 & 100 & 100 & 100 & - \\
\hline Total (N) & (270) & (347) & (299) & (300) & (283) & $(1,499)$ & - \\
\hline
\end{tabular}

- = Not applicable. 
Table 5 : Percentage distribution of mobile female sex workers, by their reasons for entry into sex work according to district, Karnataka, India

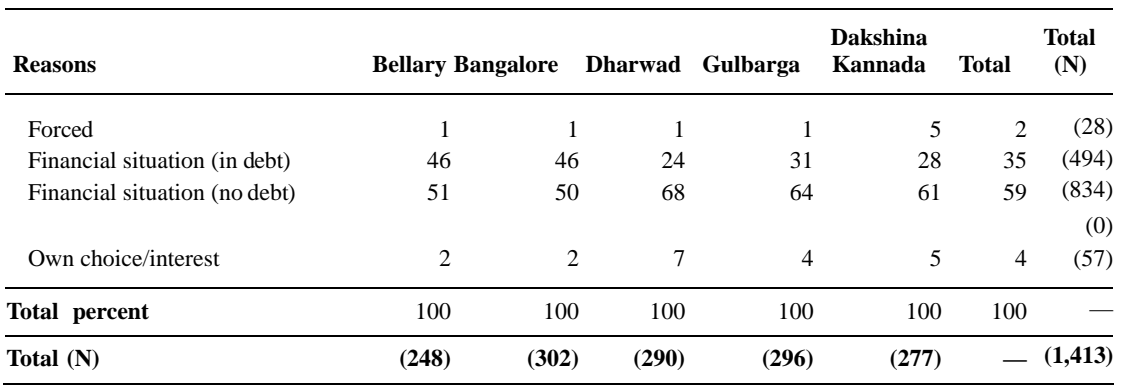

- $=$ Not applicable

Table 6 : Percentage of mobile sex workers, by their use of tobacco, alcohol and drugs, according to district, Karnataka, India

\begin{tabular}{lrrrrrr}
\hline Substance used & Bellary & Bangalore & Dharwad Gulbarga & $\begin{array}{r}\text { Dakshina } \\
\text { Kannada }\end{array}$ & Total \\
\hline Tobacco & 87 & 54 & 67 & 78 & 57 & 68 \\
Alcohol & 70 & 57 & 47 & 61 & 61 & 59 \\
Drugs & 0 & 0 & 0 & 0 & 1 & 0 \\
\hline Total (N) & $\mathbf{( 2 7 0 )}$ & $\mathbf{( 3 4 7 )}$ & $\mathbf{( 2 9 9 )}$ & $\mathbf{( 3 0 0 )}$ & $\mathbf{( 2 8 3 )}$ & $\mathbf{( 1 , 4 9 9 )}$ \\
\hline
\end{tabular}

Table 7 Percentage of mobile female sex workers who have a bank account, separate money, or a cellular telephone, by district, Karnataka, India

\begin{tabular}{lrrrrrrr}
\hline Aids to autonomy & Bellary & Bangalore & Dharwad Gulbarga & $\begin{array}{c}\text { Dakshina } \\
\text { Kannada }\end{array}$ & Total \\
\hline Separate bank account & 7 & 12 & 27 & 20 & 38 & 20 \\
Money set aside & 70 & 68 & 79 & 77 & 87 & 76 \\
Cellular telephone & 40 & 62 & 45 & 58 & 76 & 56 \\
\hline Total (N) & $\mathbf{( 2 7 0 )}$ & $\mathbf{( 3 4 7 )}$ & $\mathbf{( 2 9 9 )}$ & $\mathbf{( 3 0 0 )}$ & $\mathbf{( 2 8 3 )}$ & $\mathbf{( 1 , 4 9 9 )}$ \\
\hline
\end{tabular}


Table 8 : Percentage distribution of mobile female sex workers who reported having experienced physical violence in the past year and who perpetrated the violence, by district, Karnataka, India

\begin{tabular}{|c|c|c|c|c|c|c|c|}
\hline Frequency/perpetrator & Bellary & Bangalore & Dharwad & Gulbarga & $\begin{array}{l}\text { Dakshina } \\
\text { Kannada }\end{array}$ & Total & $\begin{array}{r}\text { Total } \\
(\mathbf{N})\end{array}$ \\
\hline \multicolumn{8}{|l|}{ Experienced violence $^{a}$} \\
\hline Often & 2 & 2 & 1 & 1 & 1 & 1 & (18) \\
\hline Sometimes & 29 & 20 & 18 & 14 & 14 & 18 & (228) \\
\hline Rarely & 8 & 3 & 11 & 15 & 9 & 9 & (119) \\
\hline Never & 62 & 75 & 69 & 70 & 76 & 71 & $(898)$ \\
\hline Total percent & 100 & 100 & 100 & 100 & 100 & 100 & - \\
\hline Total $(\mathbf{N})$ & (167) & (233) & (269) & (284) & (283) & & $(1,236)$ \\
\hline \multicolumn{8}{|l|}{ Perpetrator ${ }^{b, c}$} \\
\hline Police & 18 & 16 & 8 & 11 & 4 & 11 & $(70)$ \\
\hline Clients & 75 & 73 & 75 & 65 & 70 & 72 & (447) \\
\hline Regular sex partner & 1 & 1 & 13 & 19 & 16 & 11 & (66) \\
\hline Others & 6 & 10 & 4 & 6 & 10 & 7 & $(42)$ \\
\hline Total & 100 & 100 & 100 & 100 & 100 & 100 & - \\
\hline Total (N) & (104) & (117) & (157) & (143) & (104) & - & $(625)$ \\
\hline
\end{tabular}

- $=$ Not applicable.

a 15.7 percent are missing values (Bellary: 38 percent, Bangalore: 33 percent, and Gulbarga: 5 percent).

${ }^{\mathrm{b}}$ Among those who experienced violence.

c 12.5 percent are missing values.

Table 9 : Percentage of mobile female sex workers, by their exposure to the mass media, according to district, Karnataka, India

\begin{tabular}{lrrrrrr}
\hline Media & Bellary & Bangalore & Dharwad & Gulbarga & $\begin{array}{c}\text { Dakshina } \\
\text { Kannada }\end{array}$ & Total \\
\hline Newspaper/magazine & 13 & 22 & 10 & 15 & 36 & 19 \\
Radio & 14 & 56 & 20 & 22 & 28 & 29 \\
Movie/television & 87 & 90 & 90 & 86 & 92 & 89 \\
\hline Total (N) & $\mathbf{( 2 7 0 )}$ & $\mathbf{( 3 4 7 )}$ & $\mathbf{( 2 9 9 )}$ & $\mathbf{( 3 0 0 )}$ & $\mathbf{( 2 8 3 )}$ & $(\mathbf{1 , 4 9 9 )}$ \\
\hline
\end{tabular}


Table 10 : Percentage of female sex workers, by indicators of their vulnerability to HIV, according to district, Karnataka, India

\begin{tabular}{|c|c|c|c|c|c|c|}
\hline Indicator & Bellary & Bangalore & Dharwad & Gulbarga & $\begin{array}{l}\text { Dakshina } \\
\text { Kannada }\end{array}$ & Total \\
\hline \multicolumn{7}{|l|}{ Used condom during last sex with } \\
\hline Occasional clients & 54 & 48 & 44 & 49 & 59 & 50 \\
\hline Regular clients ${ }^{\mathrm{a}}$ & 38 & 31 & 26 & 23 & 36 & 31 \\
\hline Occasional/regular clients & 36 & 33 & 27 & 26 & 38 & 32 \\
\hline Nonpaying partner ${ }^{\mathrm{b}}$ & 15 & 40 & 46 & 33 & 40 & 37 \\
\hline Any partner & 36 & 33 & 26 & 26 & 37 & 32 \\
\hline Experienced STI symptoms & 95 & 92 & 93 & 95 & 91 & 93 \\
\hline $\begin{array}{l}\text { Experienced STI symptoms and } \\
\text { continued to have sex }\end{array}$ & 17 & 11 & 30 & 20 & 44 & 24 \\
\hline \multicolumn{7}{|l|}{ HIV risk perception } \\
\hline High & 11 & 16 & 2 & 8 & 9 & 9 \\
\hline Moderate & 44 & 29 & 40 & 42 & 40 & 39 \\
\hline Low & 46 & 55 & 58 & 49 & 51 & 52 \\
\hline Total $(\mathbf{N})$ & $(270)$ & (347) & (299) & (300) & $(283)$ & $(1,499)$ \\
\hline Tested for HIV & 50 & 63 & 38 & 45 & 51 & 50 \\
\hline Went for voluntary testing for HIV & 18 & 27 & 7 & 16 & 12 & 16 \\
\hline
\end{tabular}

a 18.1 percent are missing values for this question.

b 84.9 percent of survey participants did not answer this question, because they do not have a nonpaying partner, have not had sex in the previous week with their nonpaying partner, or did not wish to answer it.

Table 11 : Percentage of mobile female sex workers, by the availability of condoms and their ability to insist that their clients use them, by district, Karnataka, India

\begin{tabular}{lrrrrrr}
\hline Variable & Bellary & Bangalore & Dharwad & Gulbarga & $\begin{array}{r}\text { Dakshina } \\
\text { Kannada }\end{array}$ & Total \\
\hline Condom not available & 56 & 65 & 68 & 65 & 65 & 64 \\
Client refused to use condom & 70 & 78 & 84 & 84 & 73 & 78 \\
$\begin{array}{l}\text { Condom used after successful negotiation } \\
\text { with client }\end{array}$ & 85 & 93 & 72 & 76 & 72 & 80 \\
\hline Total $(\mathbf{N})$ & $\mathbf{( 2 7 0 )}$ & $\mathbf{( 3 4 7 )}$ & $\mathbf{( 2 9 9 )}$ & $\mathbf{( 3 0 0 )}$ & $\mathbf{( 2 8 3 )}(\mathbf{1 , 4 9 9 )}$ \\
\hline
\end{tabular}




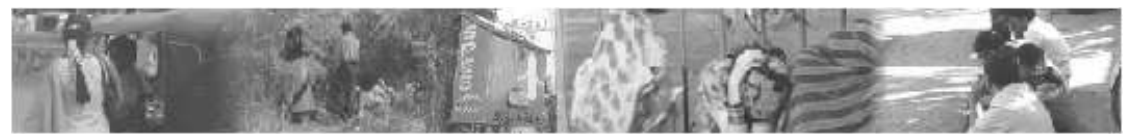

Table 12 : Percentage of mobile female sex workers, by their ability to insist that their clients use condoms and by condom use with specific types of clients, Karnataka, India

\begin{tabular}{|c|c|c|c|c|c|c|}
\hline \multirow[b]{2}{*}{ Survey question } & \multicolumn{5}{|c|}{ Used condom at last sex with } & \multirow[b]{2}{*}{ Total } \\
\hline & $\begin{array}{r}\text { Occasional } \\
\text { clients }\end{array}$ & $\begin{array}{r}\text { Regular } \\
\text { clients }\end{array}$ & $\begin{array}{r}\text { Occasional/ } \\
\text { regular } \\
\text { clients }\end{array}$ & $\begin{array}{r}\text { Nonpaying } \\
\text { partners }\end{array}$ & $\begin{array}{r}\text { Any } \\
\text { partner }\end{array}$ & \\
\hline \multicolumn{7}{|c|}{$\begin{array}{l}\text { Have there been times } \\
\text { when a condom is not } \\
\text { available and hence not } \\
\text { used? }\end{array}$} \\
\hline Yes & 31 & 12 & 13 & 8 & 13 & $(955)$ \\
\hline No & 85 & 64 & 65 & 87 & 65 & $(540)$ \\
\hline \multicolumn{7}{|c|}{$\begin{array}{l}\text { Have there been times } \\
\text { when a client refused to use } \\
\text { a condom and you agreed } \\
\text { to have sex? }\end{array}$} \\
\hline Yes & 37 & 14 & 16 & 10 & 16 & $(1,163)$ \\
\hline No & 98 & 88 & 89 & 99 & 89 & (328) \\
\hline \multicolumn{7}{|c|}{$\begin{array}{l}\text { Have there been times } \\
\text { when a client refused to use } \\
\text { a condom but you } \\
\text { convinced him to use one? }\end{array}$} \\
\hline Yes & 57 & 36 & 36 & 48 & 36 & $(1,188)$ \\
\hline No & 25 & 5 & 14 & 5 & 14 & (297) \\
\hline Total & 50 & 31 & 32 & 37 & 32 & - \\
\hline Total $(\mathbf{N})$ & $(1,472)$ & $(1,227)$ & $(1,497)$ & (226) & $(1,497)$ & - \\
\hline
\end{tabular}

$-=$ Not applicable.

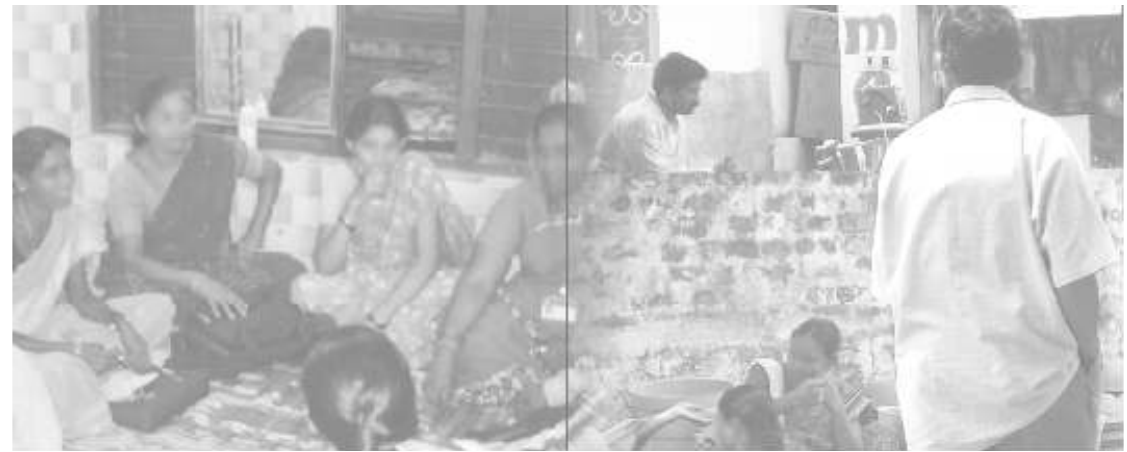




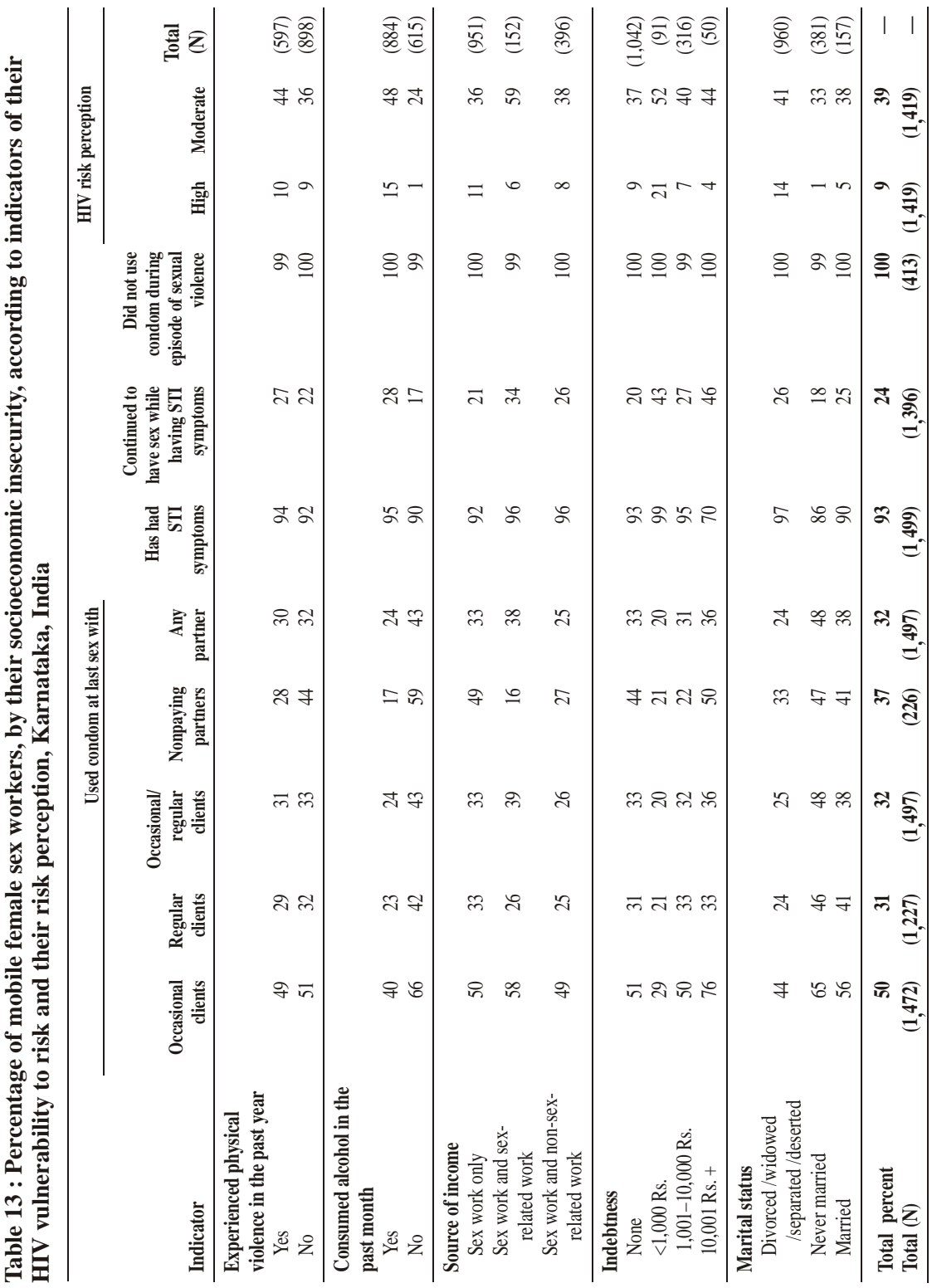



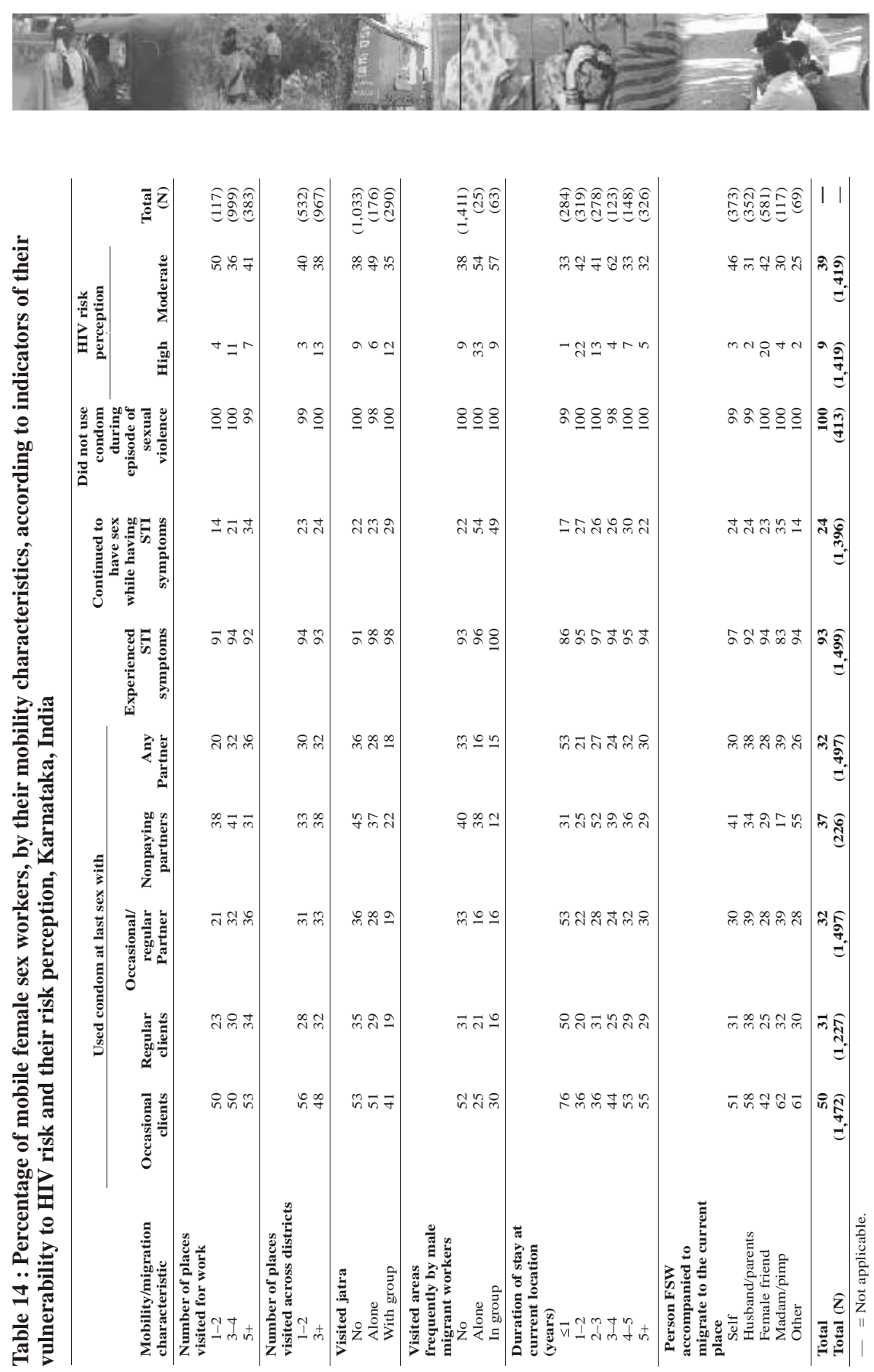

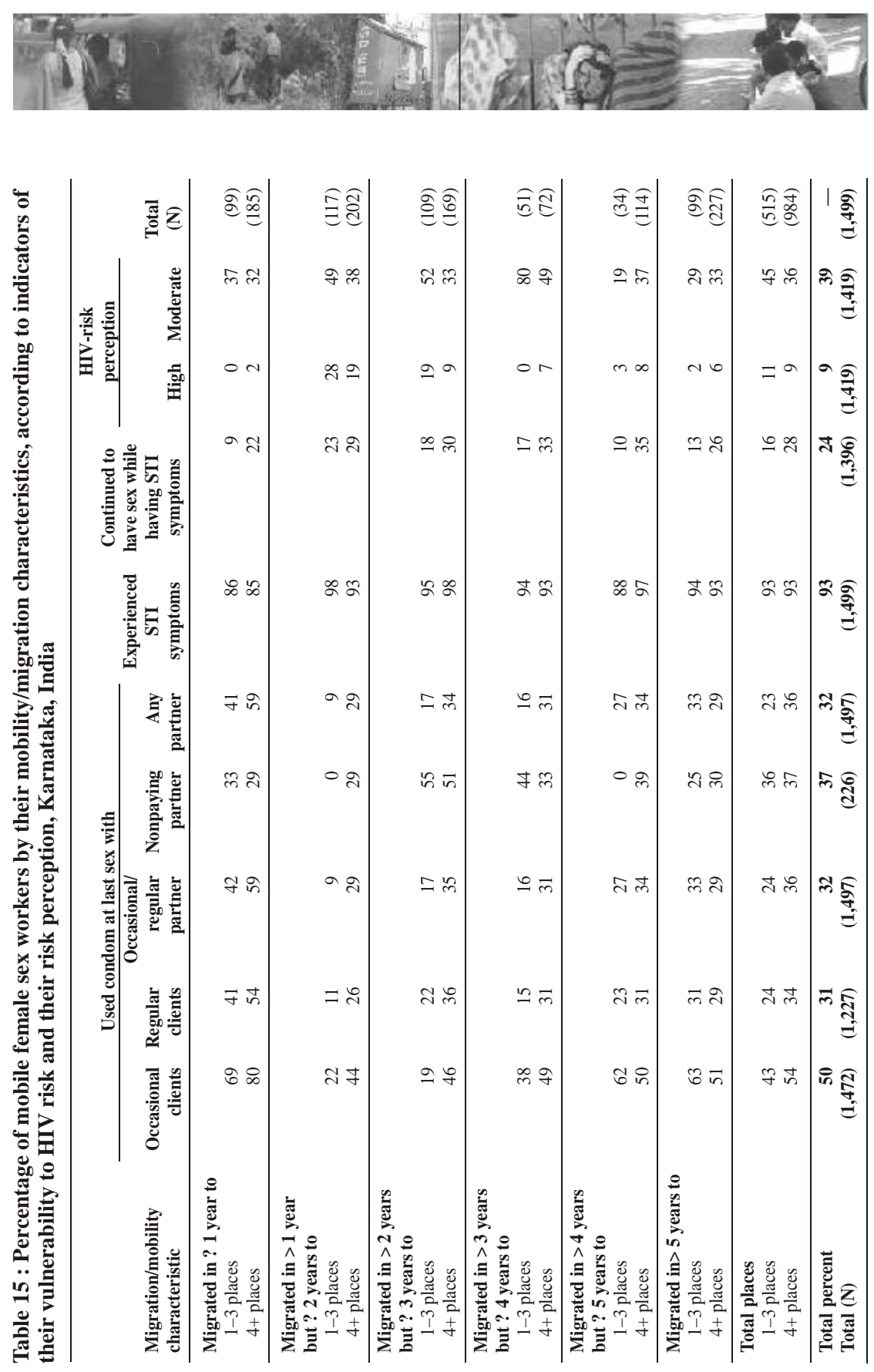


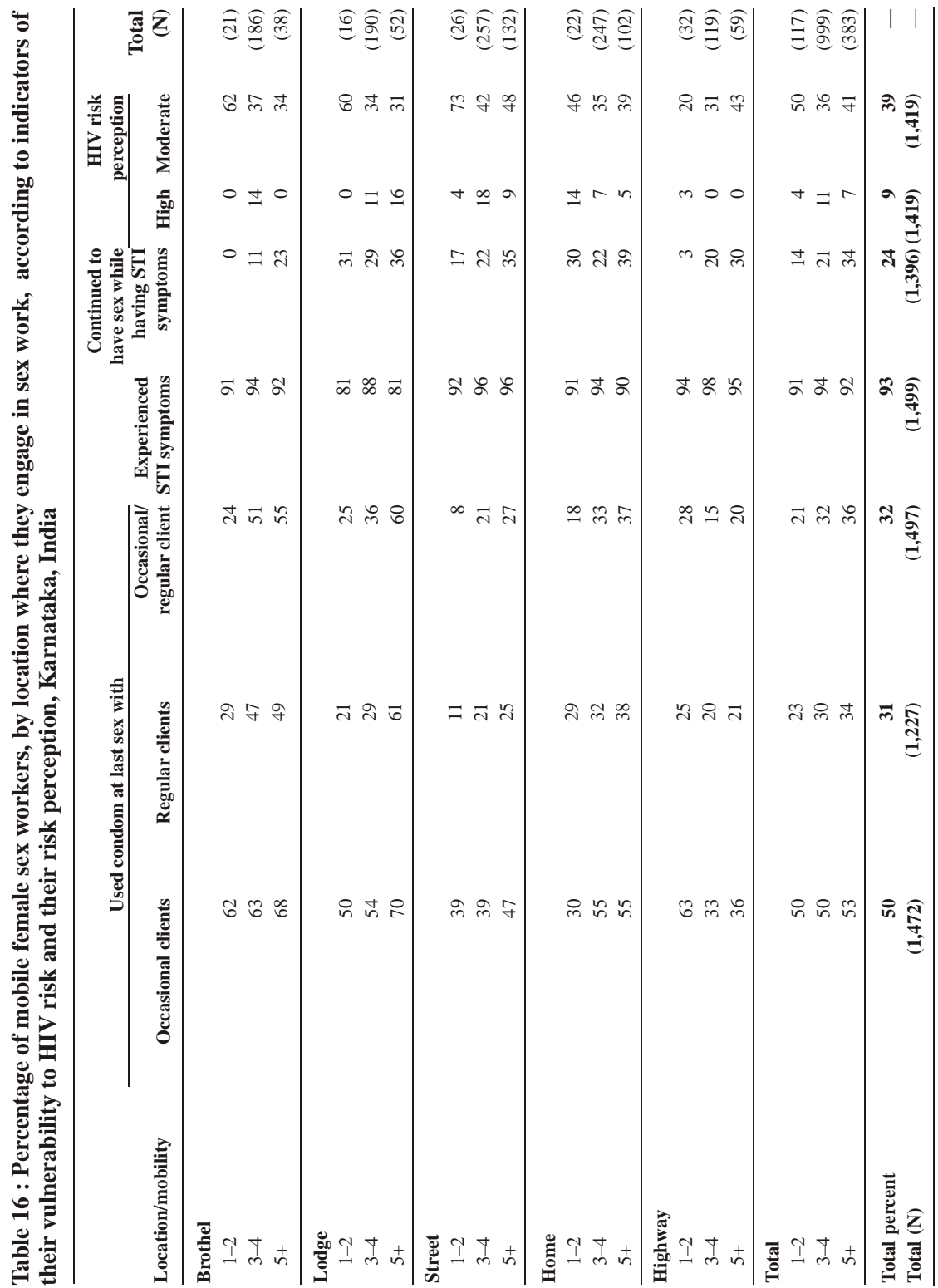




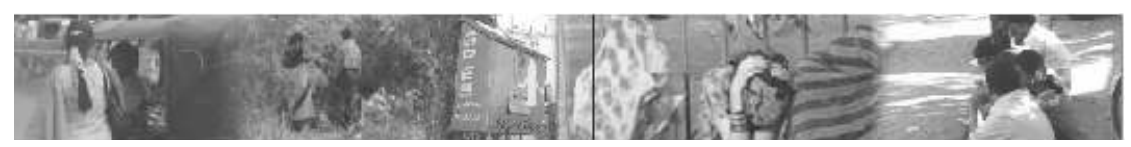

Table 17 : Percentage of mobile female sex workers, by locations where they solicit/engage in sex, according to district, Karnataka, India

\begin{tabular}{|c|c|c|c|c|c|c|}
\hline Location & Bellary & Bangalore & Dharwad & Gulbarga & Dakshina Kannada & Total \\
\hline \multicolumn{7}{|l|}{ Solicitation/means } \\
\hline Telephone & 19 & 37 & 32 & 42 & 70 & 40 \\
\hline Roadside & 27 & 34 & 32 & 37 & 16 & 30 \\
\hline Railway stations/bus stands & 33 & 13 & 29 & 38 & 25 & 27 \\
\hline Markets & 30 & 11 & 30 & 35 & 21 & 25 \\
\hline Hotels/ lodges & 6 & 20 & 16 & 17 & 56 & 23 \\
\hline Own home & 13 & 3 & 28 & 25 & 21 & 17 \\
\hline Brothels & 33 & 34 & 0 & 13 & 2 & 17 \\
\hline With mediator's help & 6 & 18 & 9 & 9 & 34 & 15 \\
\hline Fast-food places & 11 & 28 & 18 & 5 & 2 & 13 \\
\hline Cinema halls & 17 & 5 & 12 & 19 & 15 & 13 \\
\hline Rented rooms & 12 & 5 & 10 & 17 & 9 & 10 \\
\hline Clients' home & 1 & 1 & 2 & 4 & 7 & 3 \\
\hline Bars & 1 & 0 & 1 & 1 & 3 & 1 \\
\hline Vehicles & 3 & 2 & 13 & 1 & 4 & 4 \\
\hline Labor naka & 2 & 0 & 2 & 1 & 0 & 1 \\
\hline \multicolumn{7}{|l|}{ Engage in sex at } \\
\hline Hotels/lodges & 26 & 29 & 34 & 32 & 81 & 40 \\
\hline $\begin{array}{l}\text { Open spaces/forest/garden/ } \\
\text { jungle/hill/mountain }\end{array}$ & 36 & 17 & 41 & 33 & 9 & 27 \\
\hline Rented rooms & 17 & 8 & 17 & 38 & 17 & 19 \\
\hline Own home & 13 & 2 & 30 & 26 & 27 & 19 \\
\hline Brothels & 33 & 34 & 0 & 13 & 4 & 17 \\
\hline Vehicles & 11 & 27 & 23 & 5 & 1 & 14 \\
\hline Railway stations/bus stands & 18 & 5 & 10 & 12 & 6 & 10 \\
\hline Client s' home & 3 & 5 & 5 & 11 & 13 & 7 \\
\hline Roadsides & 10 & 14 & 0 & 3 & 3 & 6 \\
\hline Fast-food places & 4 & 5 & 7 & 2 & 3 & 4 \\
\hline Cinema halls & 4 & 1 & 4 & 3 & 4 & 3 \\
\hline Market areas & 2 & 1 & 0 & 0 & 1 & 1 \\
\hline Parks/bushes & 0 & 1 & 0 & 0 & 0 & 0 \\
\hline Bars & 0 & 0 & 0 & 0 & 0 & 0 \\
\hline Total $(\mathbf{N})$ & (270) & (347) & (299) & (300) & (283) & $(1,499)$ \\
\hline
\end{tabular}




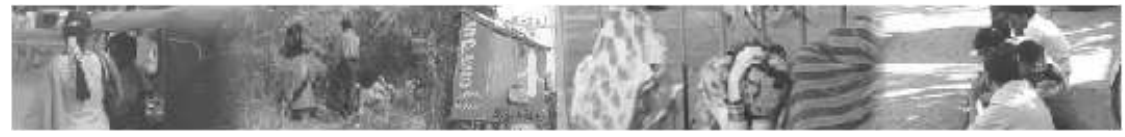

Table 18 : Percentage of mobile female sex workers, by type of sex work, according to location for soliciting/engaging in sex, Karnataka, India

\begin{tabular}{lrrrrrrr}
\hline & \multicolumn{1}{c}{ Location } \\
\cline { 2 - 8 } \multicolumn{1}{c}{ Type of sex work } & Hotels & $\begin{array}{r}\text { Railway } \\
\text { stations }\end{array}$ & $\begin{array}{r}\text { FSW's } \\
\text { home }\end{array}$ & Markets & Brothels & $\begin{array}{r}\text { Fast- } \\
\text { food } \\
\text { places }\end{array}$ & $\begin{array}{r}\text { Any of } \\
\text { these six }\end{array}$ \\
\hline Brothel & 1 & 0 & 0 & 1 & 100 & 0 & 100 \\
Lodge & 100 & 1 & 2 & 1 & 0 & 0 & 100 \\
Street & 74 & 88 & 2 & 77 & 3 & 6 & 100 \\
FSW's home & 15 & 10 & 77 & 13 & 2 & 1 & 79 \\
Highway & 1 & 2 & 1 & 0 & 1 & 89 & 90 \\
\hline
\end{tabular}

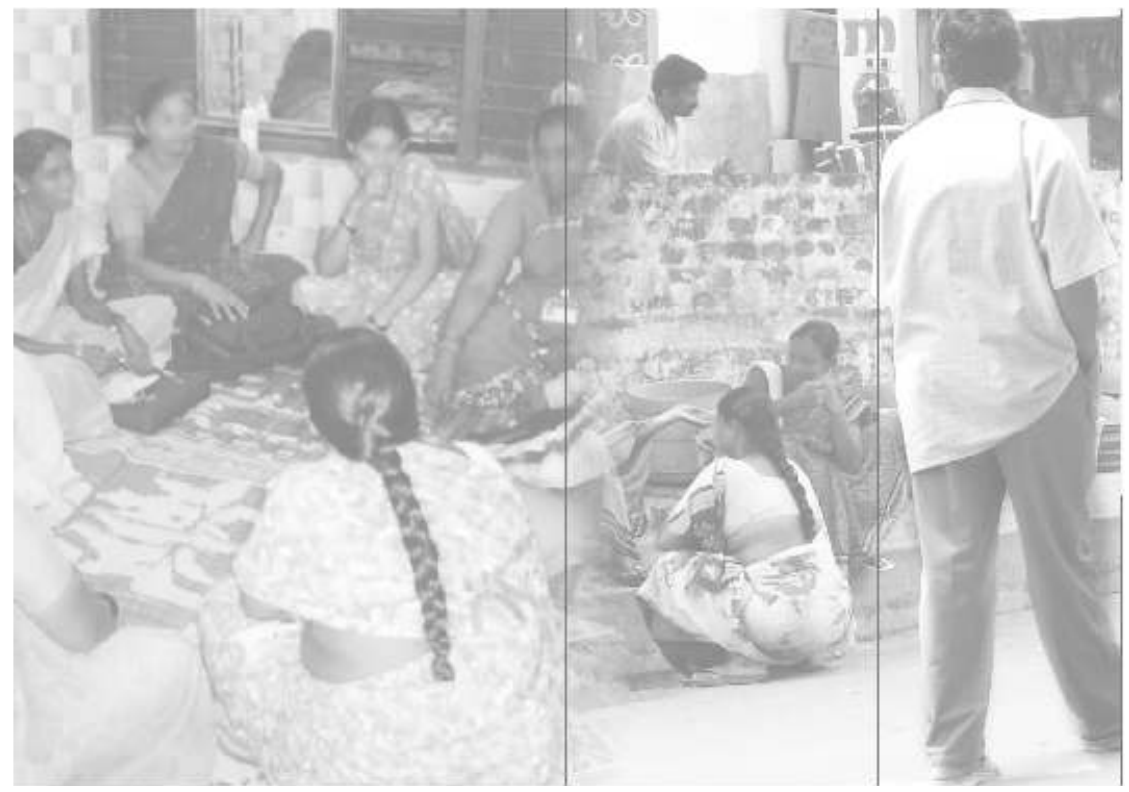




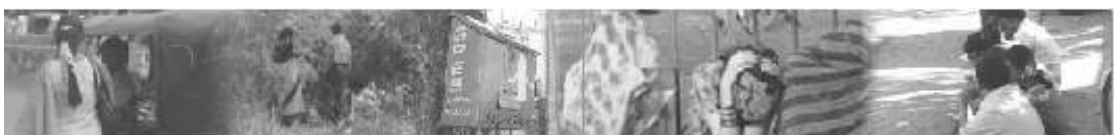

Table 19 : Percentage of mobile female sex workers, by their most frequent locations for soliciting/engaging in sex and by ancipated programme coverage with alternative scenarios, according to district, Karnataka, India

Dakshina

Location/anticipated coverage

Bellary Bangalore Dharwad Gulbarga Kannada

Total

Location

Hotels/ lodges

26

31

\section{5}

36

84

25

42

Railway stations/bus stands

Markets

FSW's home

Brothels

Fast-food places

Any of the above

Roadside

Open spaces/forest/garden/ jungle/hill/mountain

36

$\begin{array}{llll}32 & 38 & 16 & 30\end{array}$

\section{Anticipated coverage by programme implemented in}

\begin{tabular}{|c|c|c|c|c|c|c|}
\hline Hotels & 26 & 31 & 35 & 36 & 84 & 42 \\
\hline $\begin{array}{l}\text { Hotels + railway stations/bus } \\
\text { stands }\end{array}$ & 37 & 33 & 44 & 48 & 87 & 49 \\
\hline $\begin{array}{l}\text { Hotels + railway stations/bus } \\
\text { stands + markets }\end{array}$ & 39 & 34 & 47 & 50 & 90 & 51 \\
\hline $\begin{array}{l}\text { Hotels + railway stations/bus } \\
\text { stands + markets + FSW's } \\
\text { home }\end{array}$ & 52 & 36 & 70 & 74 & 98 & 65 \\
\hline $\begin{array}{l}\text { Hotels + railway stations/bus } \\
\text { stands + markets + FSW's } \\
\text { home + brothels }\end{array}$ & 84 & 69 & 70 & 88 & 98 & 81 \\
\hline $\begin{array}{l}\text { Hotels + Railway stations/bus } \\
\text { stands + markets + FSW's } \\
\text { home + brothels + fast-food } \\
\text { places }\end{array}$ & 95 & 97 & 84 & 92 & 98 & 93 \\
\hline
\end{tabular}

Number of intervention doses the sex workers would receive, if the six locations are covered by the programme

\begin{tabular}{|c|c|c|c|c|c|c|}
\hline 0 & 5 & 3 & 16 & 8 & 3 & 7 \\
\hline 1 & 64 & 84 & 51 & 52 & 58 & 63 \\
\hline 2 & 11 & 4 & 12 & 16 & 18 & 12 \\
\hline 3 & 20 & 10 & 17 & 23 & 13 & 16 \\
\hline 4 & & & 5 & 1 & 6 & 2 \\
\hline 5 & & & & & 1 & 0 \\
\hline 6 & & & & & & \\
\hline $\begin{array}{l}\text { Average number of times } S W s \text { would } \\
\text { be covered by the programme }\end{array}$ & 1.47 & 1.20 & 1.43 & 1.56 & 1.67 & 1.46 \\
\hline Total (N) & (270) & (347) & (299) & (300) & (283) & $(1,499)$ \\
\hline
\end{tabular}




\section{(1) Population Council}

www.popcouncil.org

Karnataka Health Promotion Trust

www.khpt.org/home.htm 